\title{
الأمشاط الخثبية المزخرفة باللاكيه في العصر القاجاري في ضوء مجموعة جديلة بمتحف الفن الإسلامي بالقاهرة الأهرة
}

\author{
دل دماده ثابت محمود \\ أستاذ مساعد- كلية الآثار - جامعة مدود الفيوم
}

ملخص البحث:

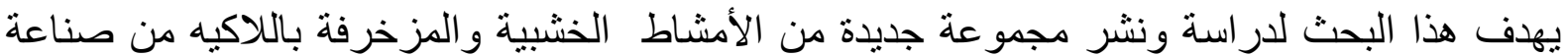

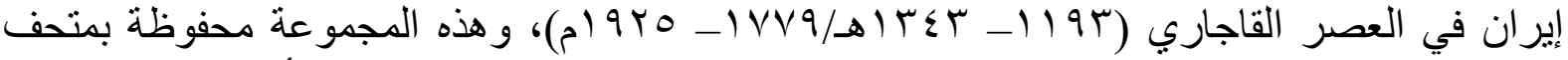

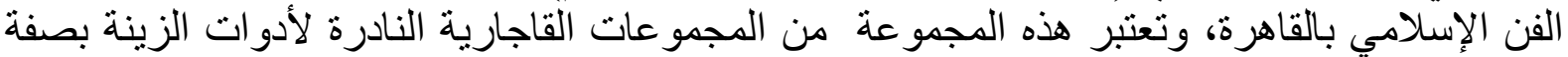

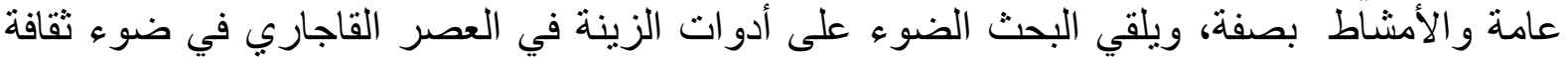

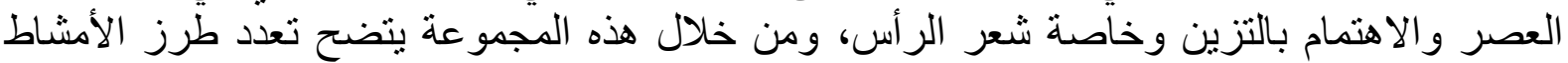

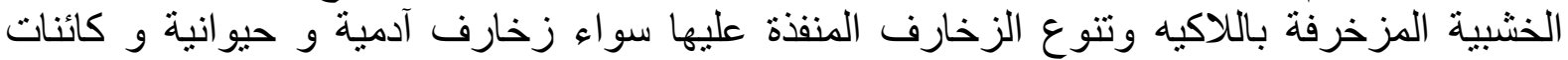

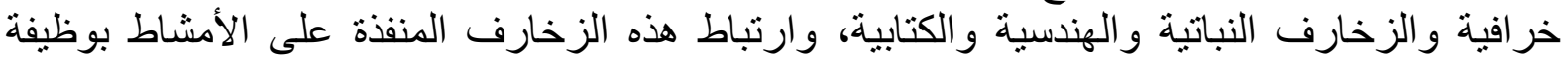

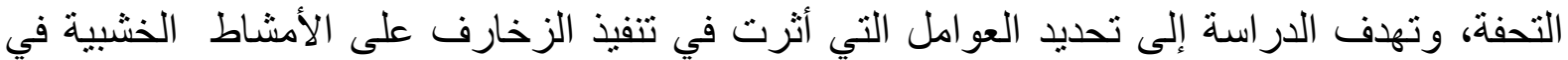

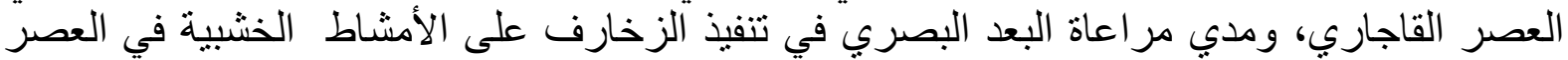

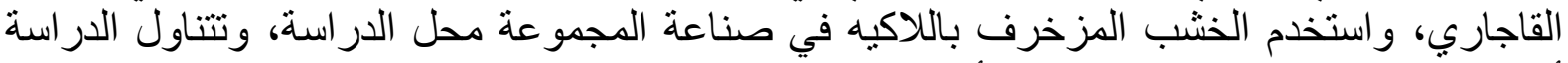

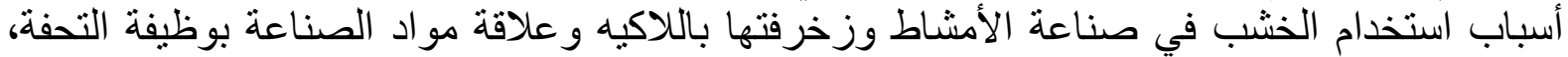

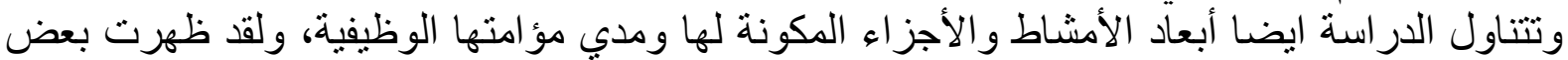
التأثير ات الاوربية على الزخارف المنفذة على المجمو عة محل الدر اسة وهو ما سوف توضحه الداف الدر اسة.

\section{الكلمات المفتاحية :(خشب، لاكيه، قاجاري، ايران، مشط، زينة، شعر )}

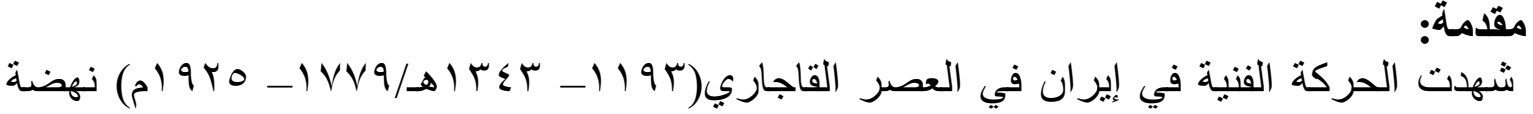

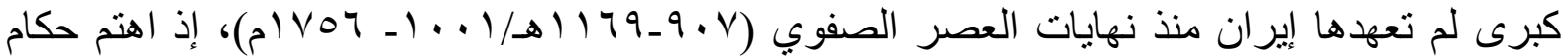

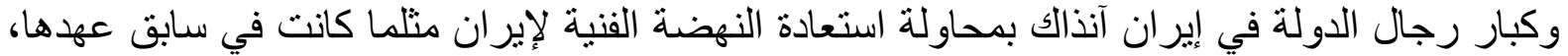

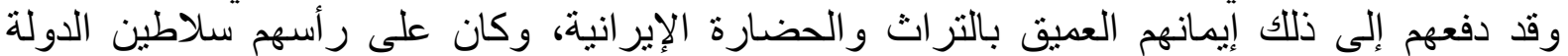

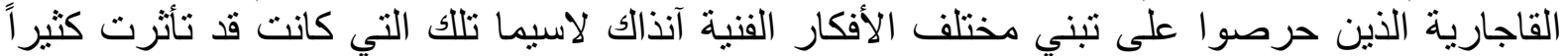

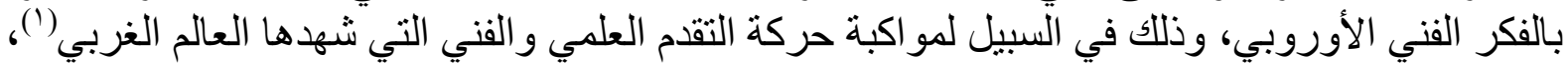
أملاُفي التخلص من عباءة التخلف الفني والحضاري التي ارتدتها و وعانت منها الحركة الفنية الإيرانية

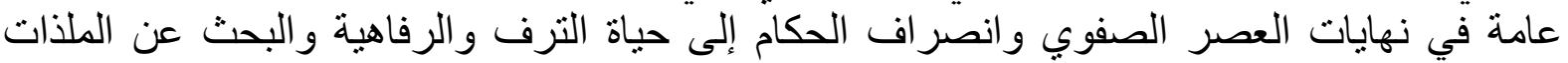
الثخصية الخاصة بهم, و هم من اصطلح على تسميتهم بـر عاة الفن وهم الذين في كنفهم وبر عايتهم تنهض الفه الحركات الفنية المختلفة والعكس صحيح، فاهتم ملوك آل قاجار بالفن والفناء الفنانين، فمنحوهم الألقاب،

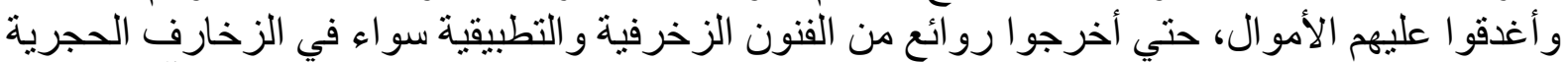

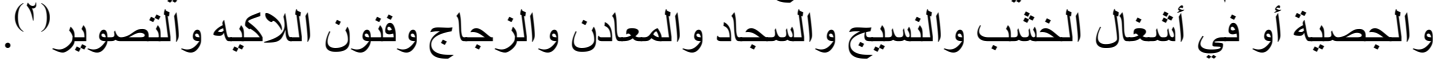




\section{الاهتمام بالزينة وأدواتها في العصر القاجاري}

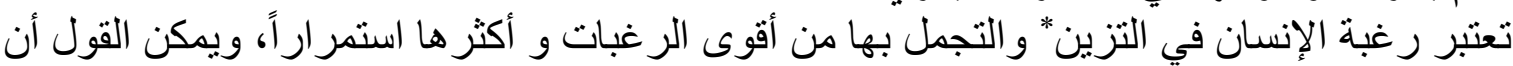

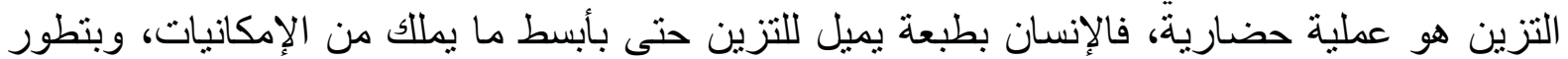

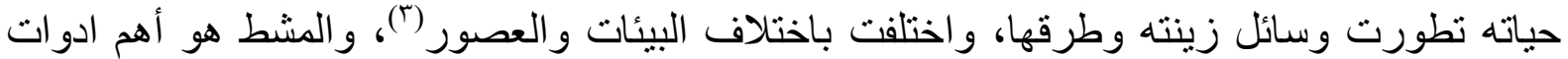

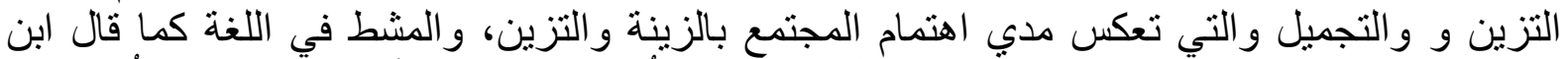

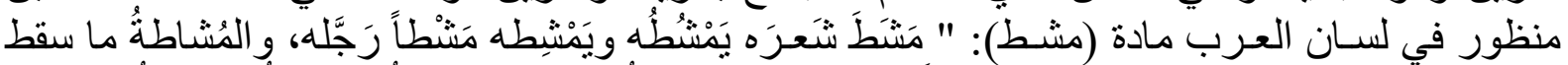

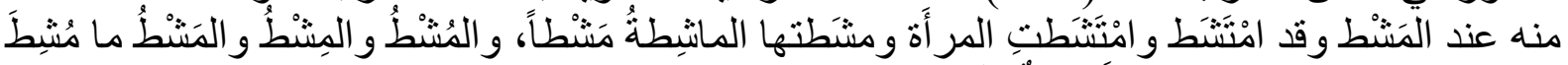

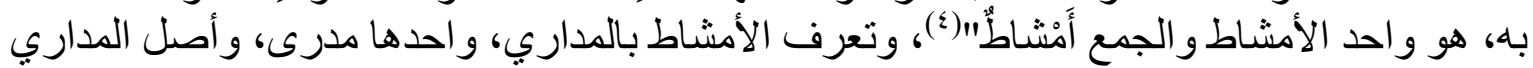

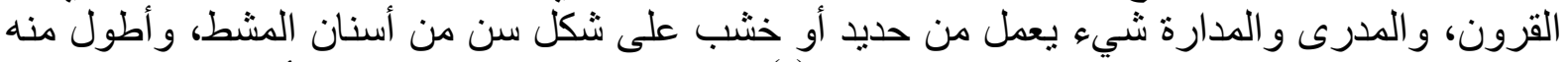

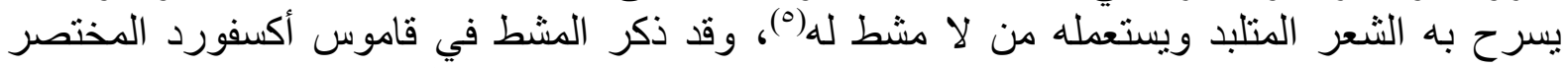

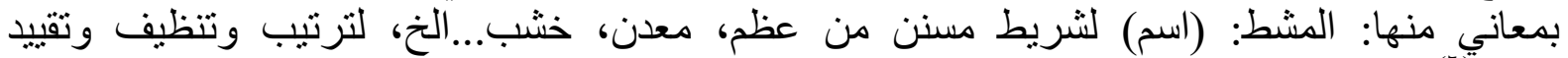

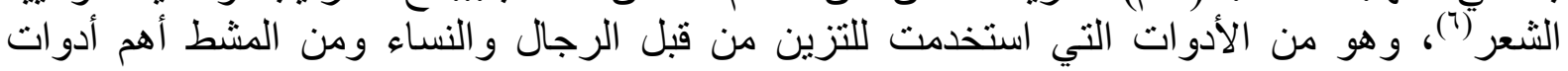
المانشطة*.

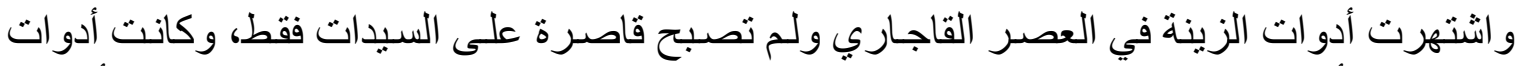

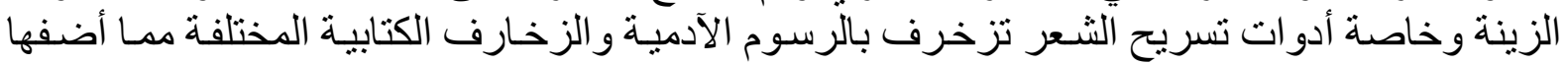

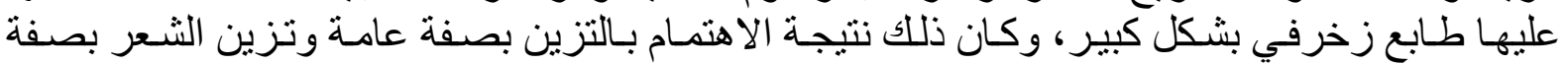

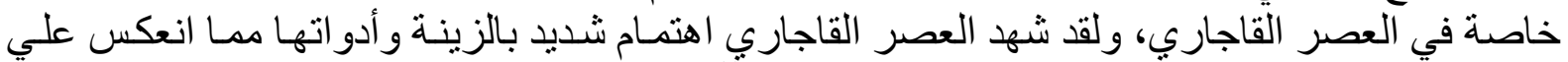

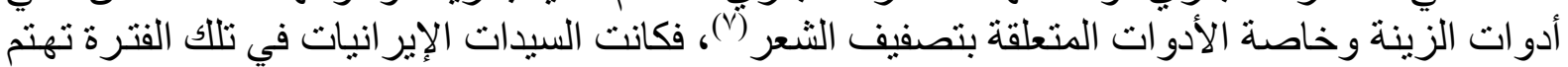

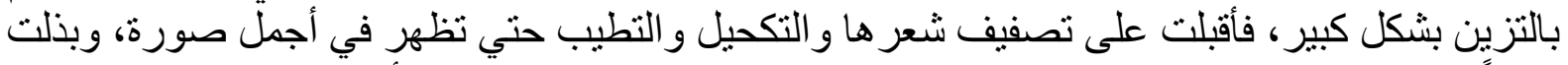

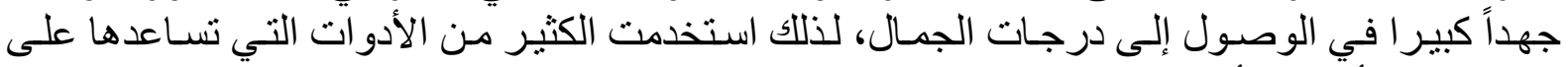

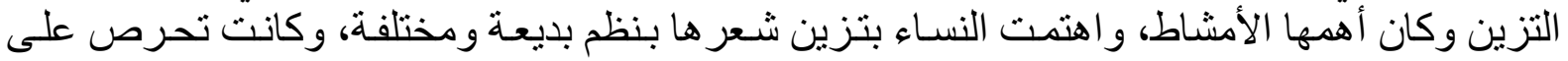

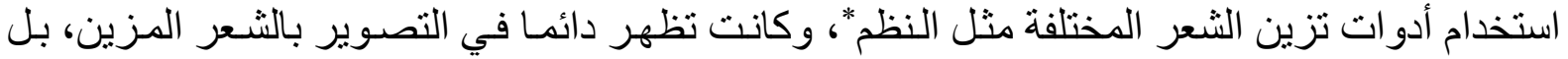

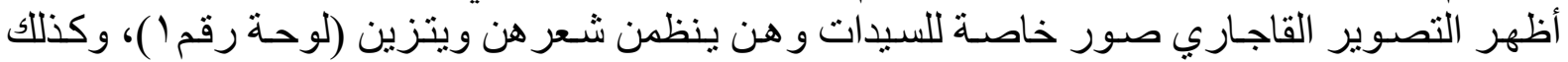

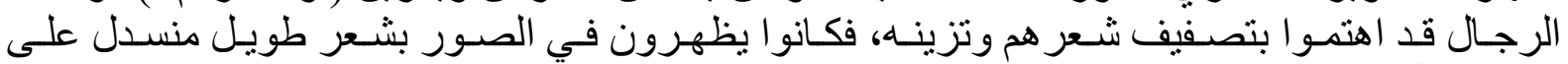

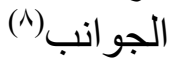

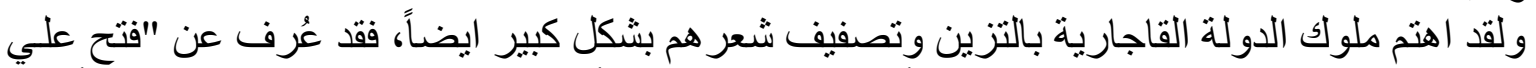

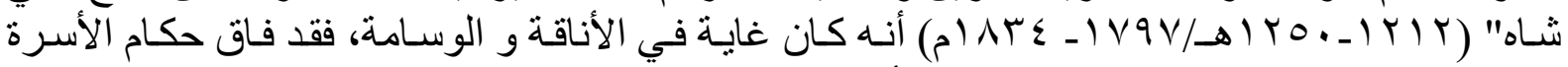

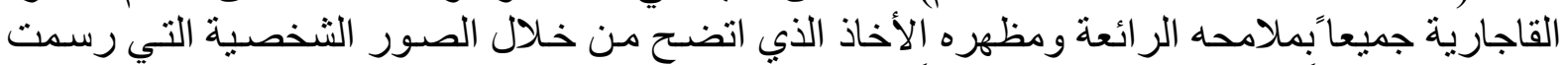

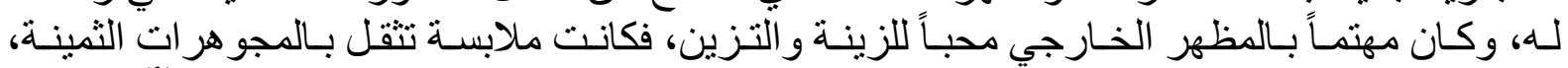

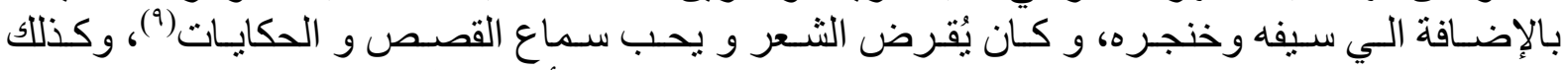

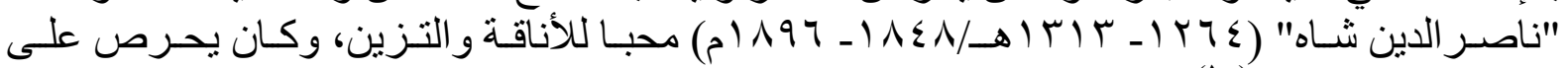

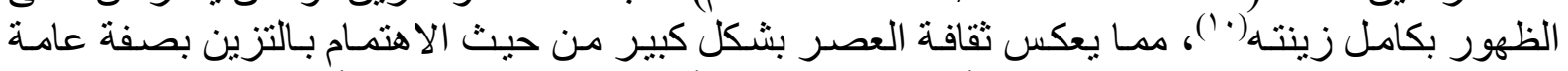

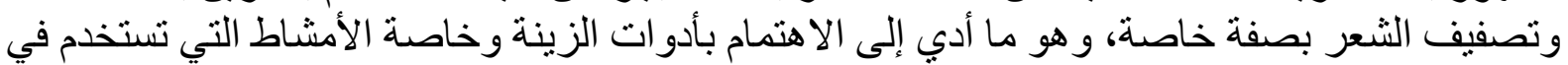
تصفيف الشعر. 

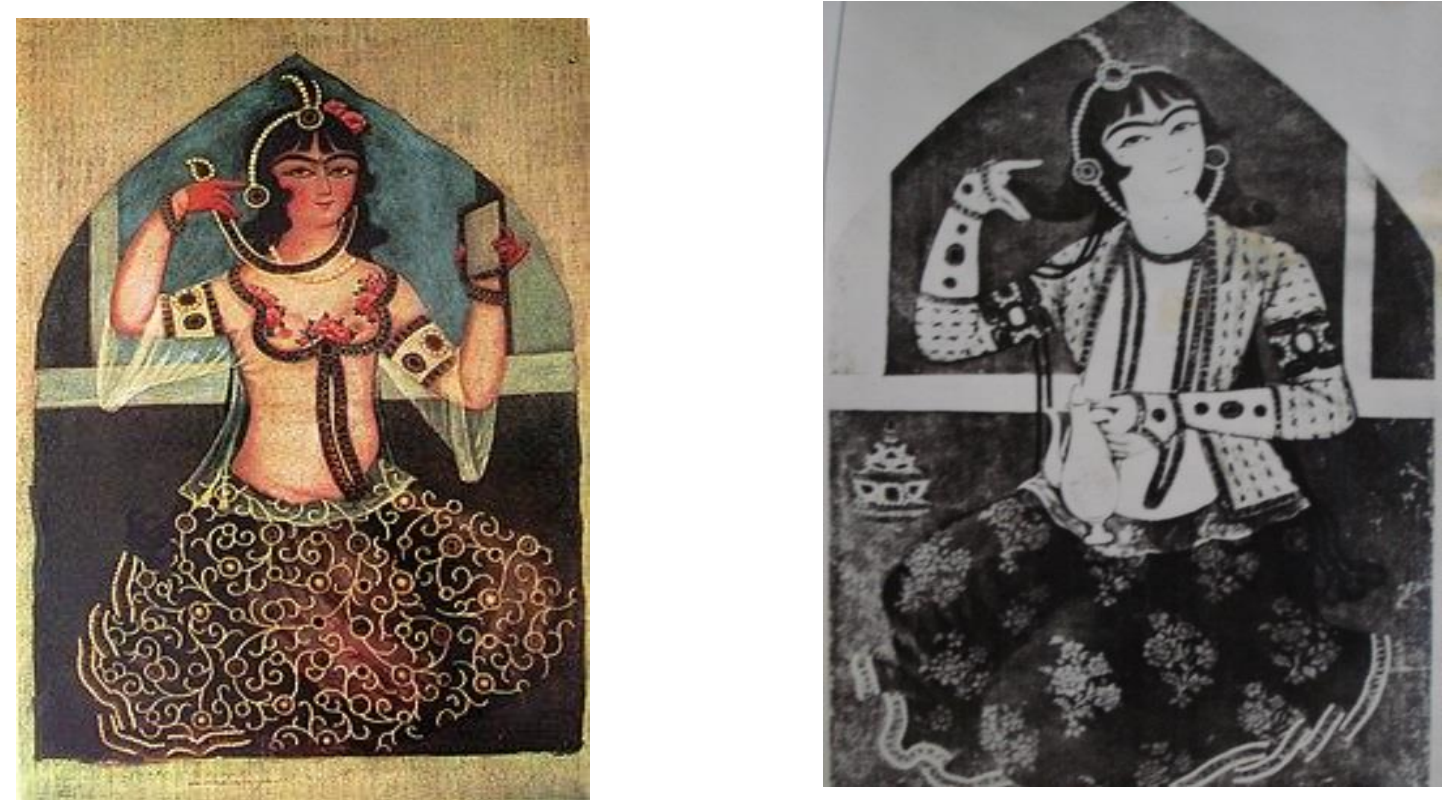

(أ): امر أة تتزين، لوحة زيتية، متحف الفنون الزخرفية (ب): امر أة تنظم شعر ها، لوحة زيتية، متحف الفنون الزخرفية

$$
\begin{aligned}
& \text { بتفليس. }
\end{aligned}
$$

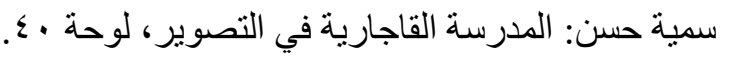

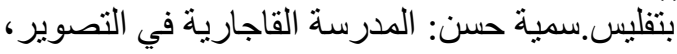

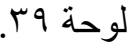

$$
\begin{aligned}
& \text { لوحة رقم (1): لوحات زيتية توضح اهتمام المر أة الاير انية في العصر القاجاري بتزين وتصفية فيف شعرئ ها. }
\end{aligned}
$$

أولاً: الاراسة الوصفية:

يحتفظ متحف الفن الإسلامي بالقاهرة بمجمو عة من الأمشاط الخشبية المزخرفة باللاكيه و عددها خمسة

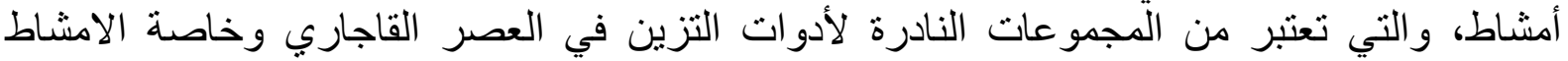

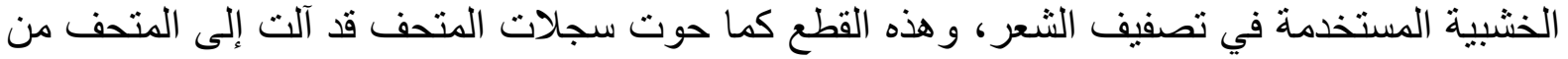
خلال ضبطية قضائية*، و فيما يلي در اسة وصفية لهذية لهذه القطع: التحفة الاولي:

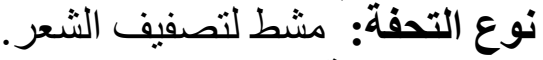
مواد الصناعة: الخشب المطلي.

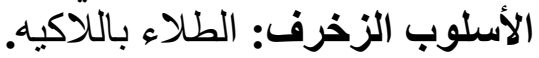

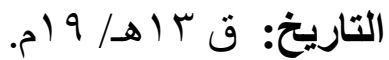
مكان الحفظ: متحف الفن الإسلامي بالقاهرة.

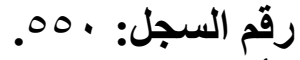

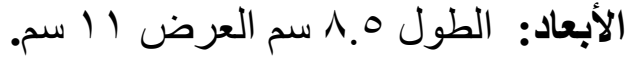
حالة التحفة: مكتمل وفي في حالة جيدة التئ. اللوحات: لوحات رقم ( ب، "r). الوصف:

مشط من الخشب مستطيل الشكل كامل، وأسنان المشط في كلا الجهتين بنفس السمك ومتساوية في

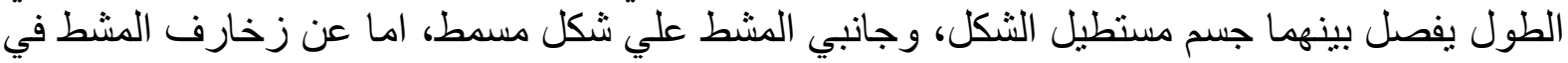

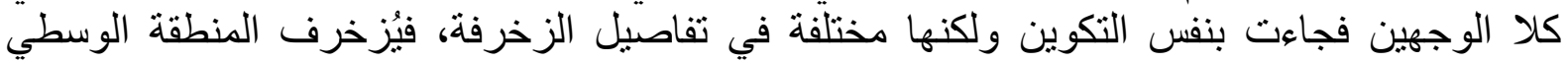
المحصورة بين أسنان المشط في الوجه الأول جامة مفصصة تحتوي بداخلها على زخارف كتابية عربية 


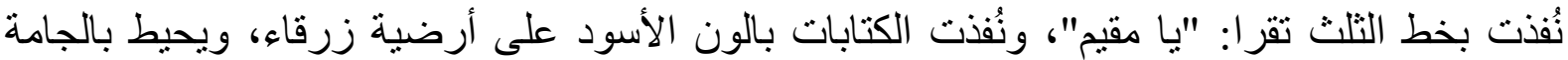

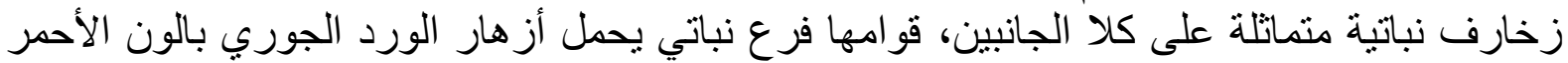

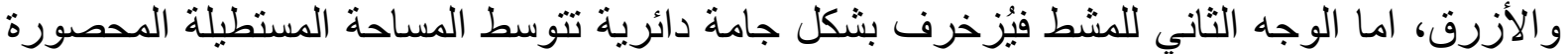

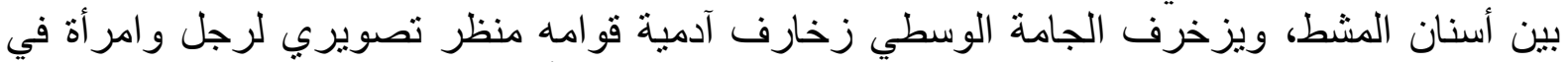

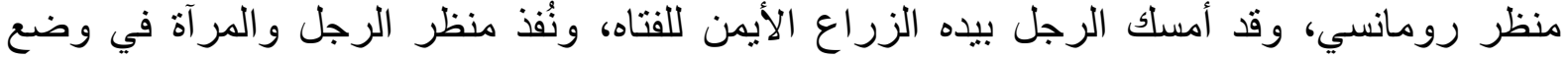

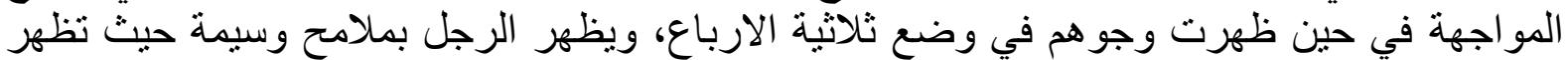

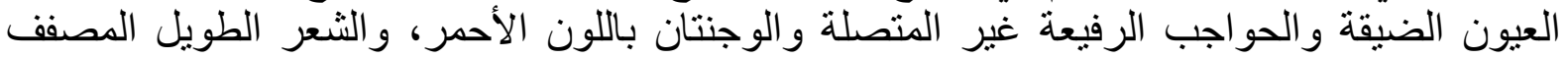

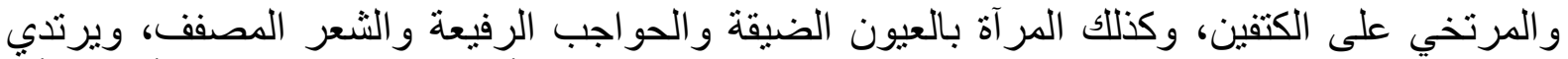

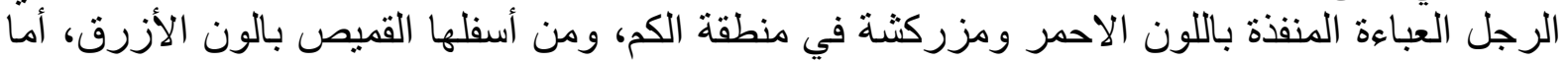

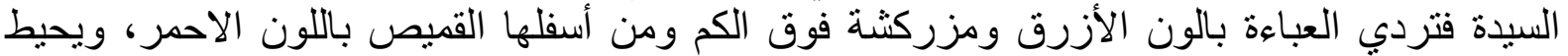

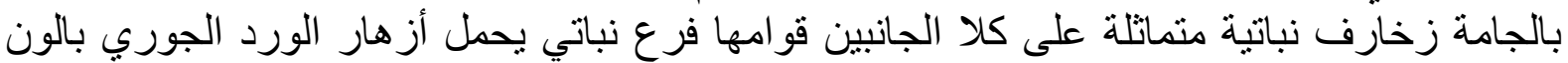

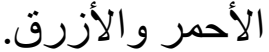

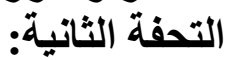

نوع التحفة: مشط لتصفيف الثُعر. مواد الصناعة: الخشب المطلي. الأسلوب الزخرف: الطناء الناء باللاكيه.

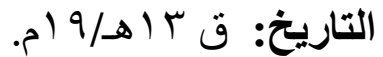
مكان الحفظ: متحف الفن الإسلامي بالقاهرة.

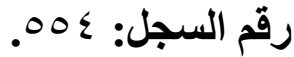

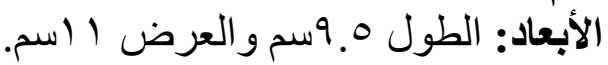
حالة التحفة: مكتمل وفي حالة جيدة. اللوحات: لوحات رقم ( ع، 0) الوصف:

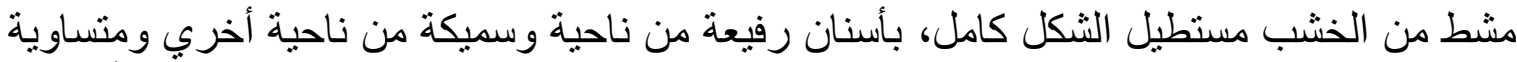

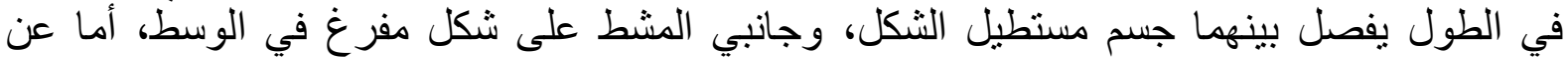

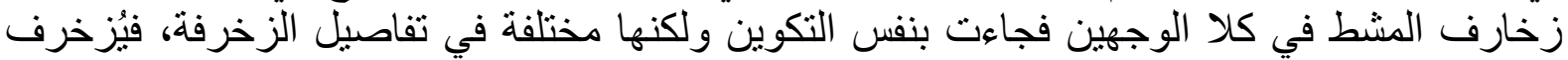

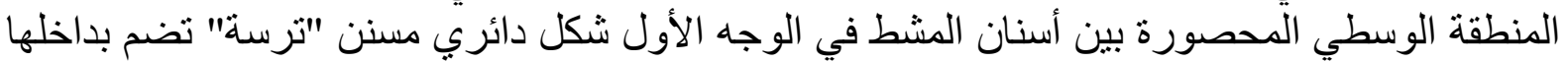

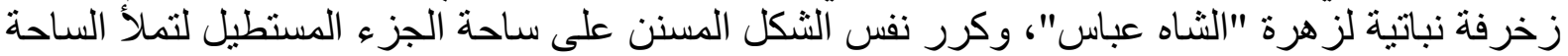

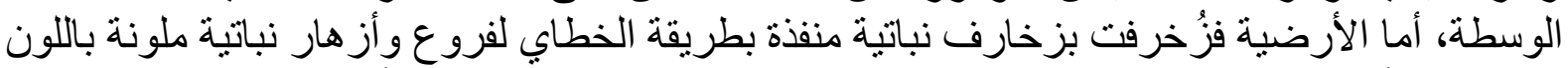

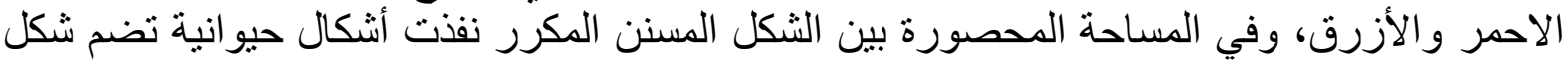

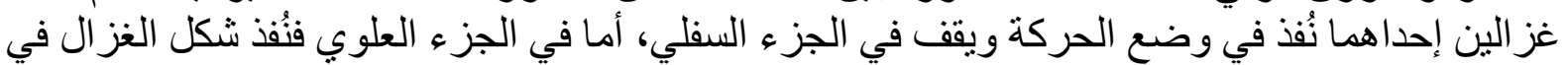

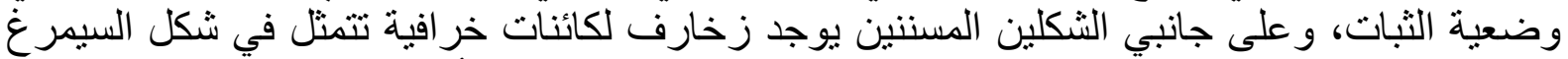

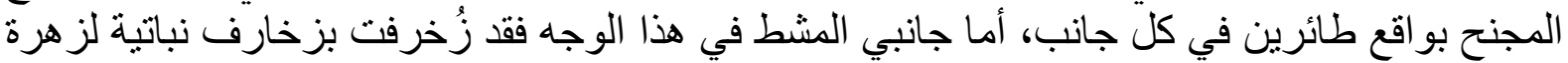

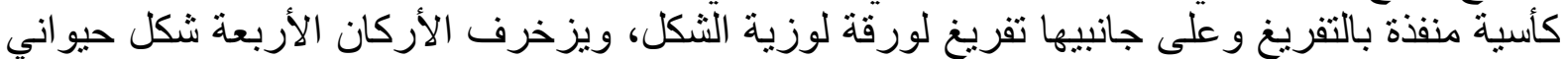

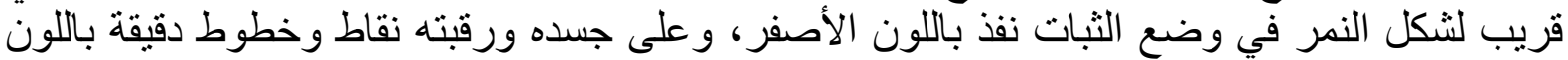

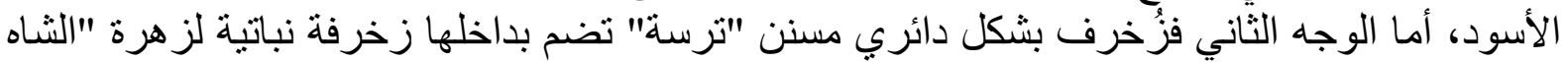

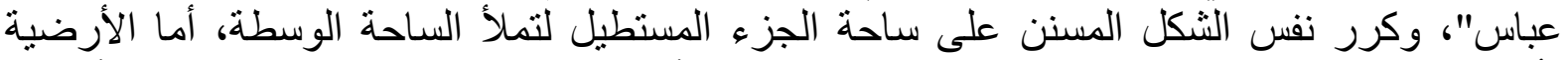

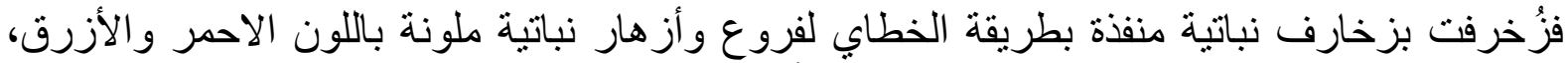
وجانبي المشط في هذا الوجه بنفس تصميم الوجه الأول.

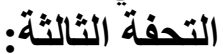
نوع التحفة: مشط لتصفيف الثعر. 


$$
\begin{aligned}
& \text { مواد الصناعة: الخشب المطلي. } \\
& \text { الأسلوب الزخرف: الطلاء بالناكيه. }
\end{aligned}
$$

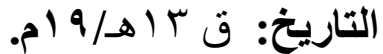

$$
\begin{aligned}
& \text { مكان الحفظ: متحف الفن الإسلامي بالقاهرة. } \\
& \text { رقم السجل: }
\end{aligned}
$$

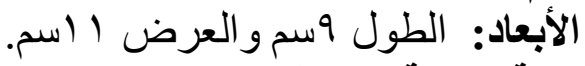

$$
\begin{aligned}
& \text { حالة التحفة: مكتمل وفي حالة جيدة. } \\
& \text { اللوحات: لوحات رقم(T)، V). }
\end{aligned}
$$

مشط من الخشب مستطيل الثكل كامل، بأسنان رفيعة من ناحية وسميكة من ناحية أخري ومتساوية

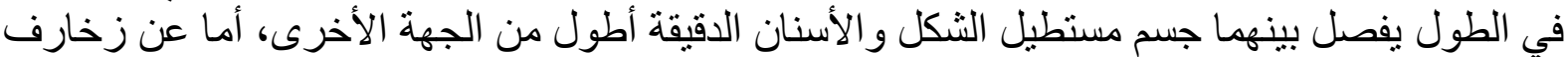

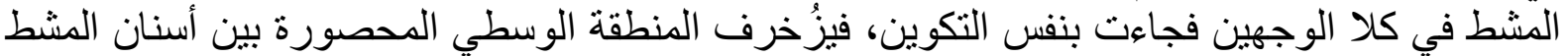

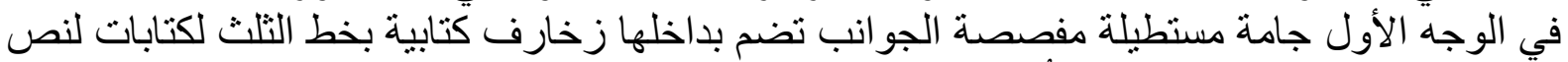

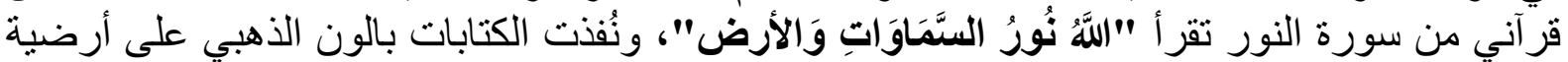

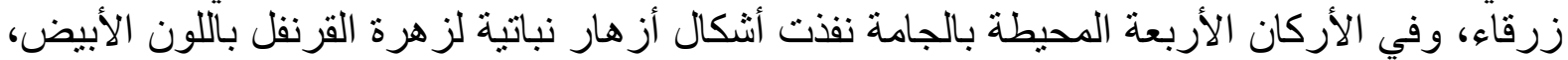

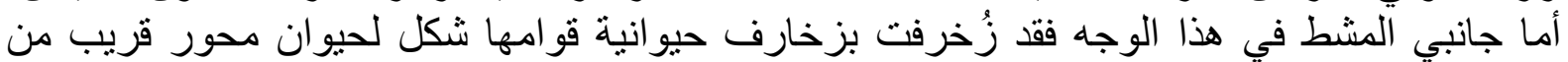

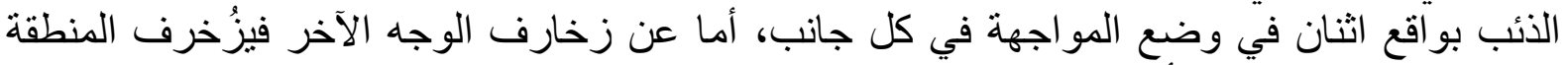

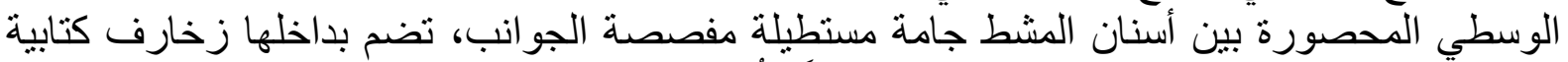

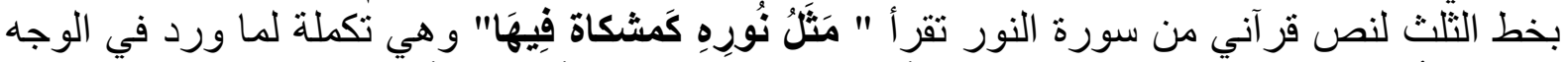

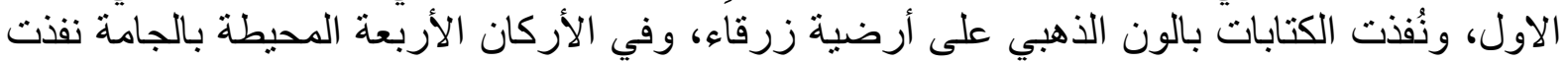

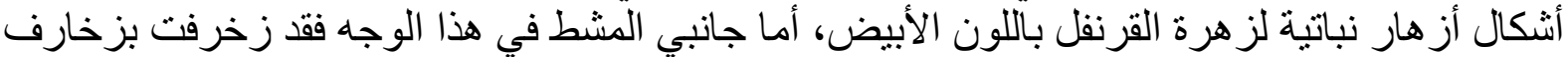

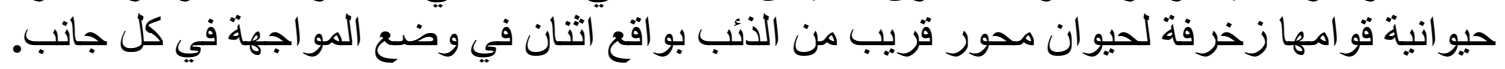

$$
\begin{aligned}
& \text { التحفة الرابعة: } \\
& \text { نوع التحفة: مشط لتصفيف الثُعر. }
\end{aligned}
$$

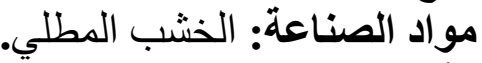

$$
\begin{aligned}
& \text { الأسلوب الزخرف: الطلاء بالناكيه. }
\end{aligned}
$$

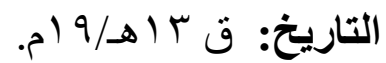

$$
\begin{aligned}
& \text { مكان الحفظ: متحف الفن الإسلامي بالقاهرة. } \\
& \text { رقم السجل: 000. }
\end{aligned}
$$

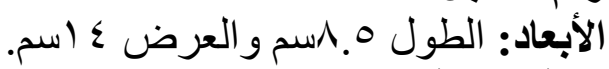

$$
\begin{aligned}
& \text { حالة التحفة: مكتمل وفي حالة جيدة. }
\end{aligned}
$$

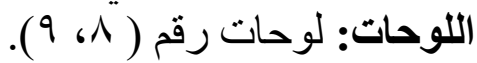

مشط من الخشب مستطيل الشكل كامل، بأسنان رفيعة من ناحية وسميكة من ناحية أخري ومتساوية

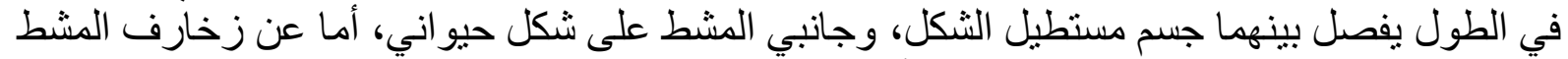

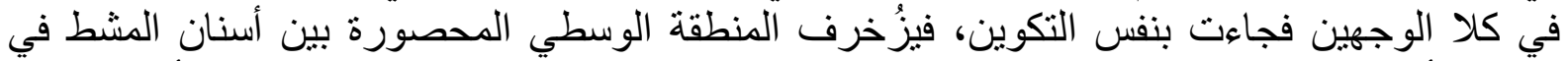
الوجه الأول جامة بيضاوية، تضم بداخلها زخارف كتابية بخط النستعليق لكتابات فارسية تقر أ

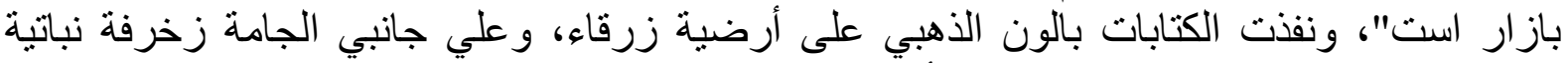

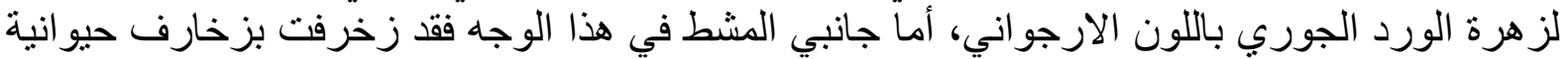

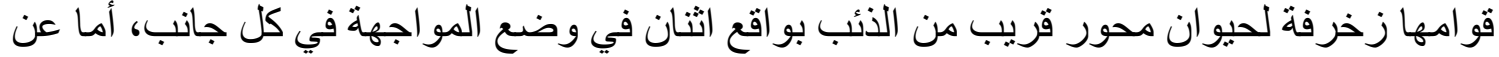


زخارف الوجه الآخر فجاءت مماثلة تماماً لزخارف الوجه الاول.

التحفة الخامسة:

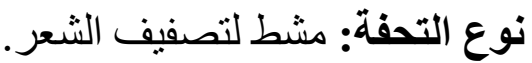

مواد الصناعة: الخشب المُة المطلي. الأسلوب الزخرف: الطلاء باللاكيه.

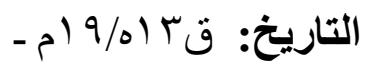

مكان الحفظ: متحف الفن الإسلامي بالقاهرة:

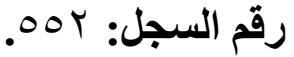

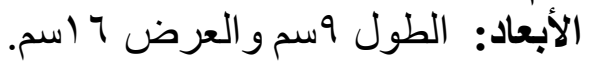

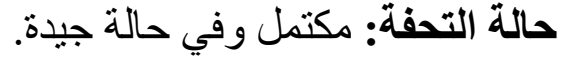

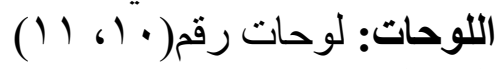
الوصف:

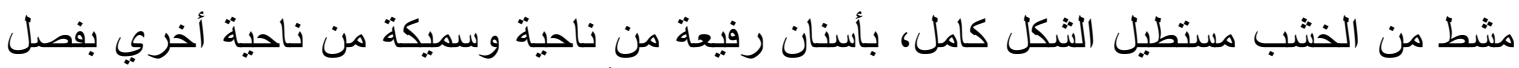

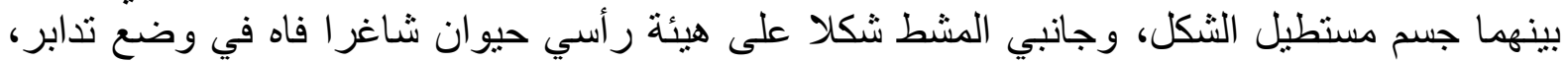

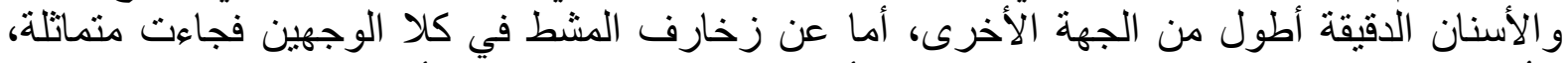

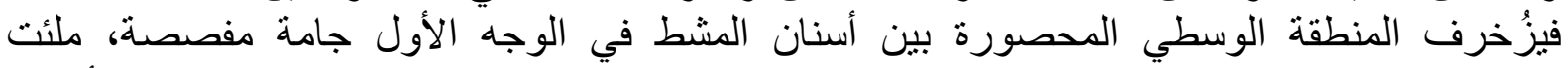

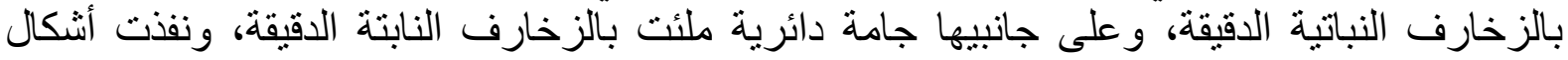

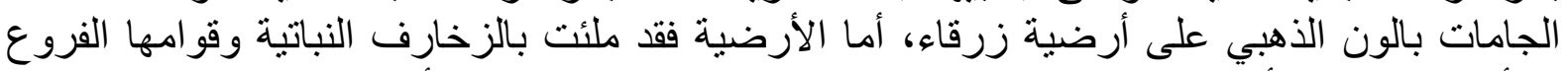

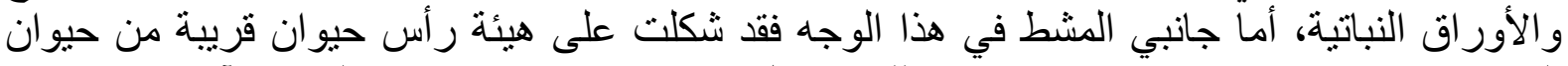

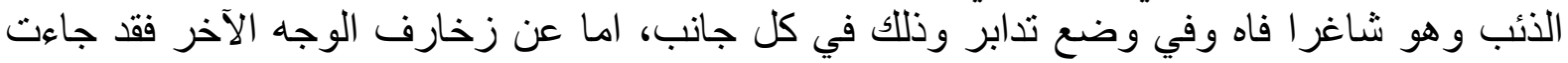

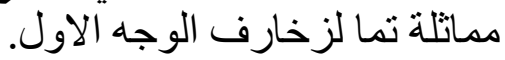

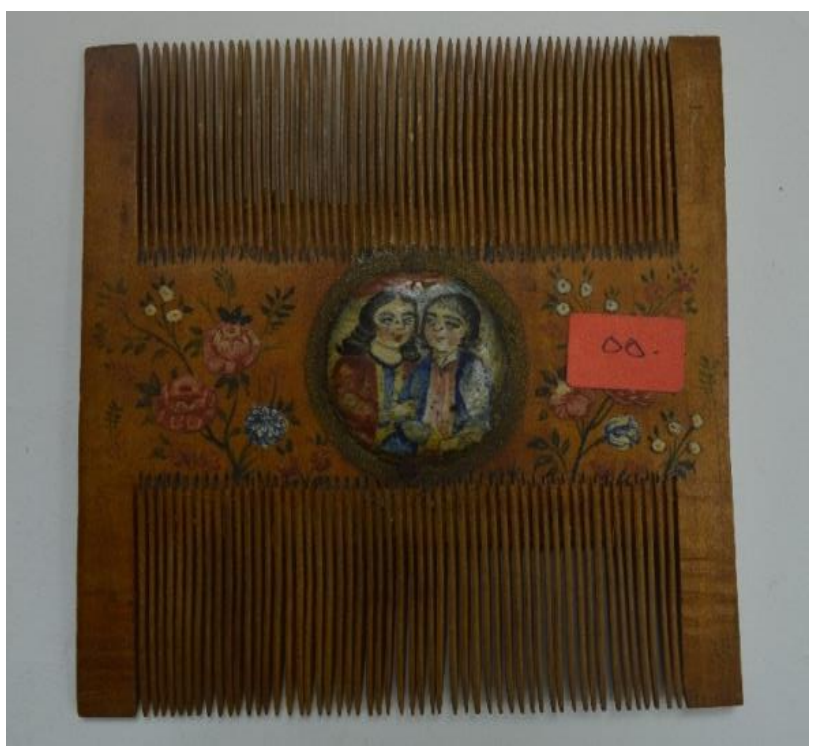

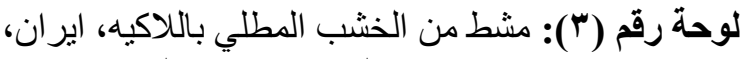
ق ت اهـ/9 (م، متحف الفن الإسلامي بالقاهرة.

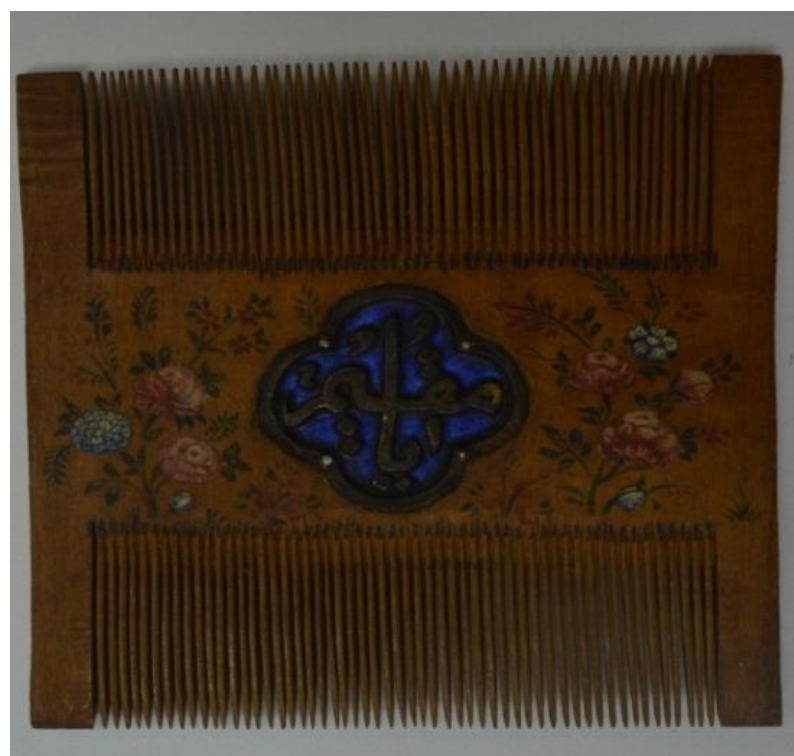

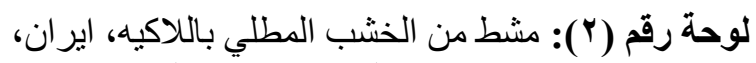
ق ت ا هـ/9 ( ام، متحف الفن الإسلامي بالقاهرة. 


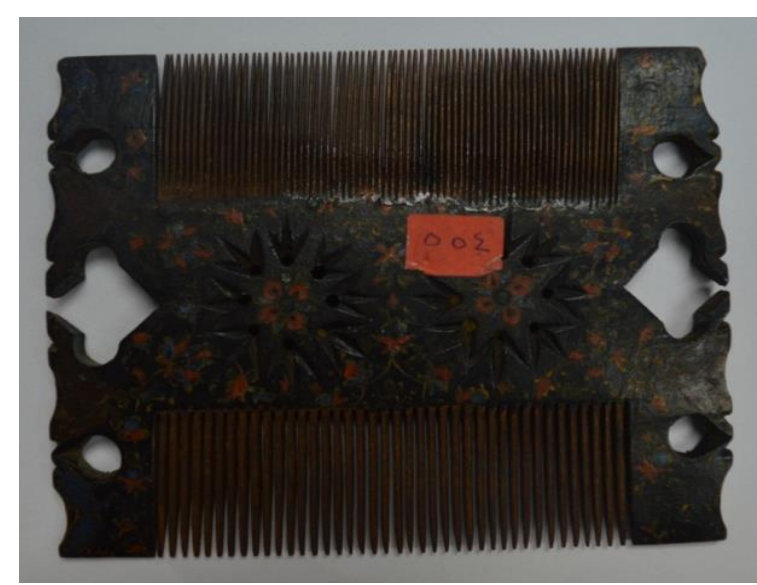

لوحة رقم (0): مشط من الخشب المطلي باللاكيه، ايران، ق با أهـ/9 (م، متحف الفن الإسلامي بالقاهرة.

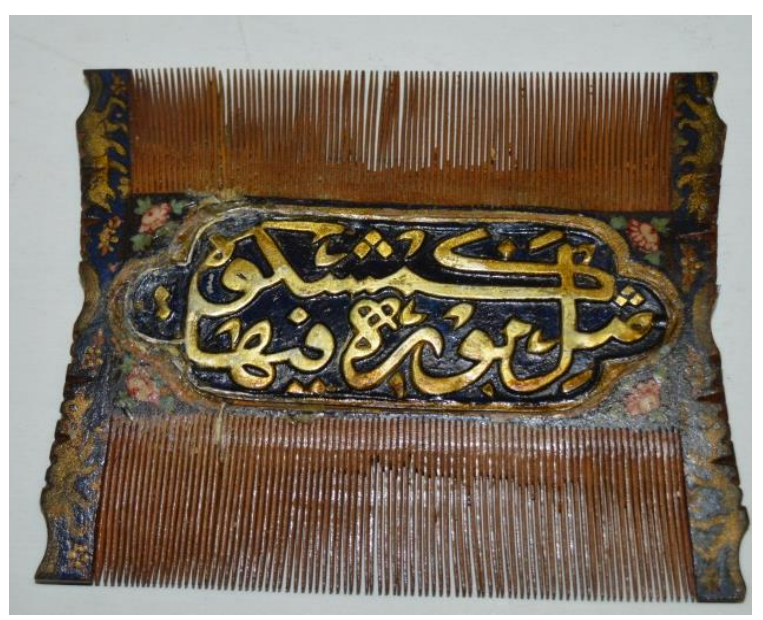

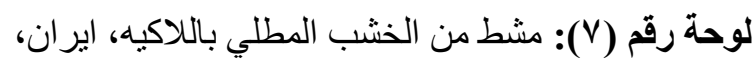
ق T اهـ/9 ( م، متحف الفن الإسلامي بالقاهرة.

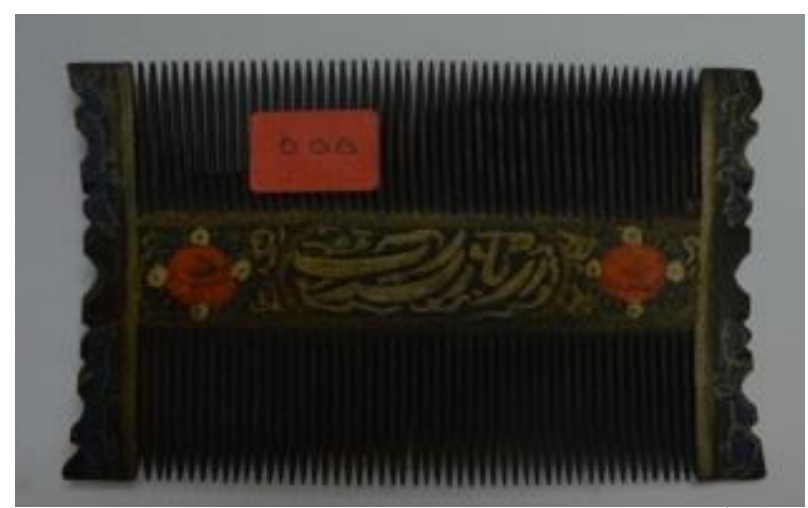

لوحة رقم (9): مشط من الخشب المطلي باللاكيه، ايران، ق ب أهـ/9 ( م، متحف الفن الإسلامي بالقاهرة.

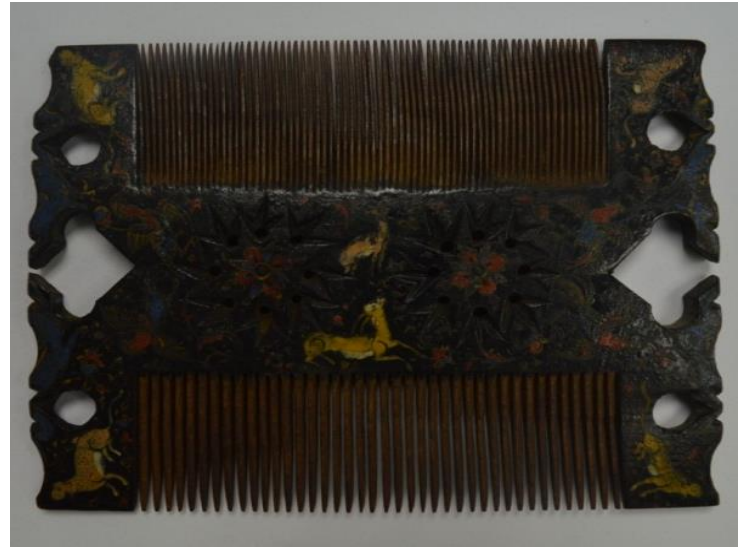

لوحة رقم (ع): مشط من الخشب المطلي باللاكيه، ايران، ق ب أهـ/9 (م، متحف الفن الإسلامي بالقاهرة.

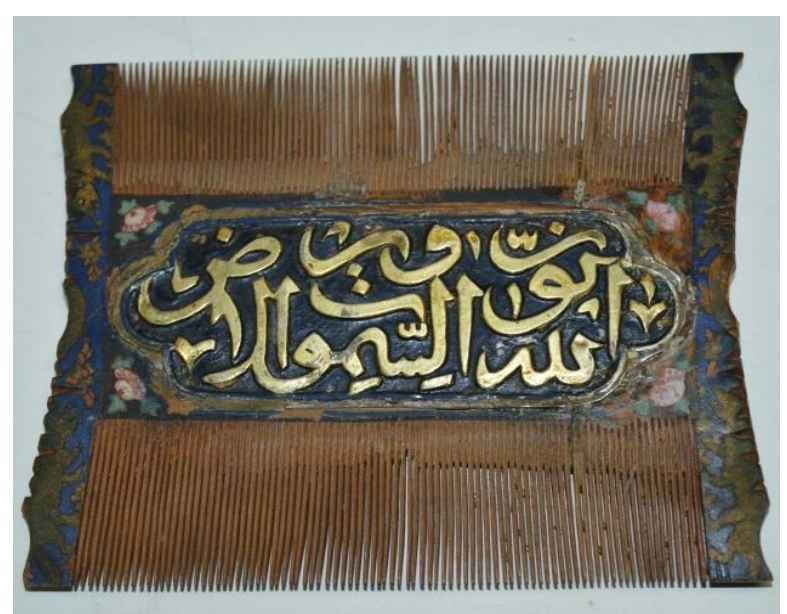

لوحة رقم (ך): مشط من الخشب المطلي باللاكيه، ايران، ق ب أهـ/9 ( م، متحف الفن الإسلامي بالقاهرة.

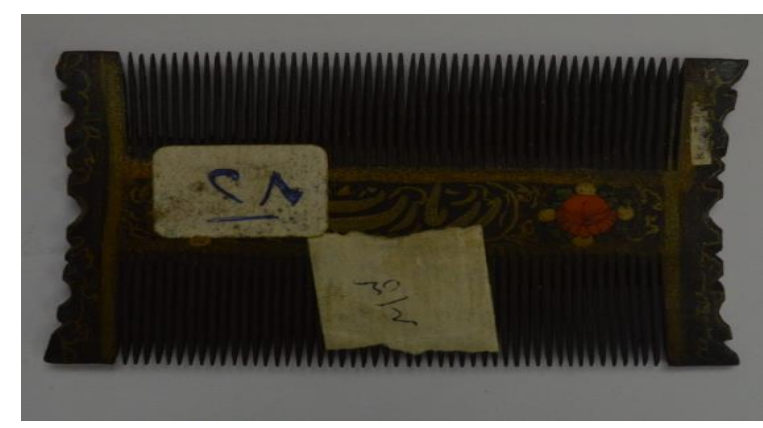

لوحة رقم (N): مشط من الخشب المطلي باللاكيه،

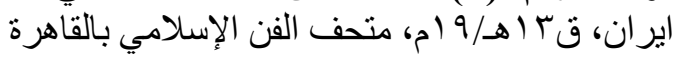




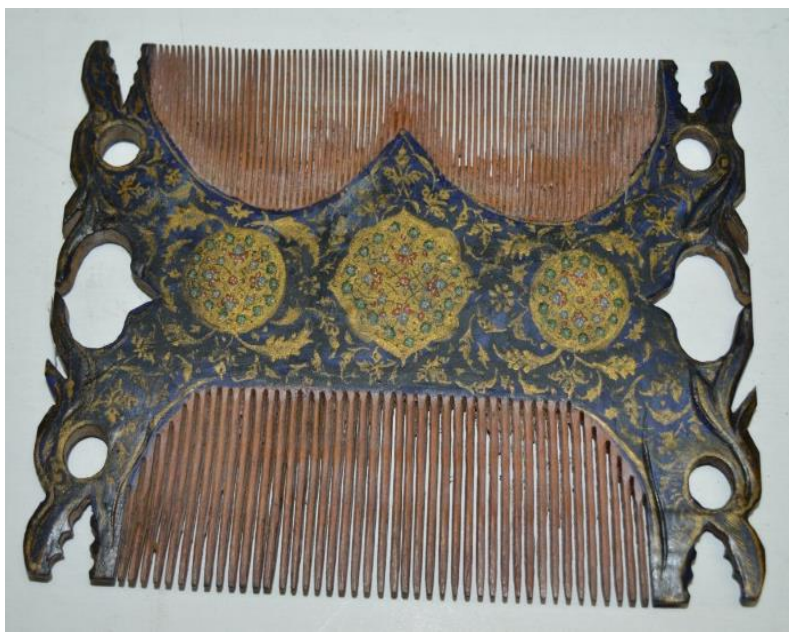

لوحة رقم (1 (1) ): مشط من الخشب المطلي باللاكيه، اير ان، ق ب أهـ/9 (1م، متحف الفن الإسلامي بالقاهرة.

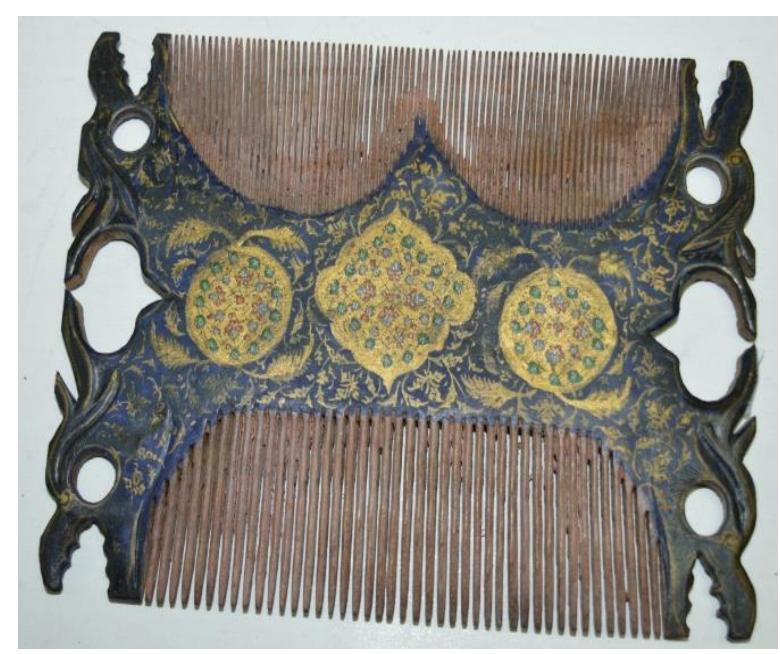

لوحة رقم ( • 1): مشط من الخشب المطلي باللاكيه، اير ان، ق بـ (19 (1) (م، متحف الفن الإسلامي بالقاهرة.

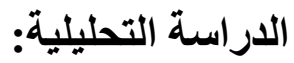

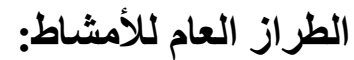

الطراز العام أو الهيئة العامة* للأمشاط، ويتكون المشط من منطقة مستطبلة محصورة بين أسنان

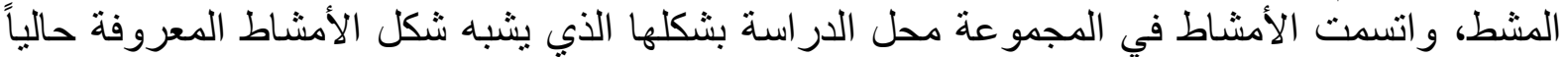

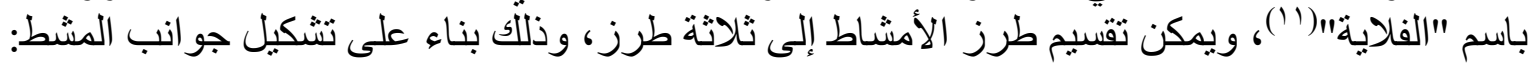

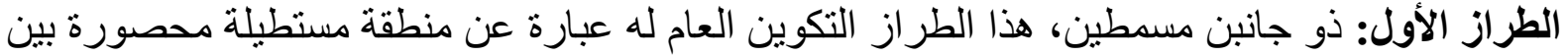

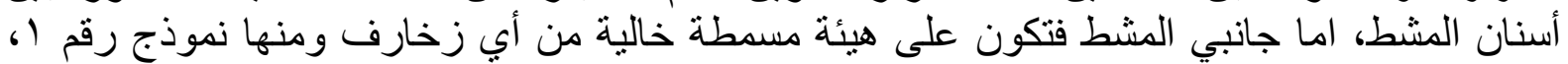

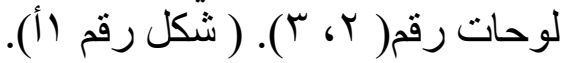

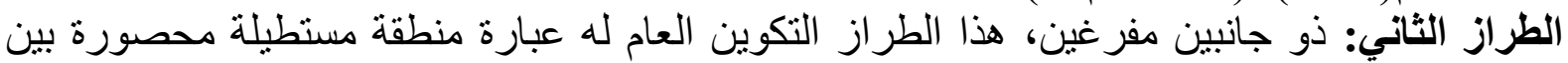

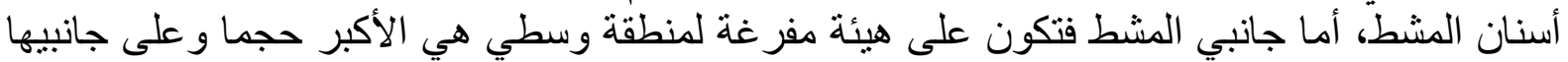

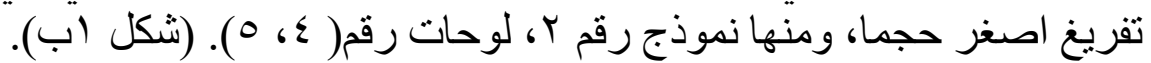

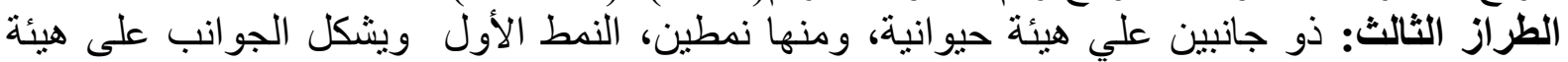

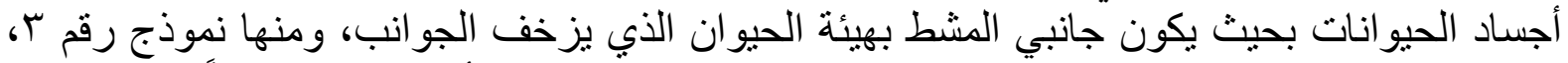

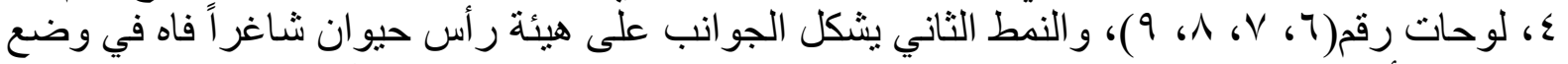

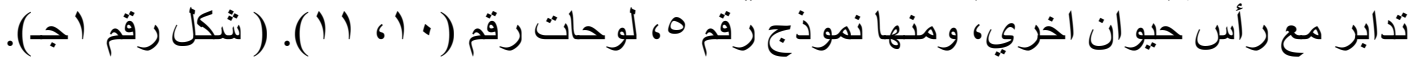



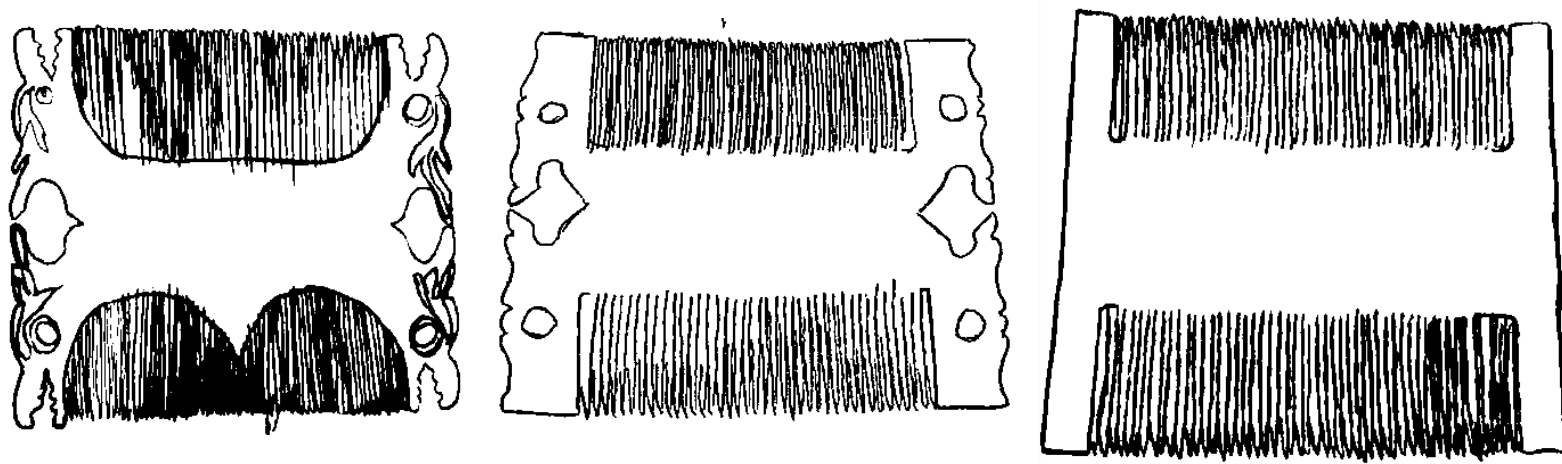

$$
\text { (أ): المشط ذو الجانبين المسمطين (ب): المشط ذو الجانبين المفرغين (ج): المشط ذو الجانبين على الهيئة }
$$

مواد وطرق الصناعة: - ماعن

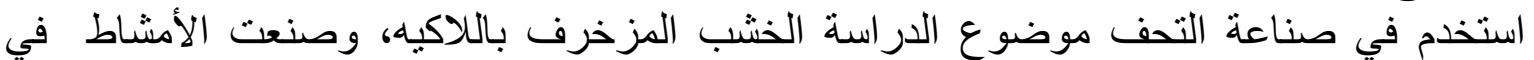

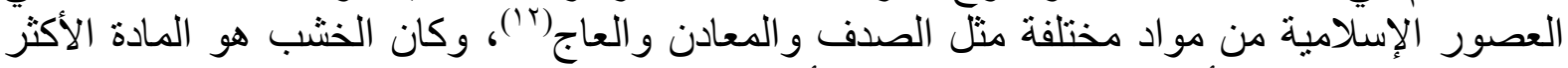

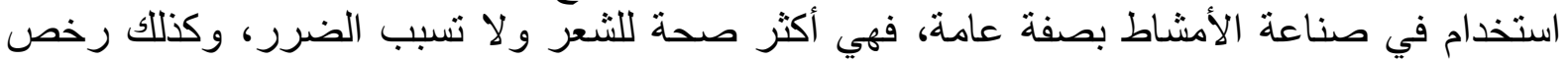

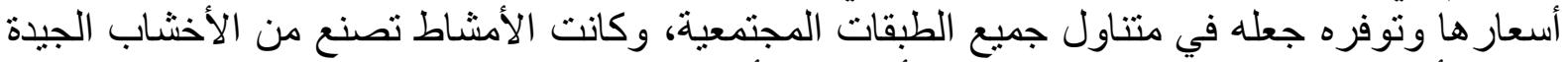

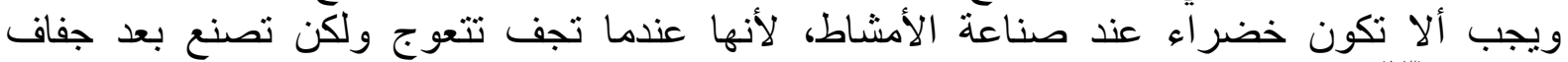

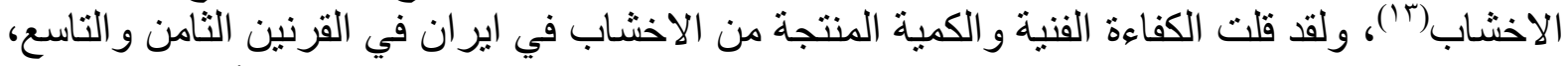

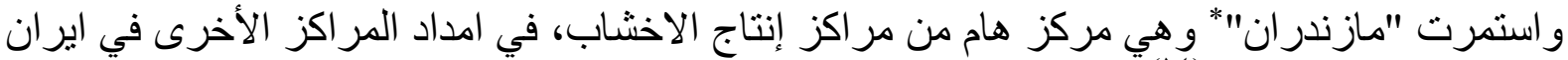

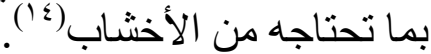

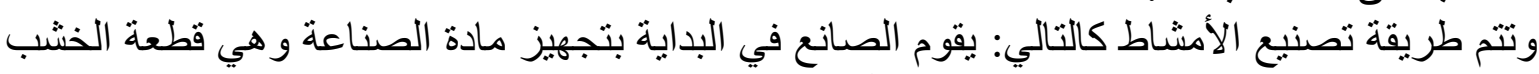

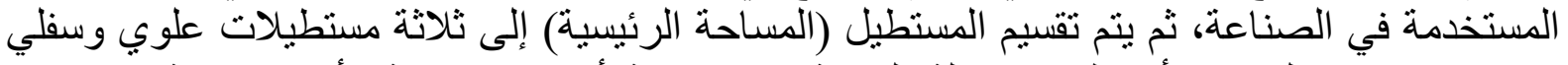

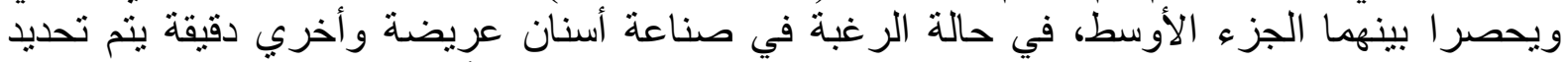

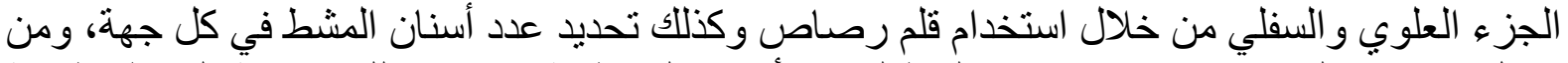
خلال استخدام المنشار يتم تفريغ مكان النقط لتحديد أسنان المشط، ثم تتم بعد ذلك زخرفة زئة المشط بطريقة

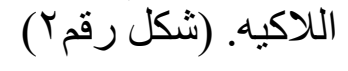

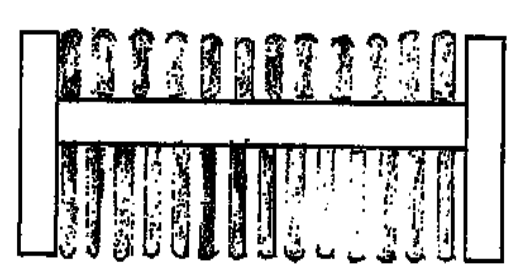

(ج)

(ب)

شكل رقم (r): خطوات صناعة المشط، عن: فايزة عبد الخالق الوكيل: الثوار ( جهاز العروس في مصر ) في عصر

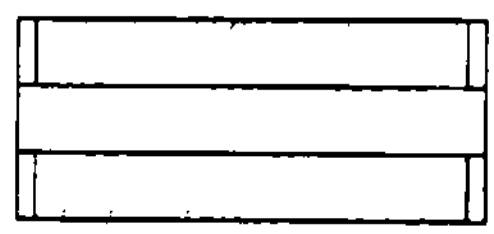

(ا)

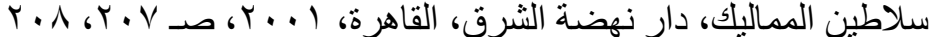


وبعد تشكيل المشط يتم زخرفته بطريقة اللاكيه، و اللاكيه هو طلاء أو ورنيش بستخدم لإعطاء طبقة صلبة

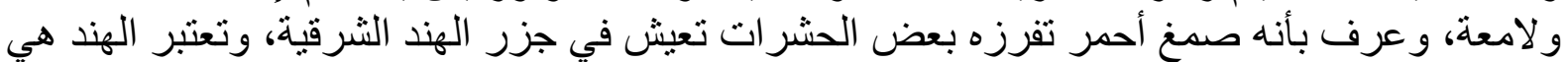

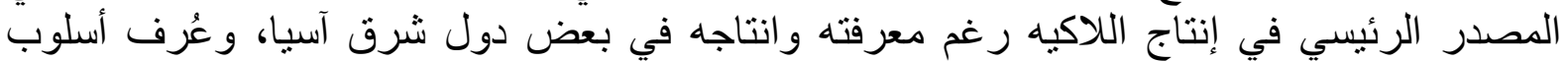

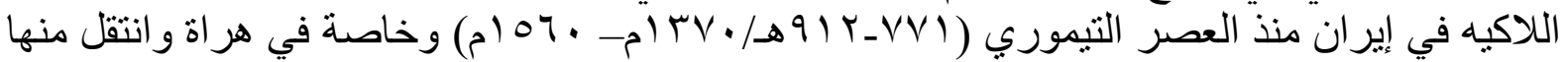

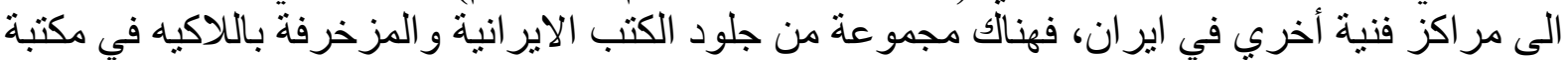

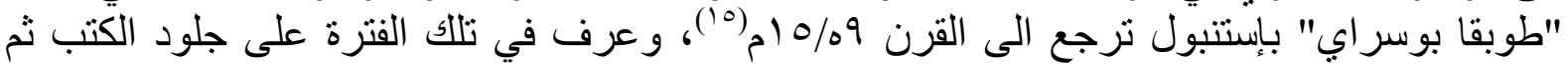

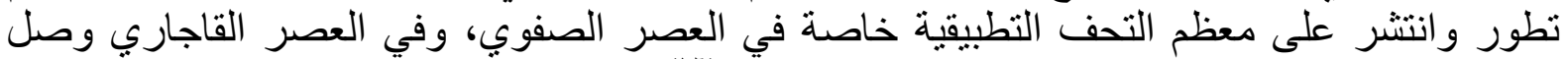

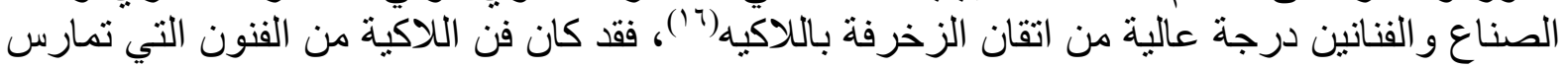

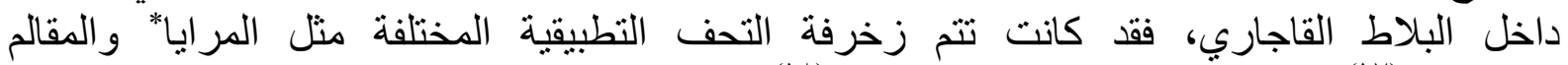

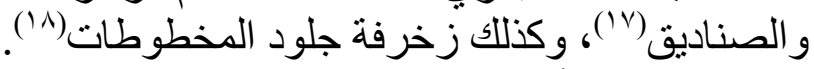

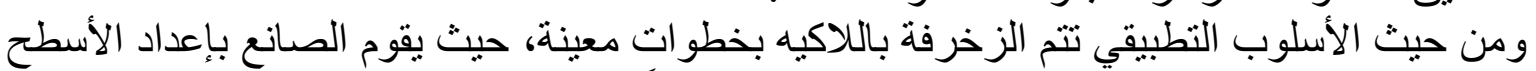

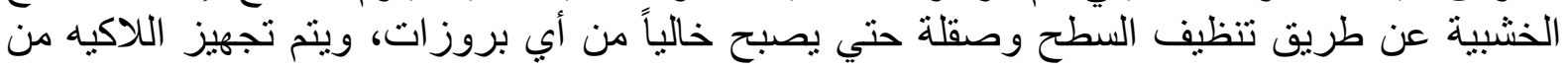

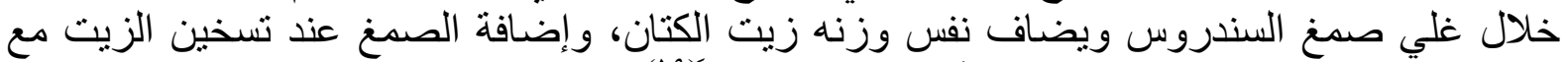

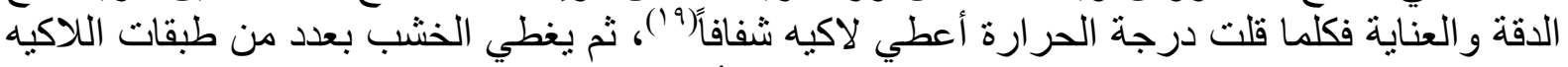

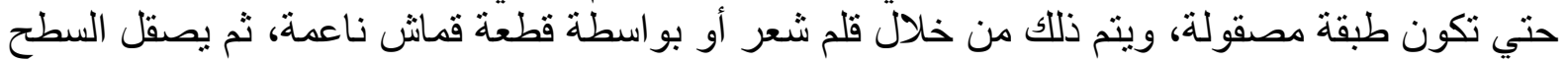

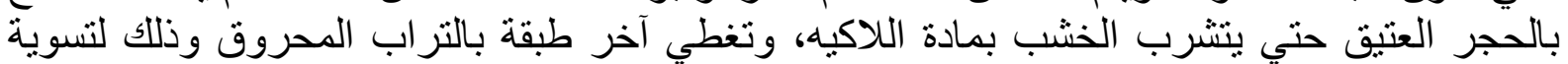

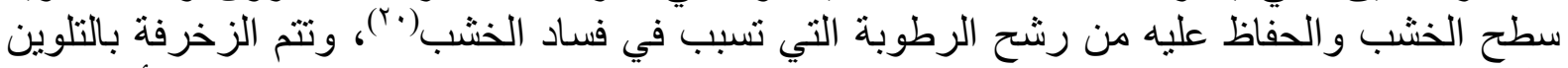

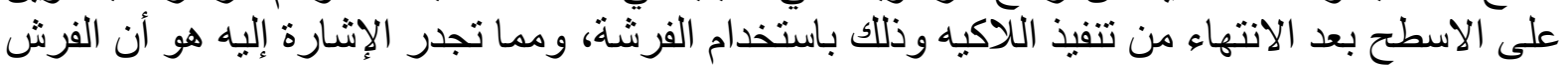

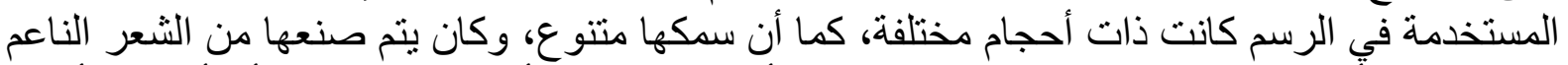

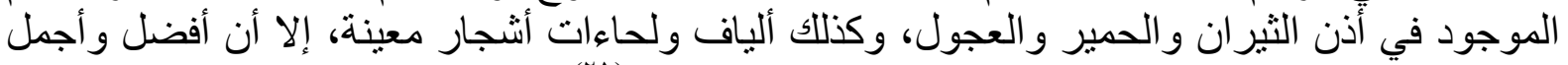

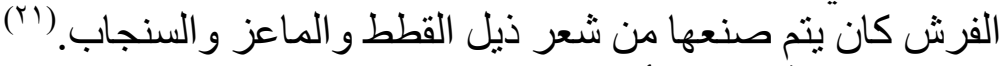
الزخاف المنفذة على الأمثاط:

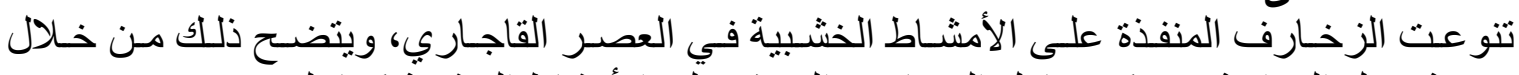

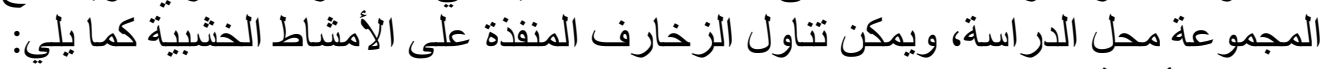

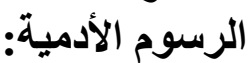

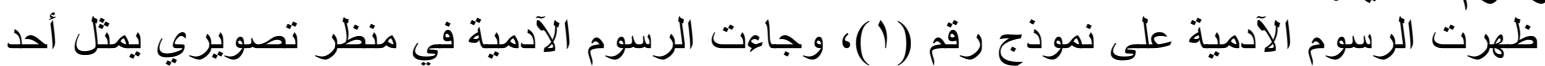

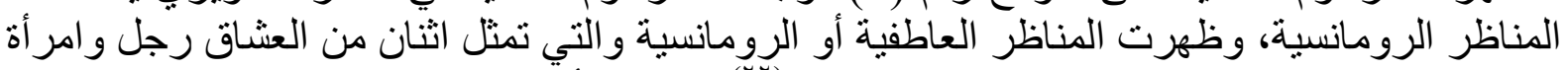

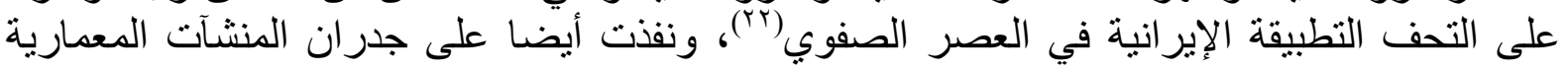

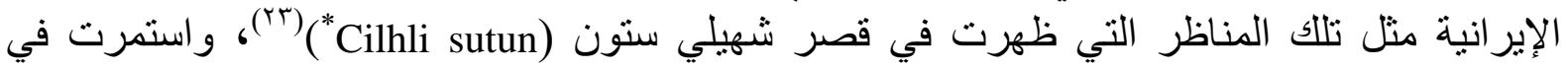

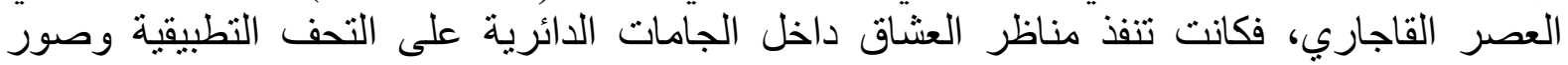

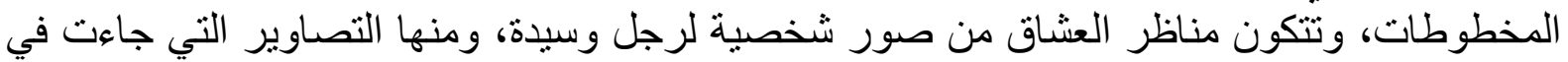

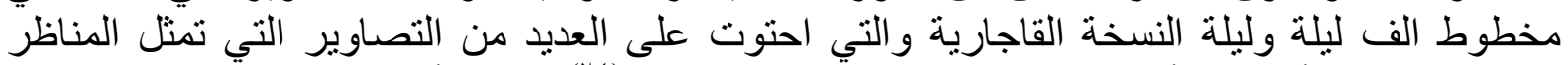

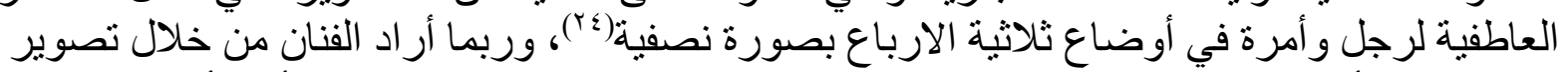

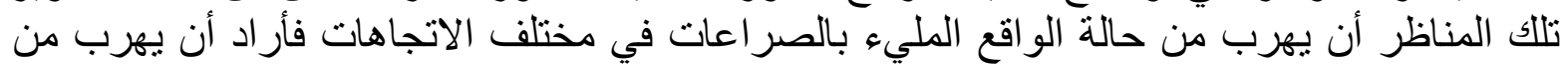

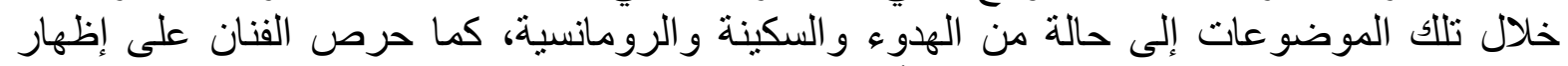

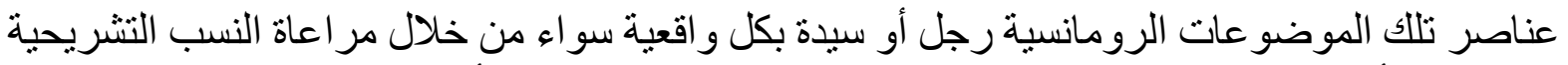

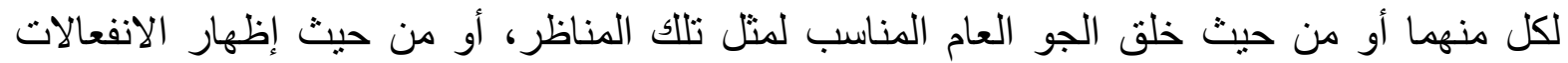

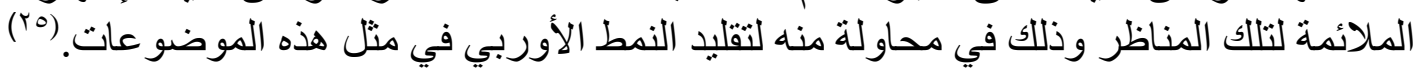

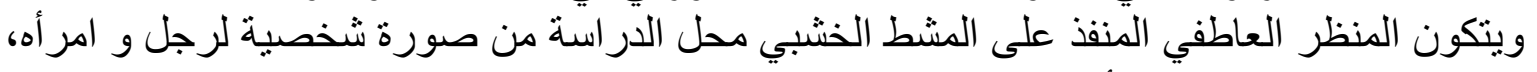
وتعتبر الصور الثخصية* من أهم الزخارف المنفذة على التحف التطبيقية في العصر القاجاري، فقد شهد الته 
العصر القاجارى* قمة التطور في فن الصور الثخصية، نتيجة لاهتمام الملوك القاجاريين بالصور

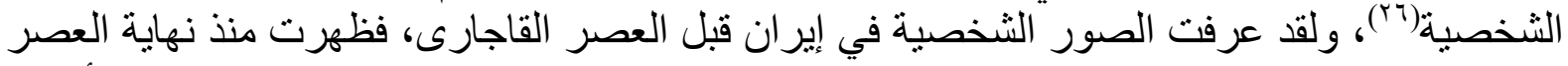

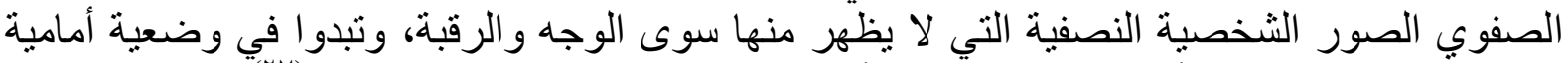

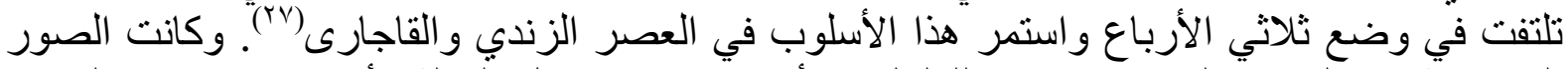

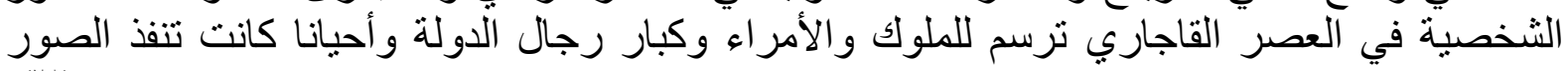

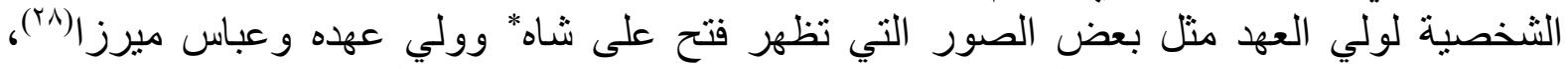

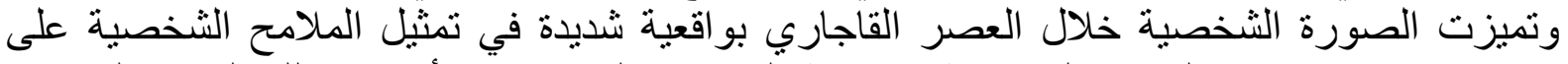

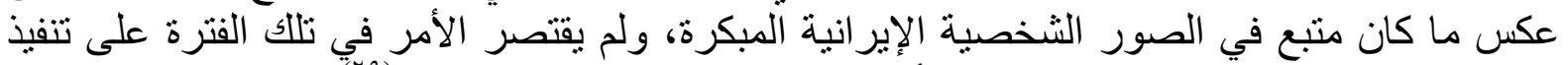

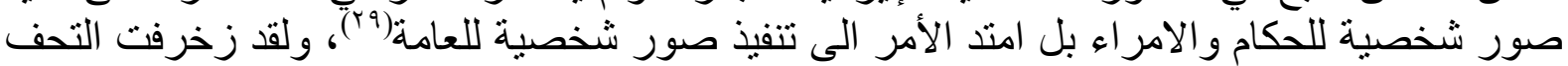

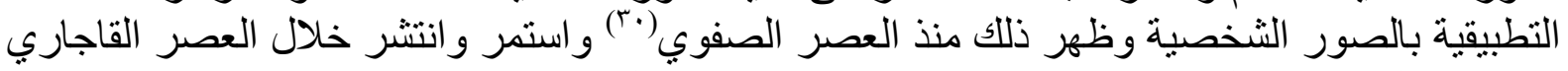

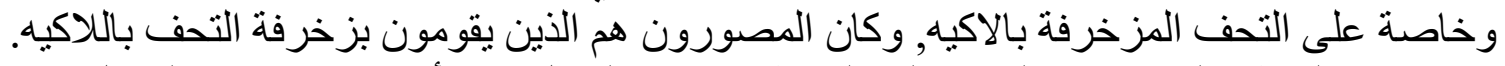

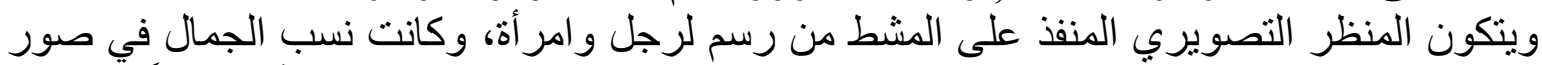

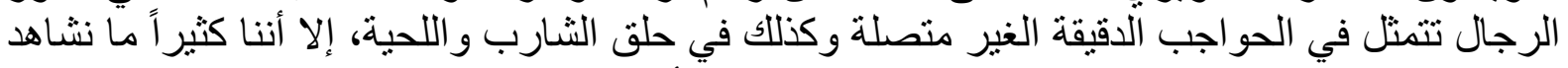

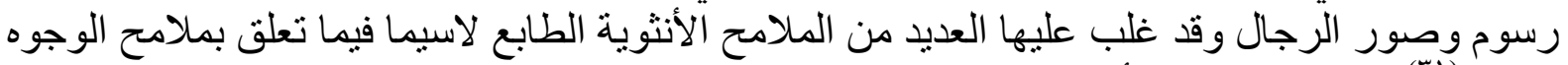

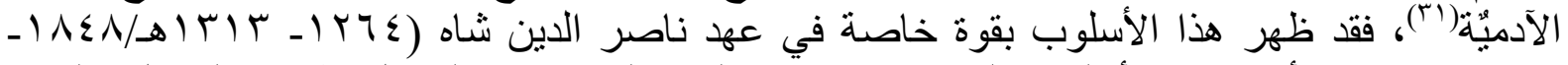

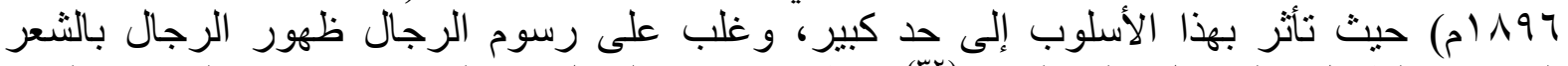

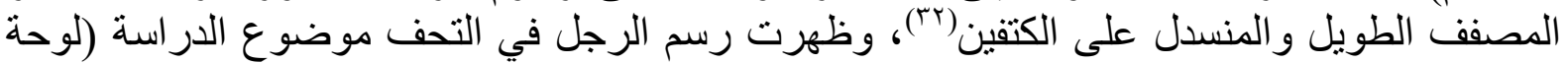

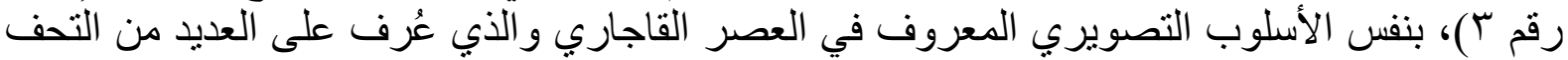

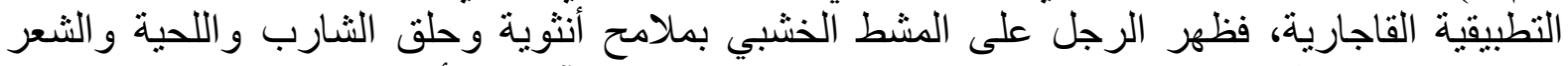

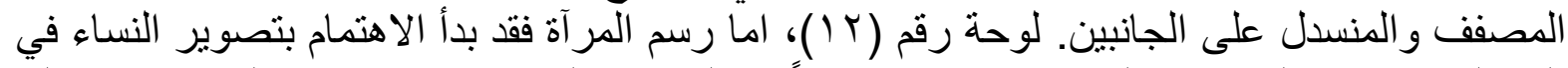

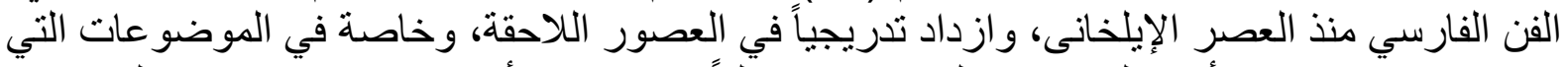

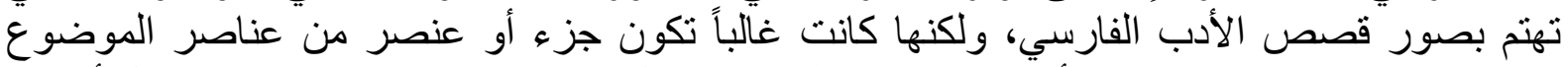

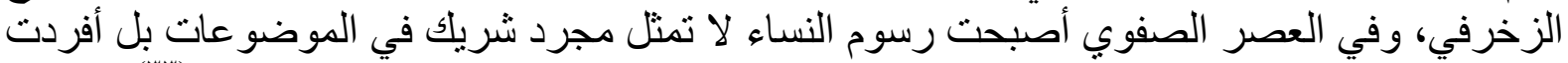

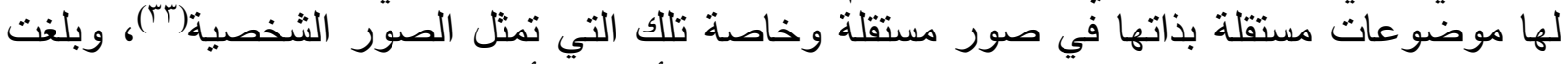

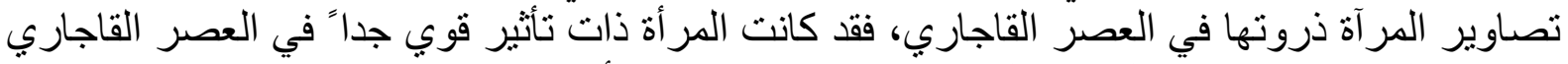

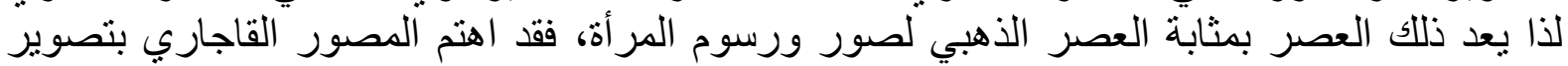

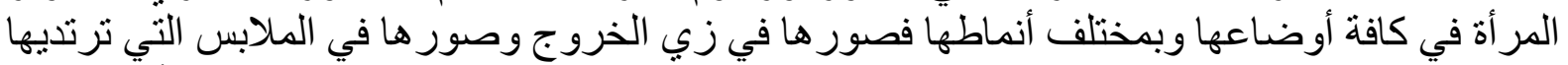

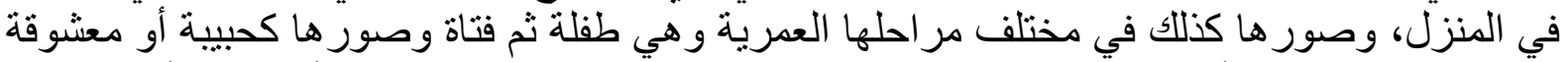

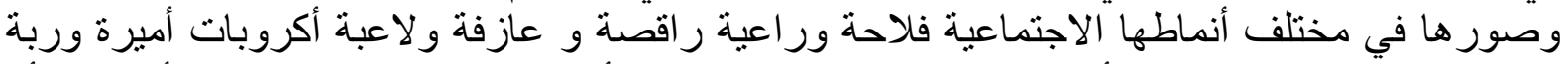

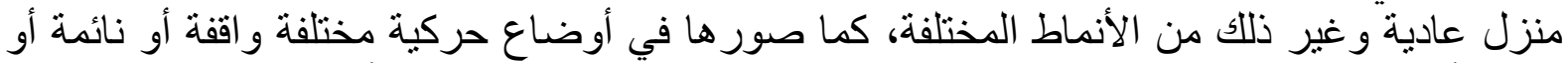

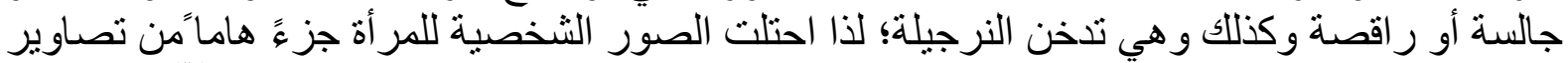

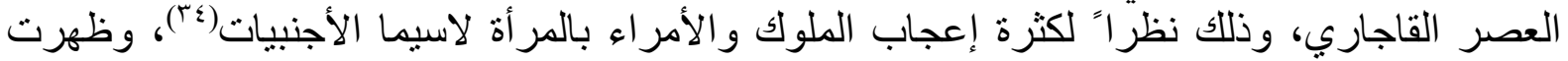

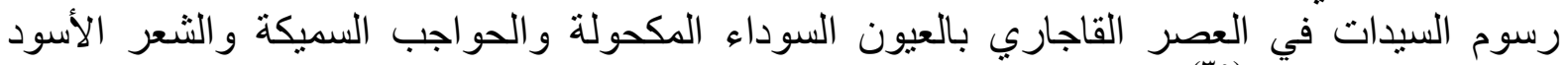

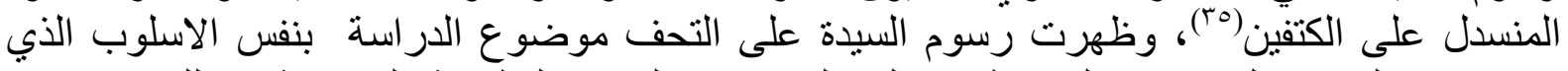

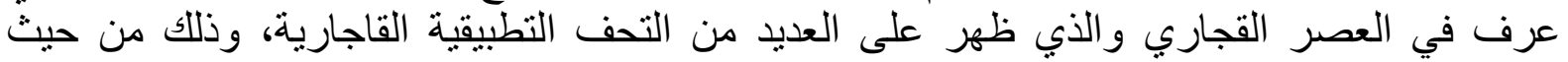

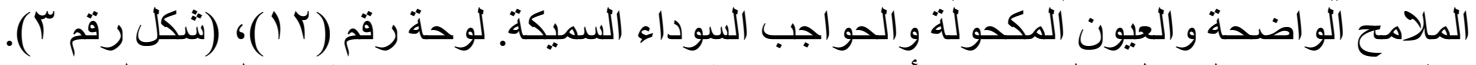

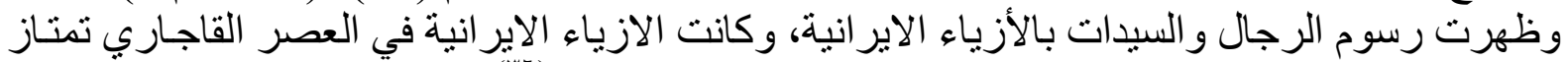

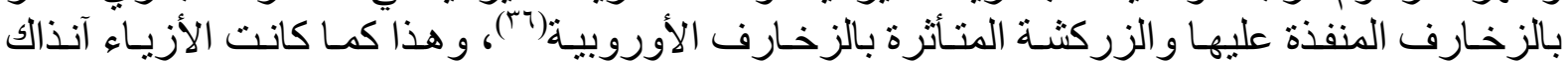

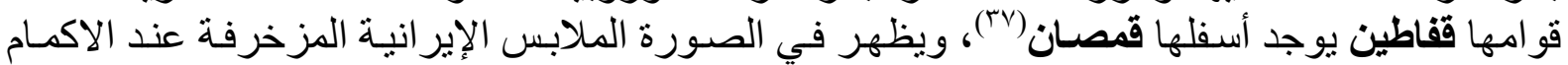

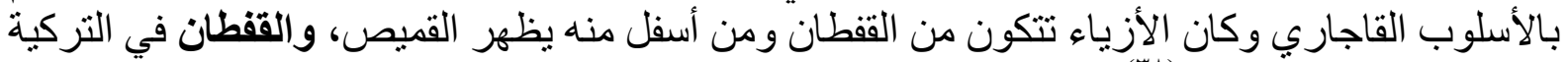

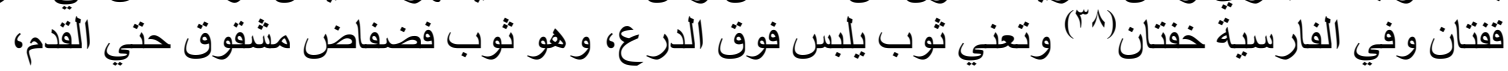


يضم طر فيه بحز ام وله كمان قصير ان يصـلان الى المرفقين وقد يتدلى حتي يبلغ منتصف السـاقين وقد

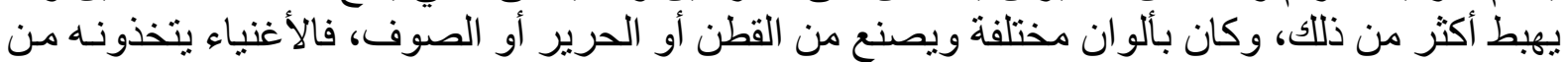

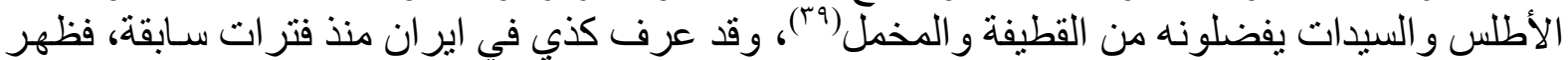

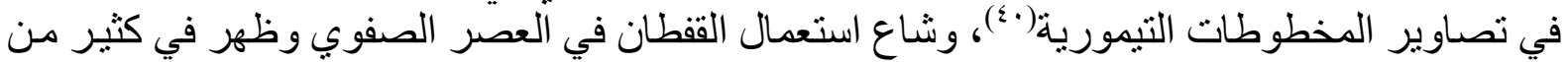

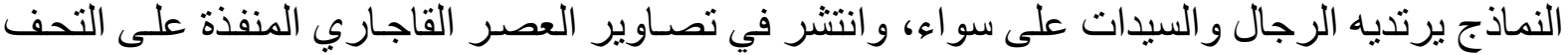

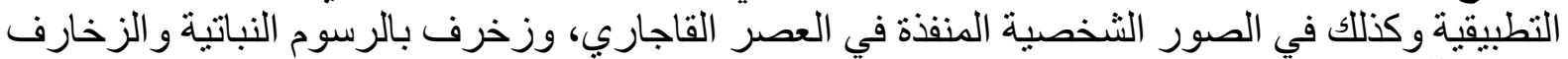

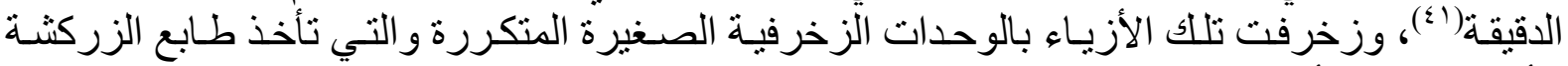

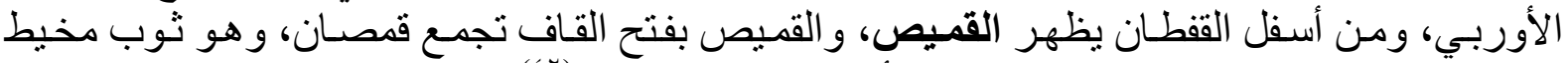

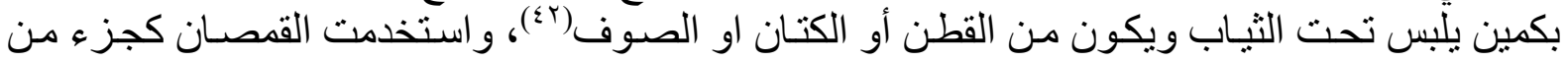

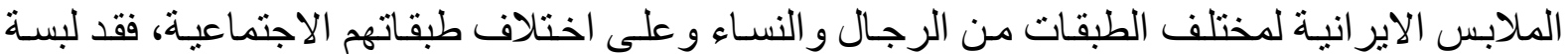

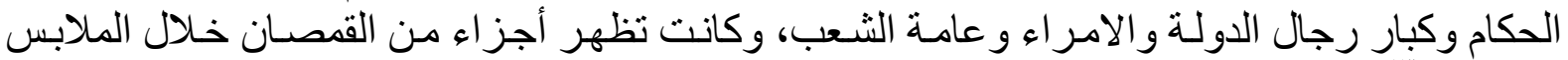
الخارجية"(َّ)، وقد عرف القميص ايضا كذي في اير ان منذ فتر ات سابقة، فظهر في تصاوير المخطوطات

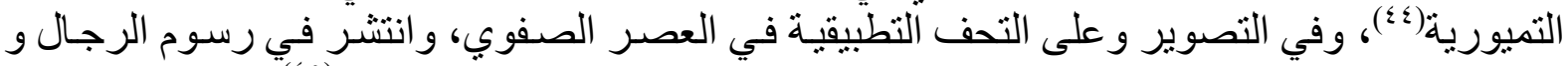
السيدات على التحف التطبيقية في العصر القاجاري فظهرت على الخزف و المعادن (0) و التحف الخشبية.
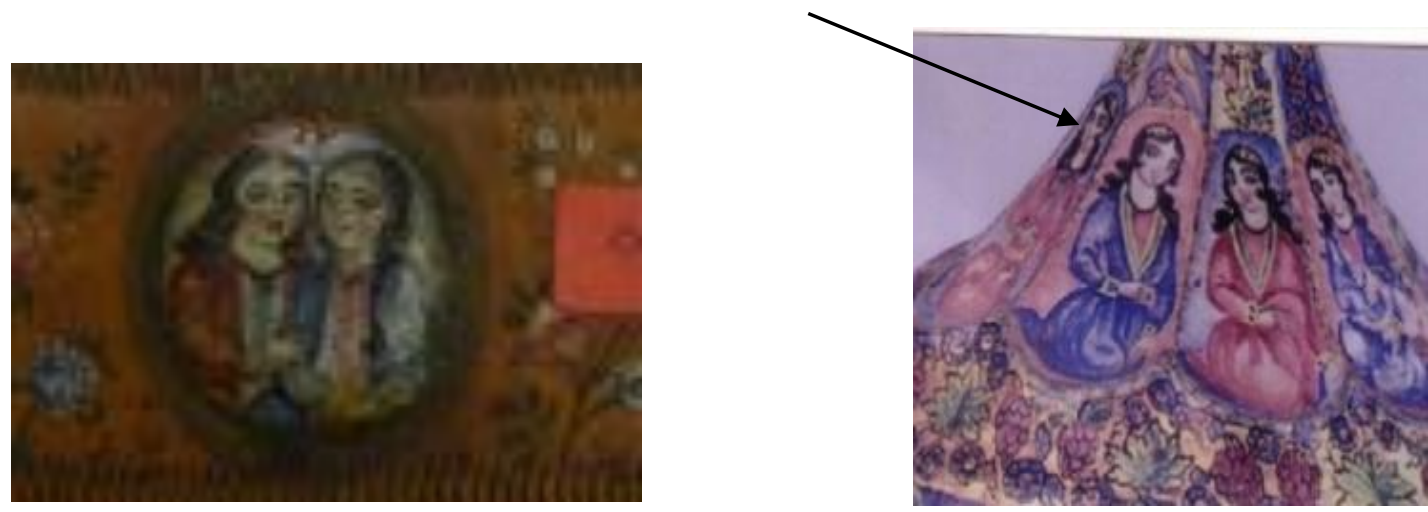

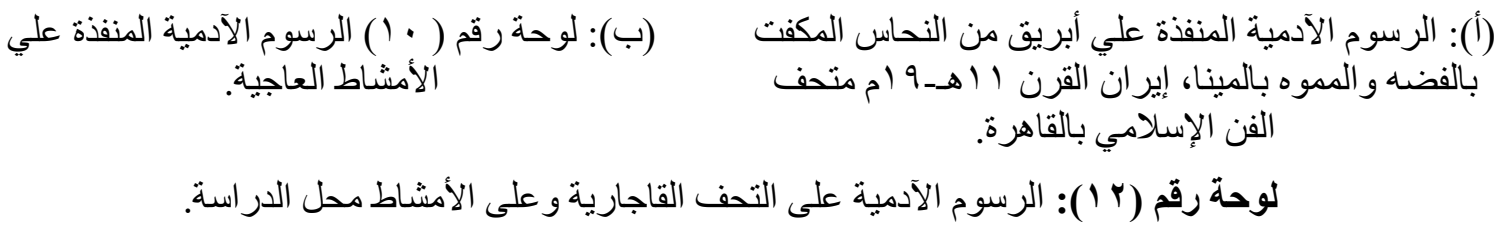

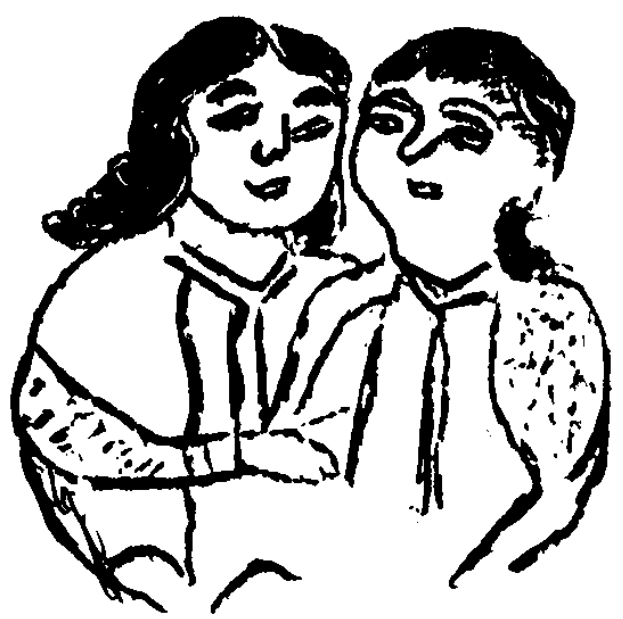

شكل رقم (ّ): الزخارف الآدمية على الأمشاط الخشبية في العصر القاجاري 
الزخارف الحيو انية:

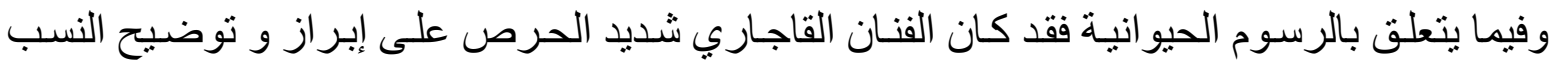
التشريحية وقد اثبت قدرة فائقة في تصوير أحاسيسه بمصداقية أكثر من أي فنان أخر من السـابقين عليه،

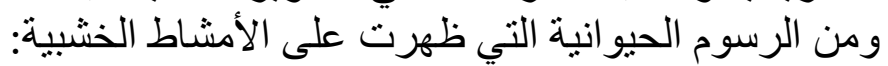

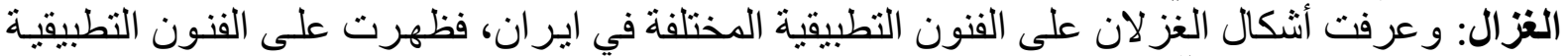

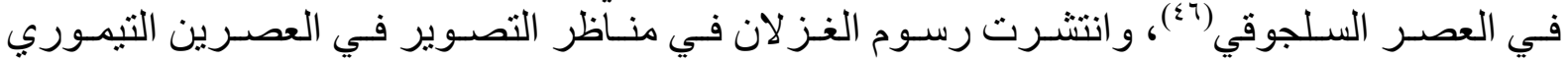
و الصفوي، وظهرت على مختلف المنتجات الفنية في العصر الصفوي، وكذللك على المنشـآت المعماريـة

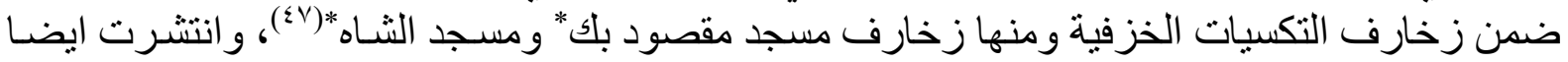

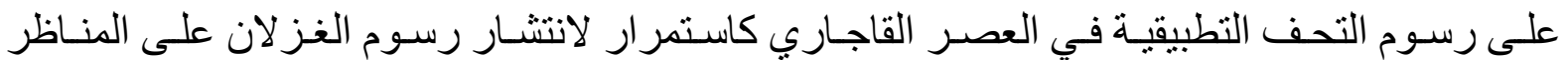

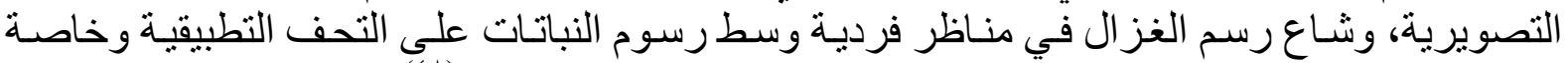

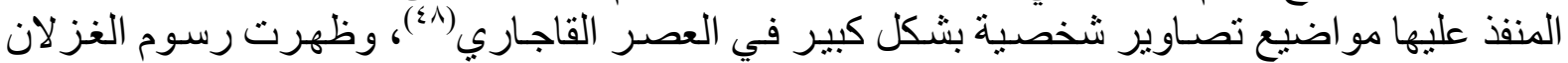

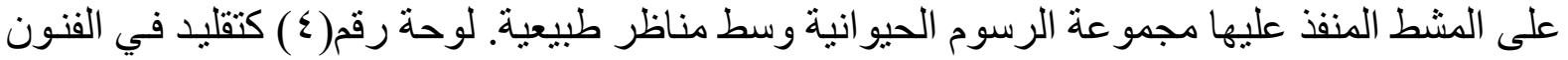

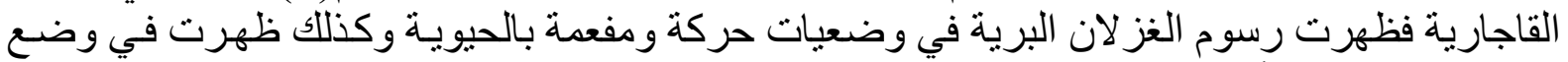
ثبات. ( شكل رقم ع أ).

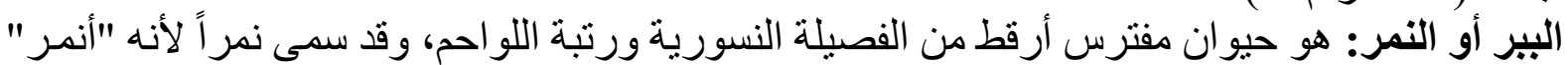

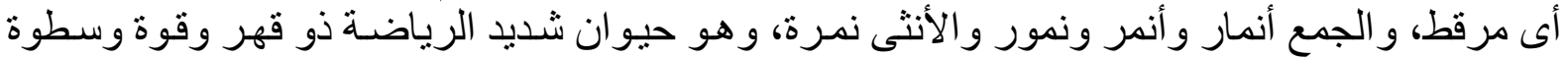

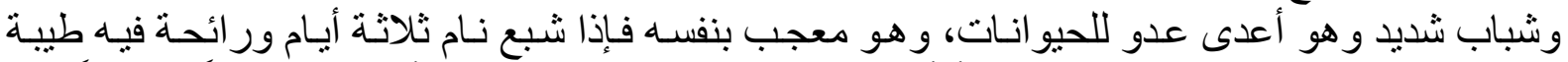

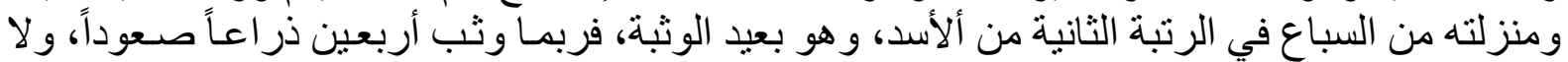

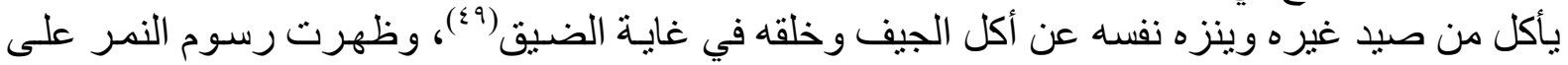

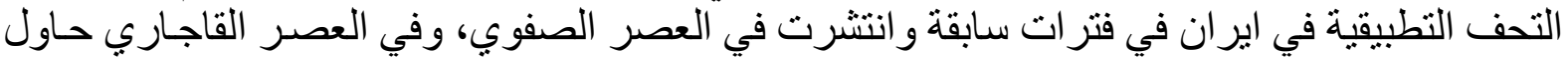

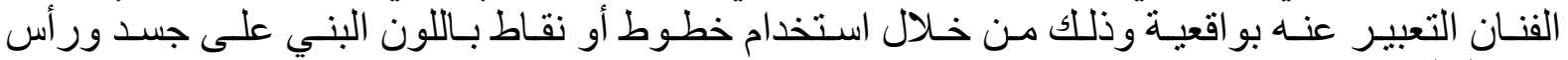

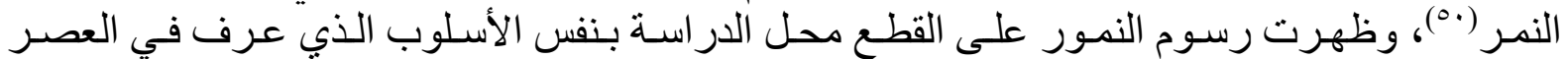

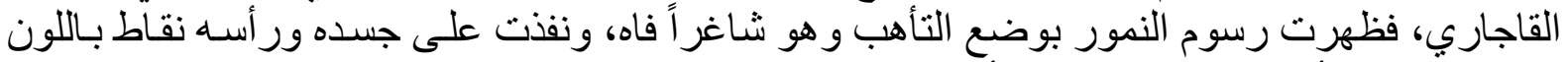

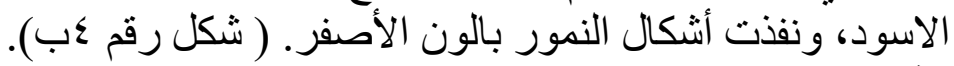

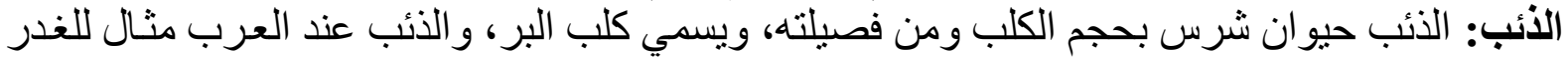

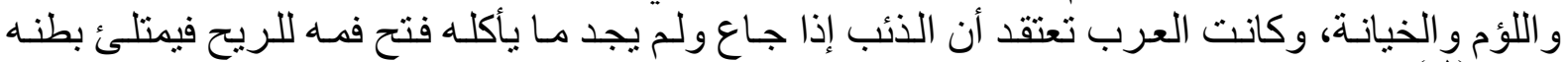

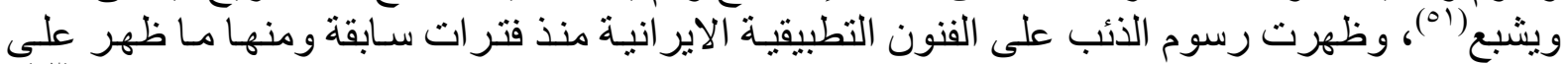

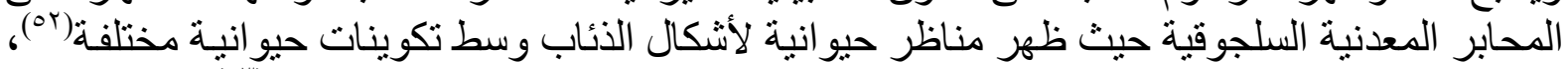

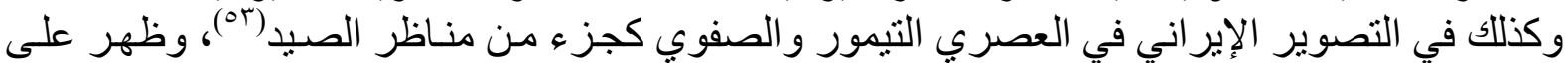

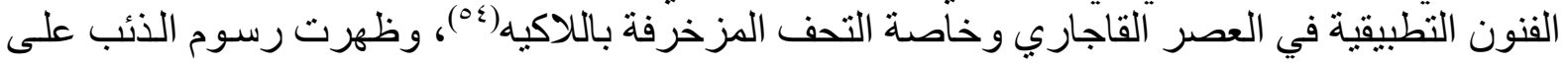

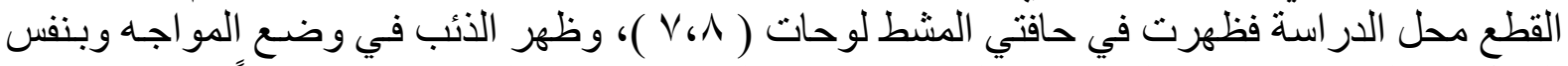

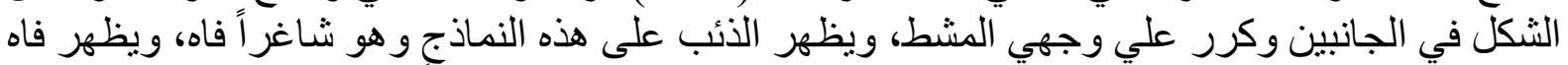

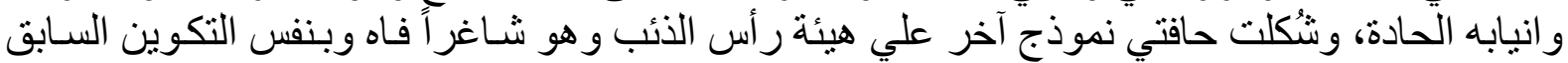

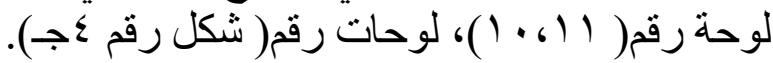

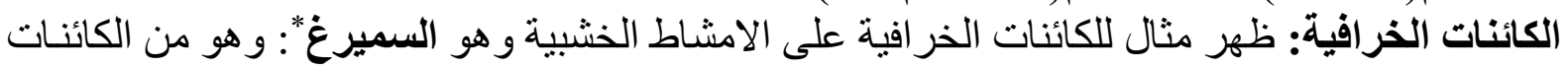

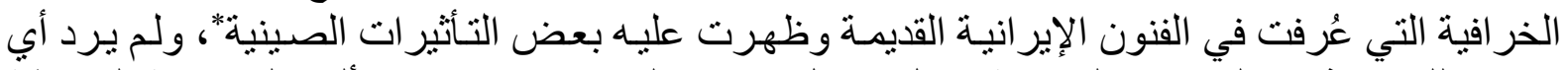

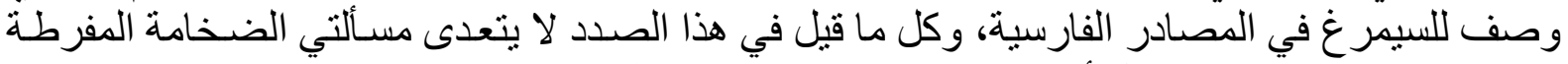

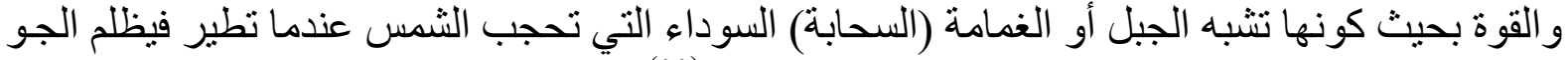

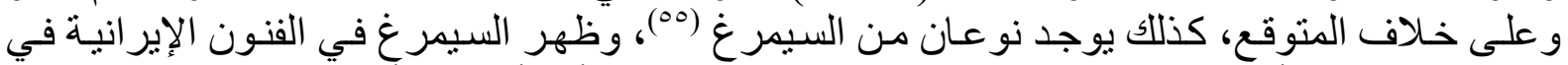

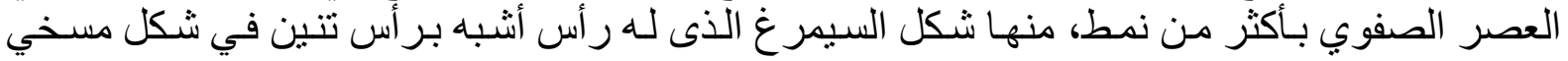

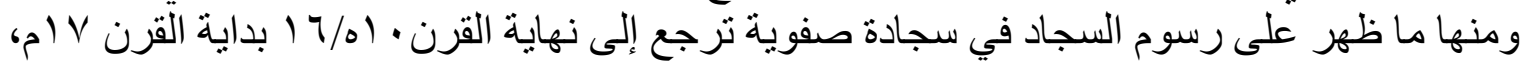




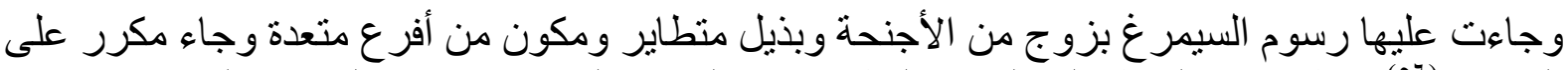

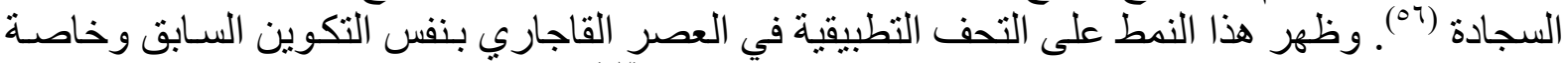

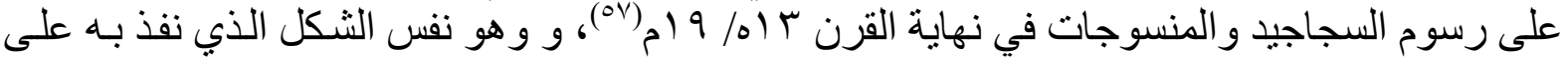
الأمشاط العاجية فظهر رأس تشبه رأس التنين وبزج من الاجنحة وله زيل منطاير . (شكل رقم ه)
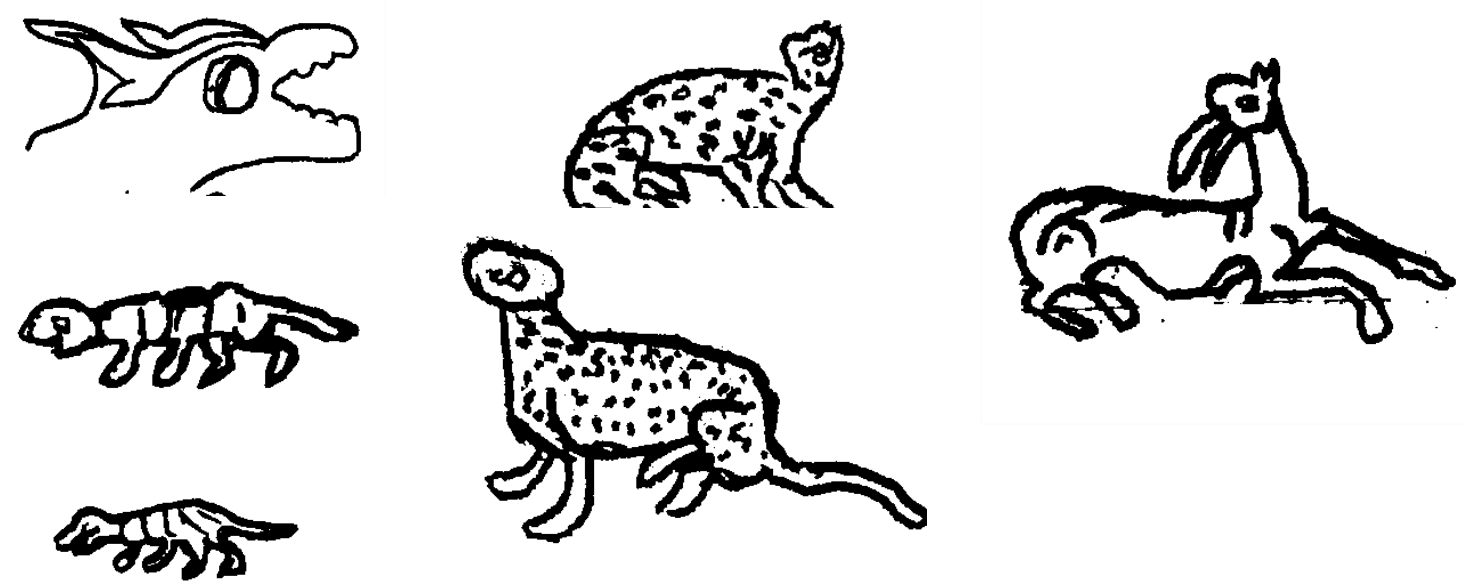

(ج): أشكال الذئاب

(ب) : (ب) أشكال النمور

شكل (ع): أثكال الحيو انات المنفذة على الأمشاط القاجرية

(أ): شكل الغزال
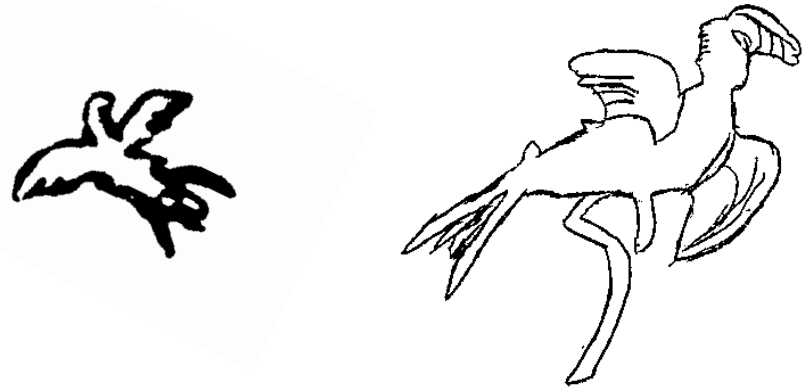

شكل (0): أشكال الكائنات الخر افية (السيمرغ) المنفذة على الأمشاط القاجارية

الزخارف الكتابية

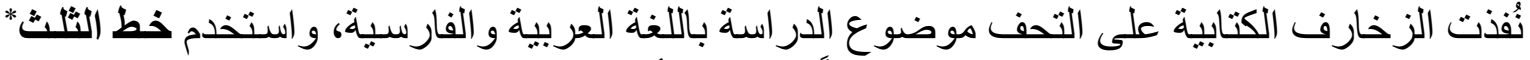

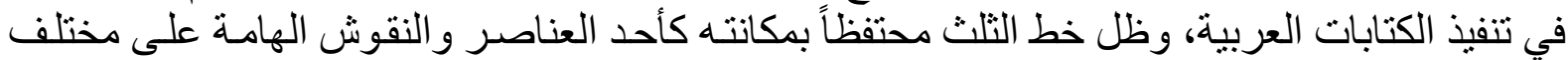

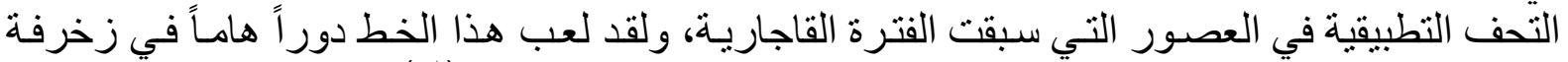

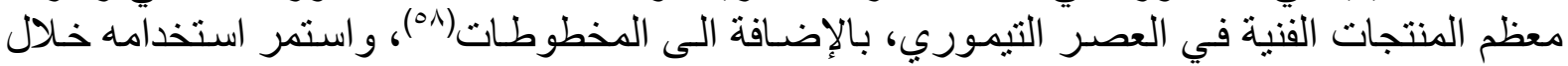

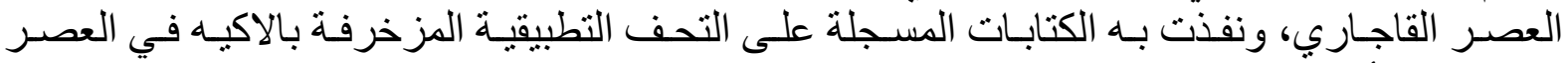

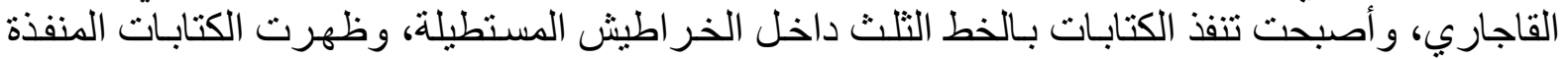

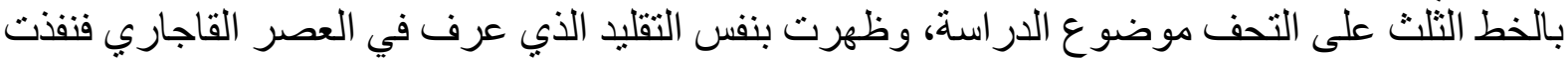

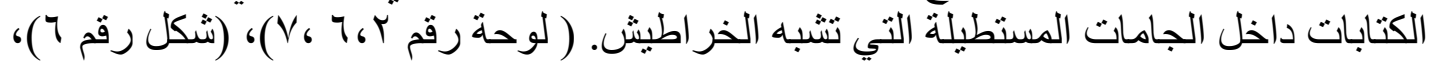

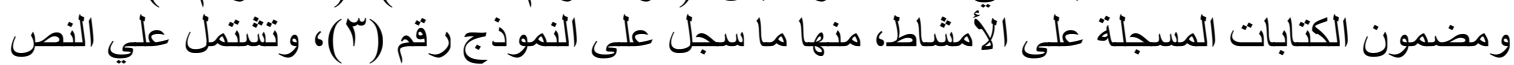




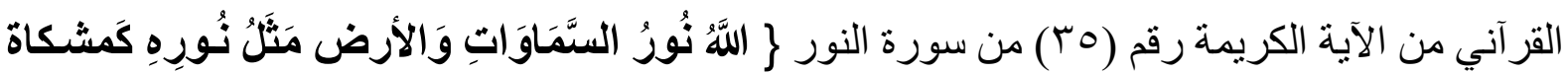

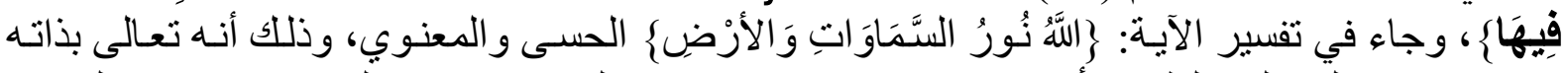

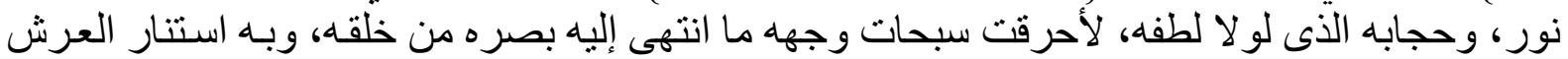

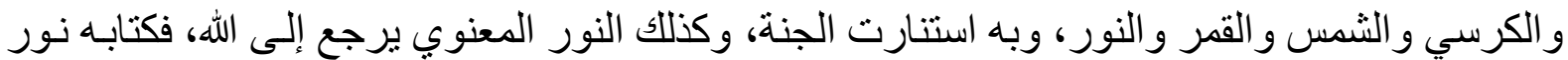

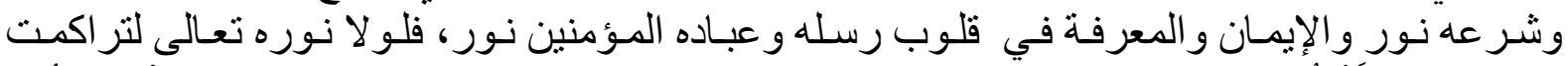

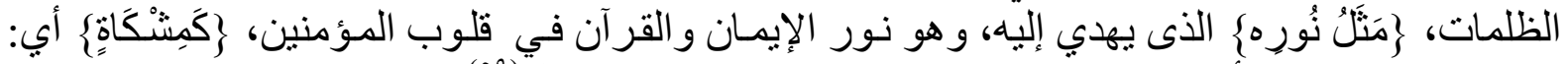

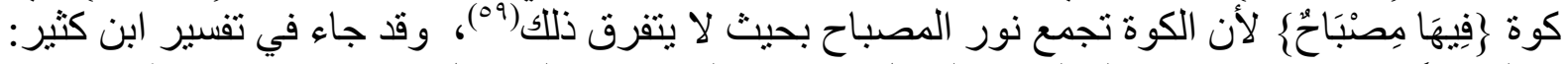
فقو له:

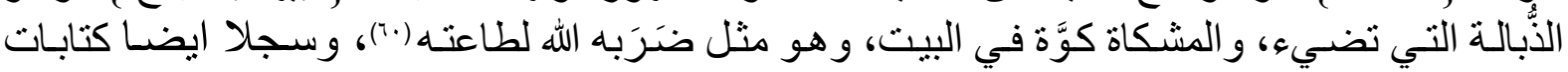

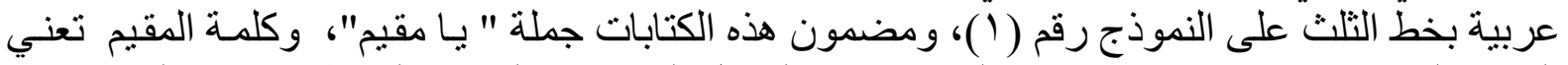

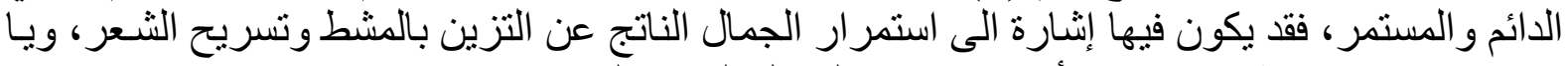

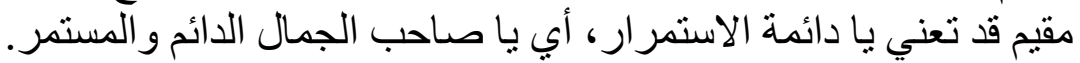

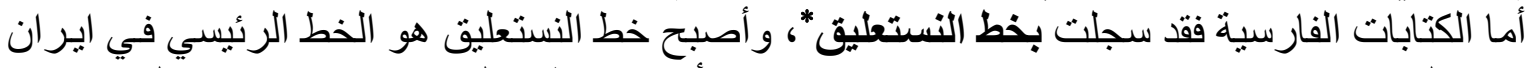

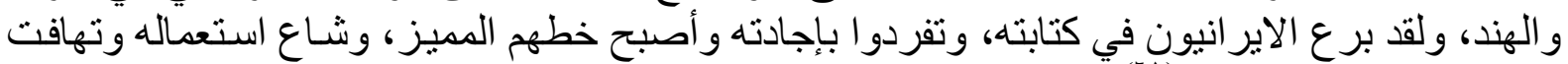

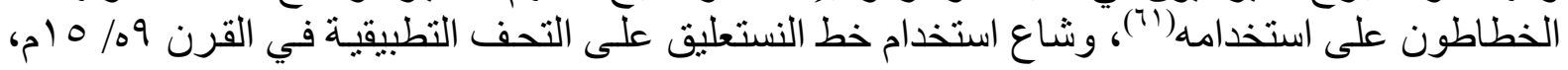

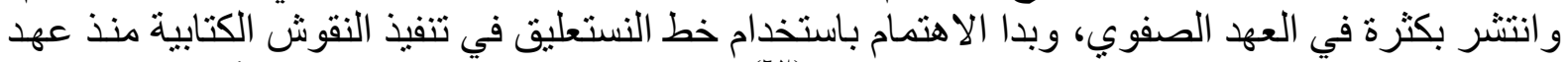

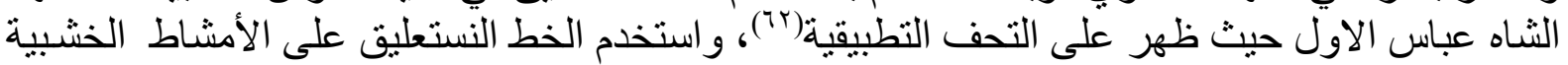

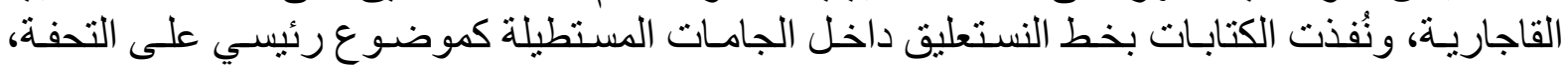

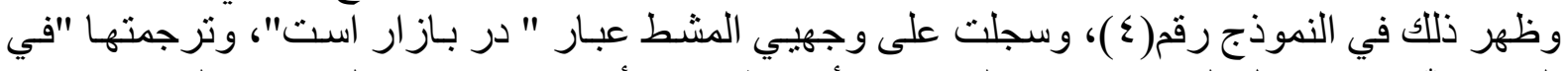

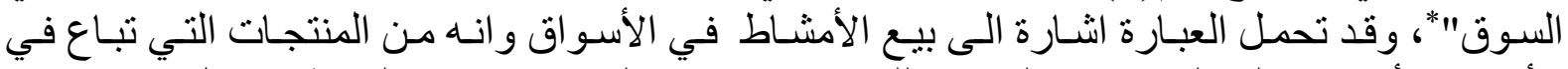

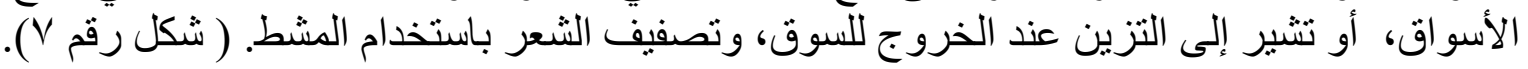
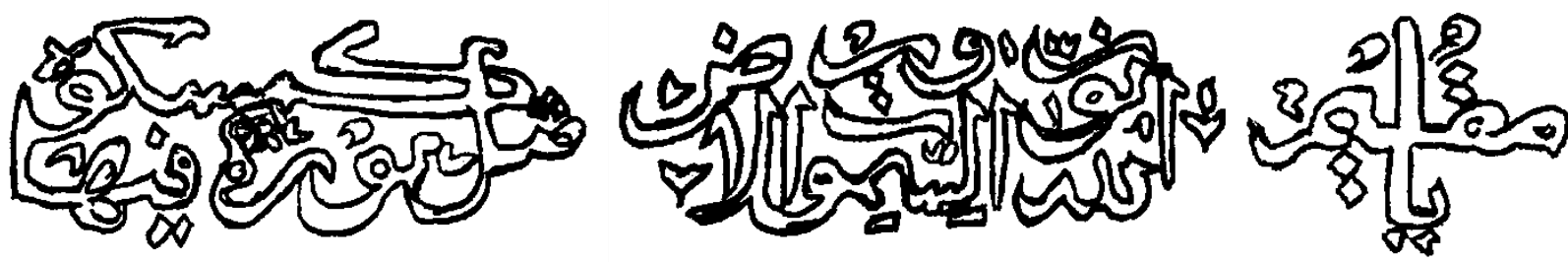

شكل رقم (†"): الكتابات العربية المنفذة على الأمشاط القاجارية.
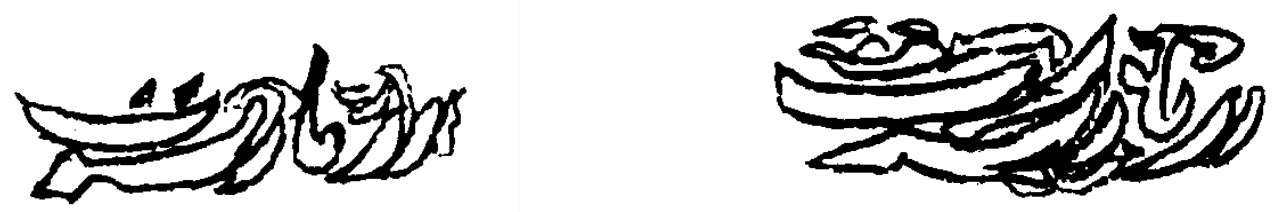

شكل رقم V: الكتابات الفارسية المنفذة على الأمشاط القاجارية. 


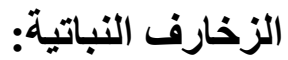

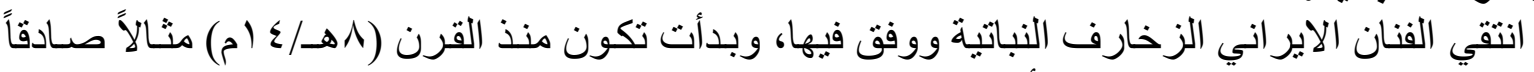

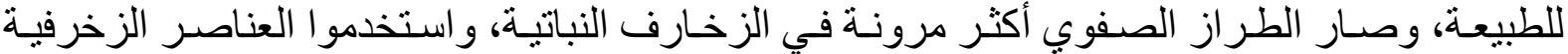

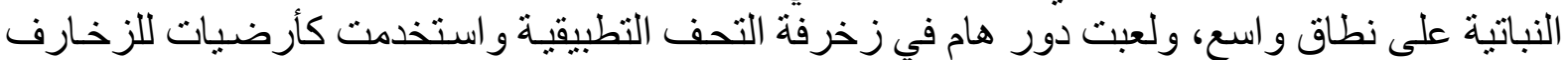

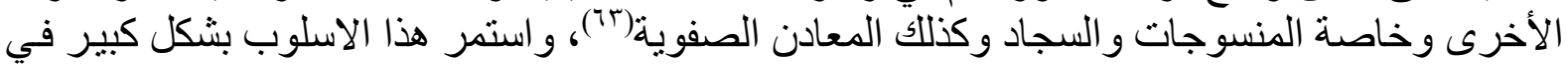

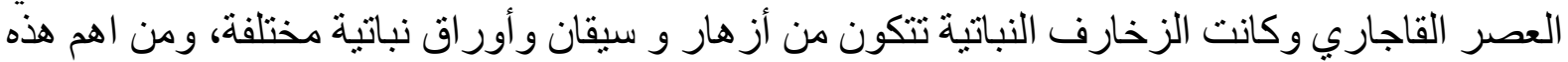

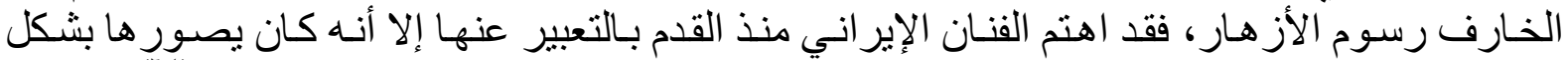

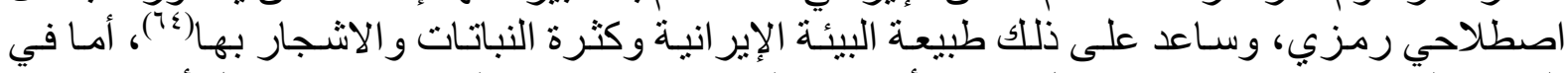

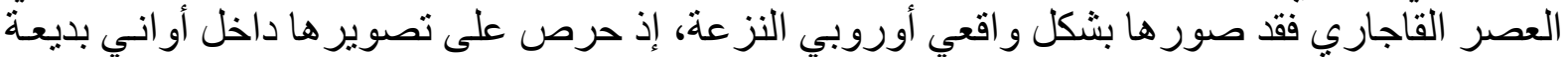

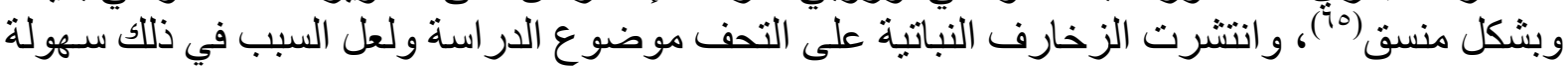

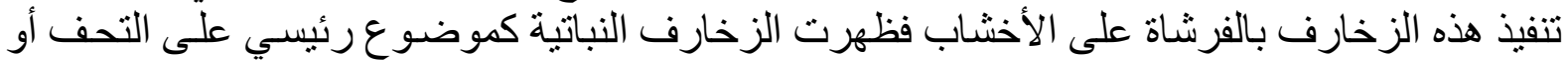
كخلفيات لزخارف الكائنات الحية المختلفة.

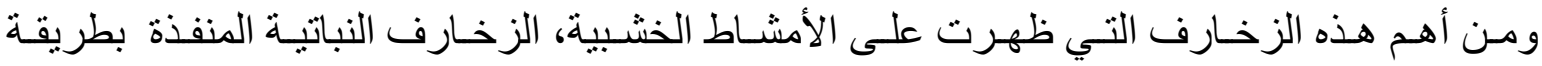

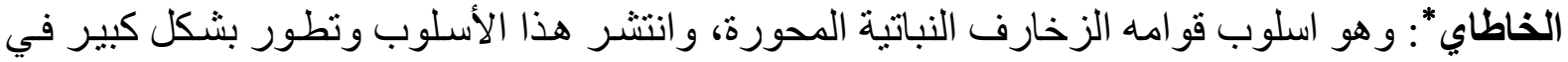

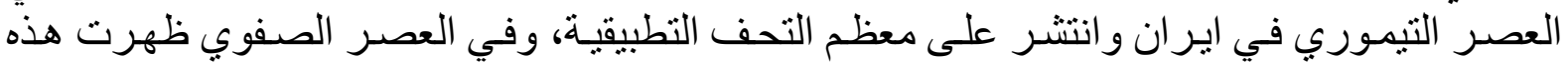

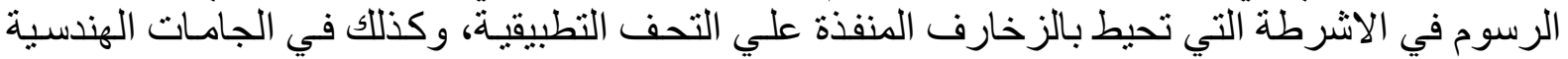

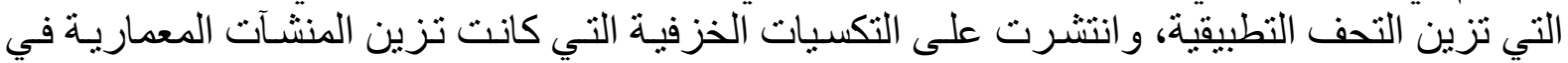

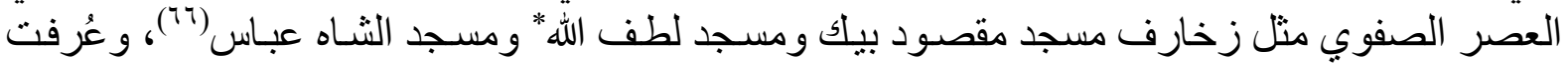

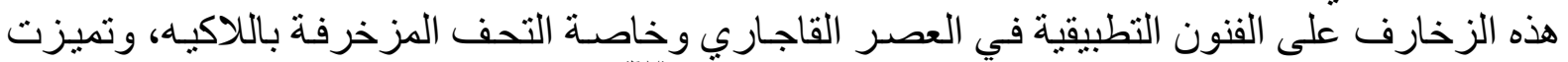

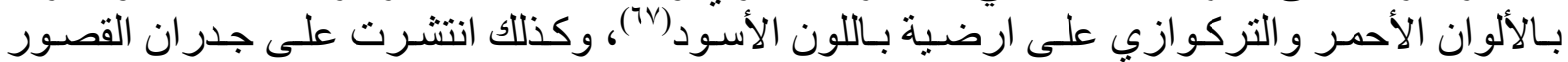

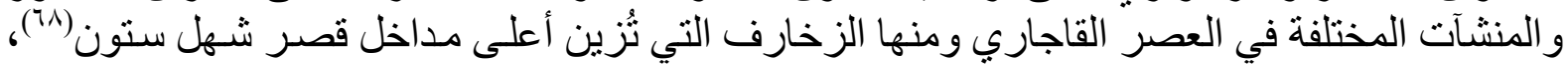

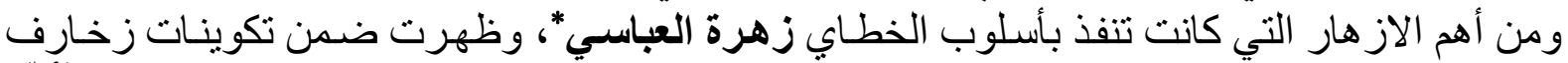

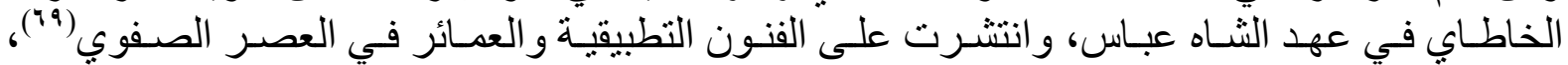

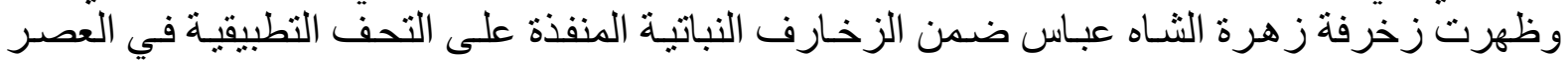

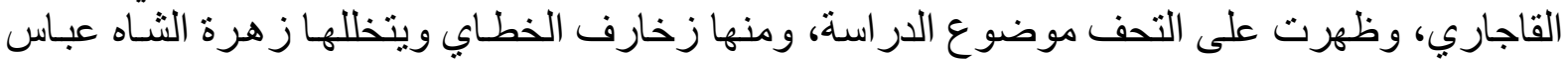

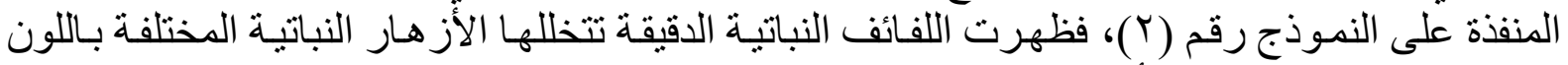

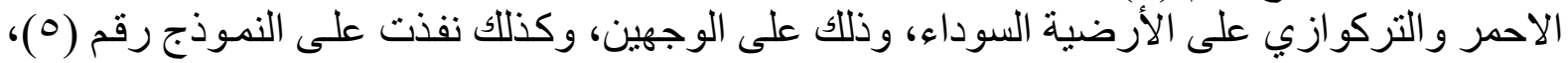

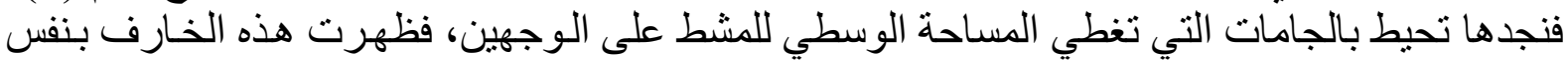
الاسلوب الذي عرف وتطور في ائران في النص الثاني من القرن الثالث عشر الهجرئ الثري، وبنفس الالوان

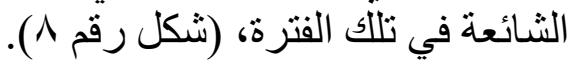

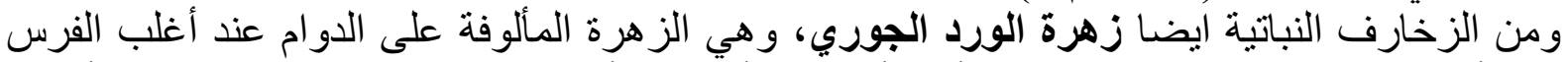

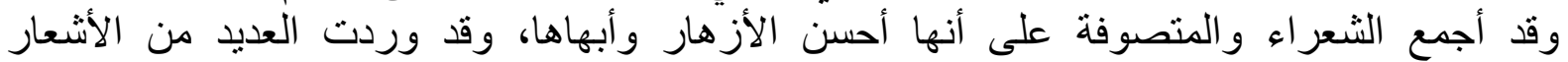

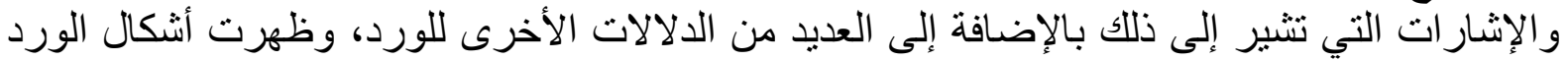

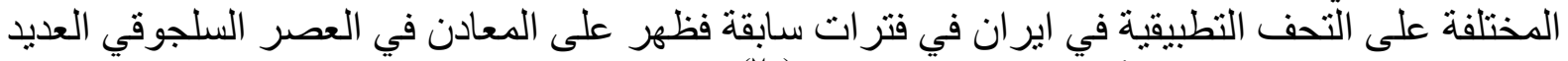

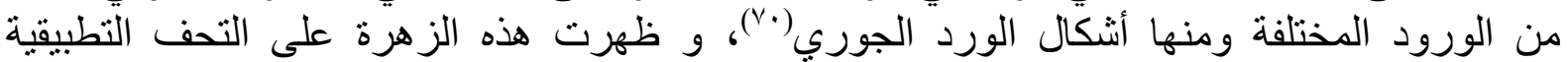

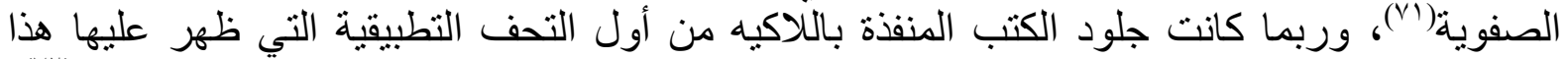

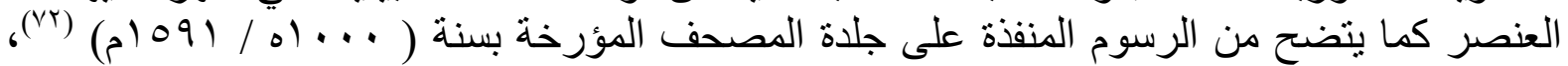

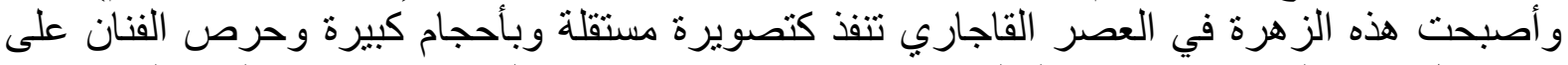

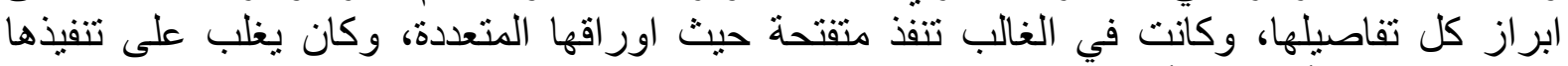

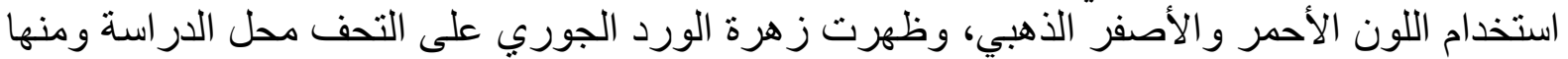

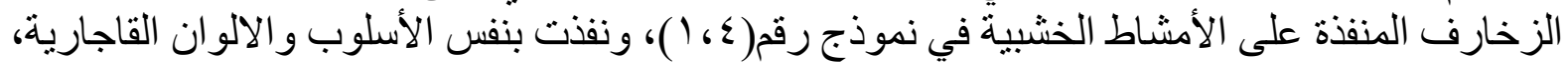


فجاءت باللون الأصفر والأحمر والازرق، وظهرت متفتحة وأظهر الفنان تفاصيلها وأوراقها الكبيرة

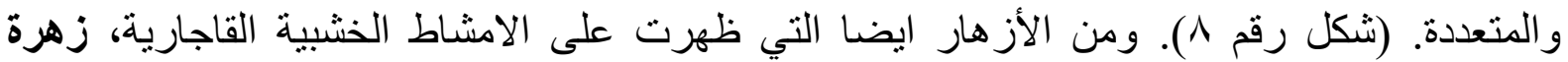
القرنفل وكان بطلق عليها باللغة الفارسية "كل قرنفل" و "كل سيخك وحشى" "وكل يغلمون"، و القرنفل

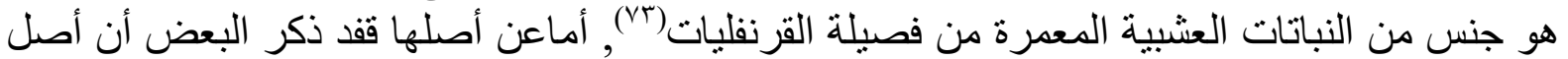

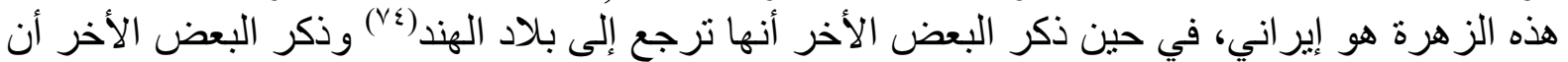

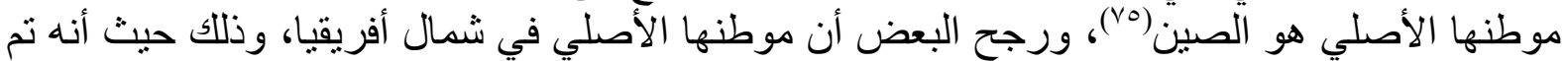

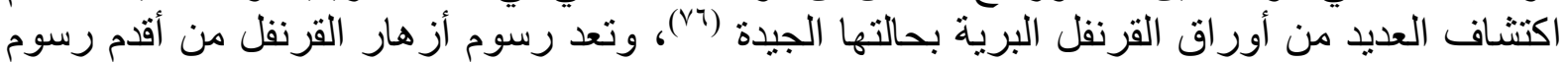

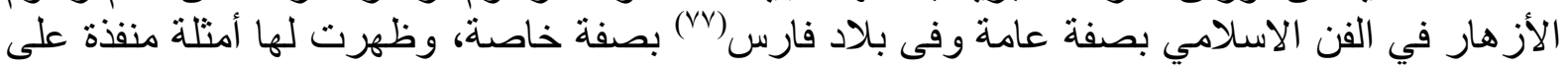

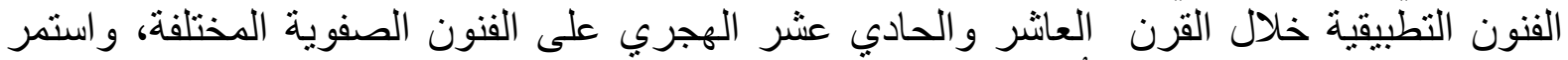

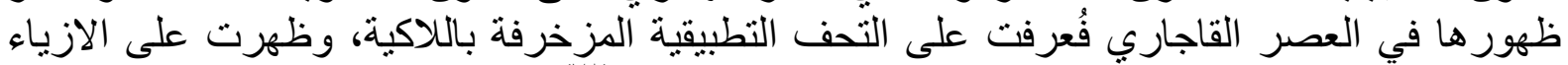

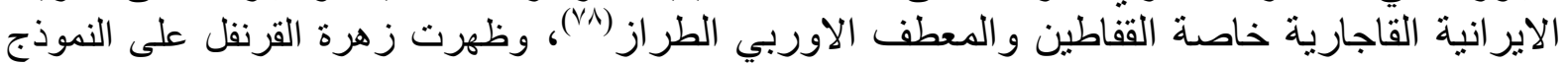

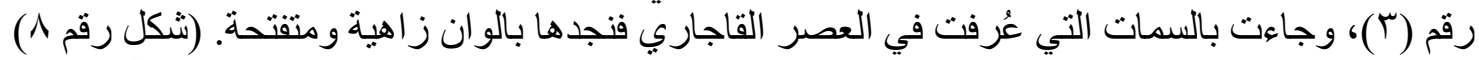
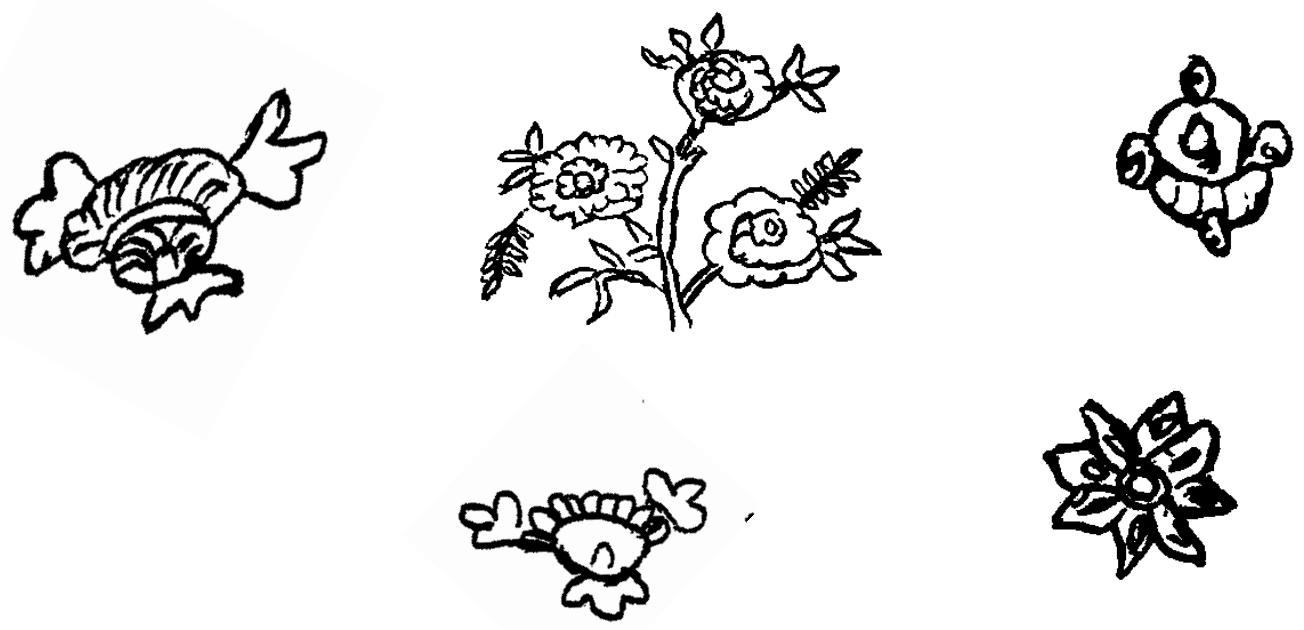

شكل رقم( ^): الزخارف النباتية المنفذة على الأمشاط في العصر القاجاري

الزخارف الزهندية:

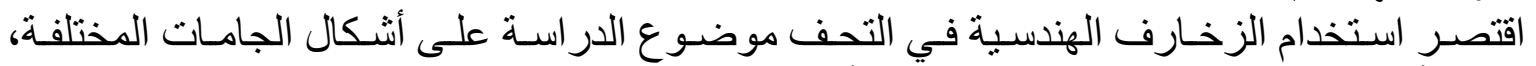

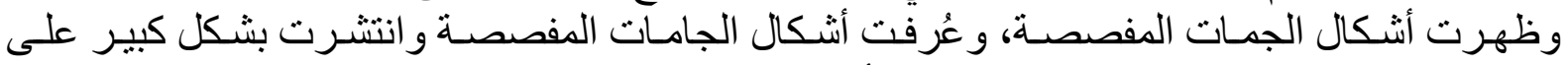

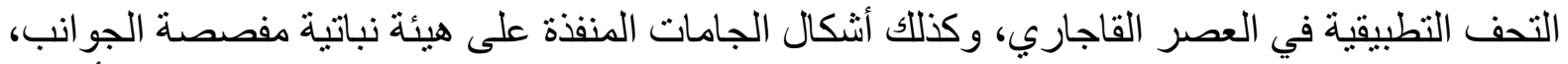

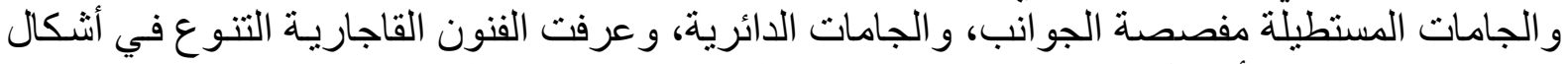

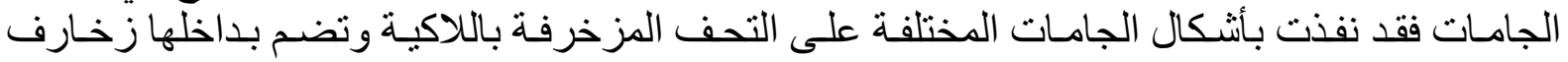

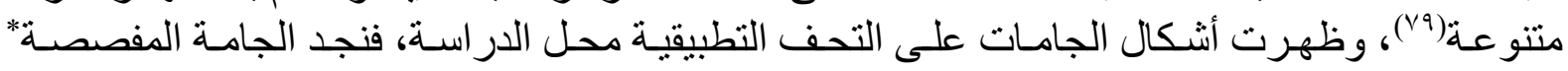

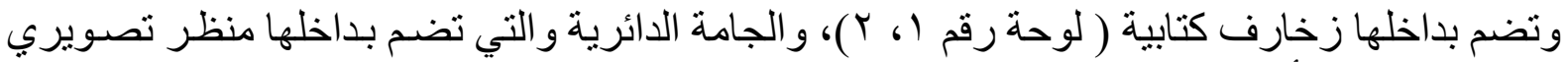

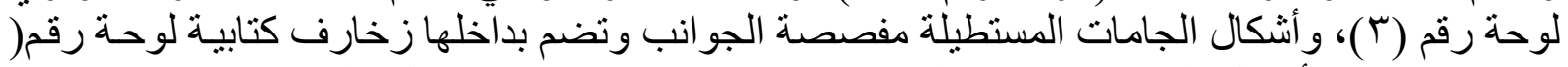

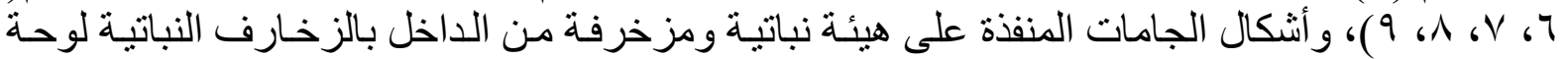

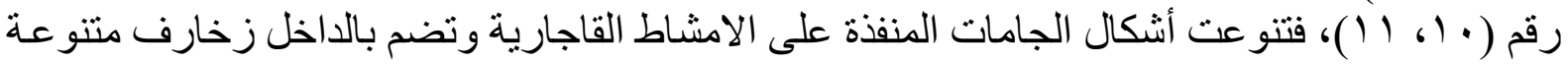

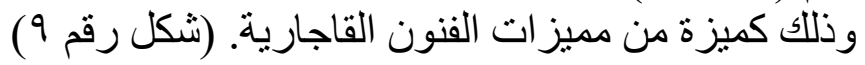



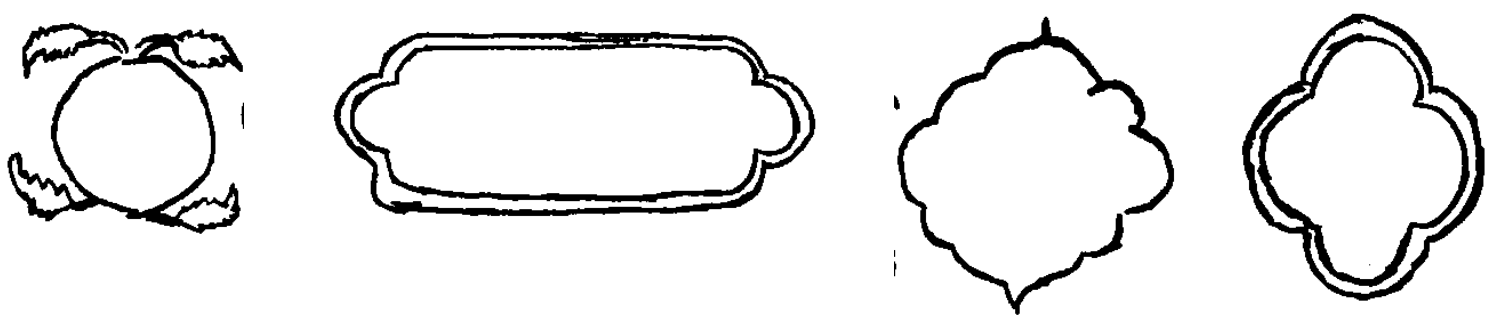

شكل رقم (9): أنثال الجامات المنفذة على الأمشاط في العصر القاجاري.

تنوع الزخارف وعلاقتها بوظيفة التحفة*:

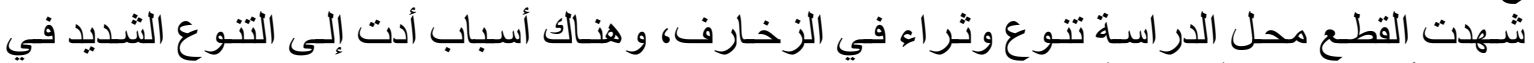

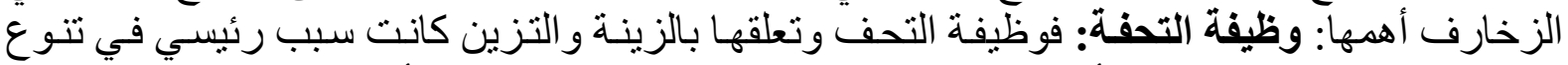

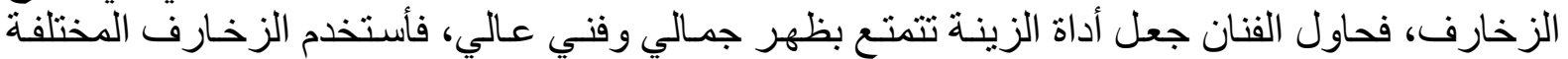

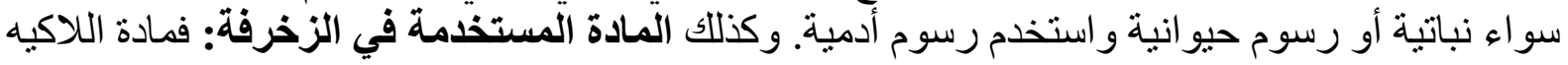

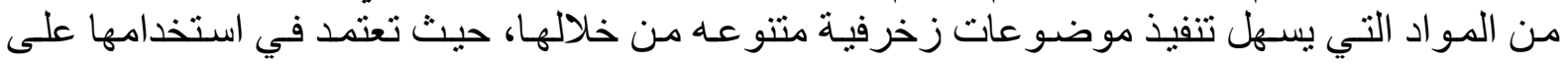

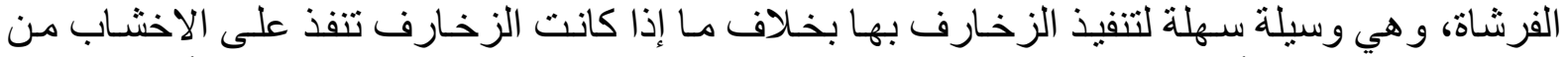

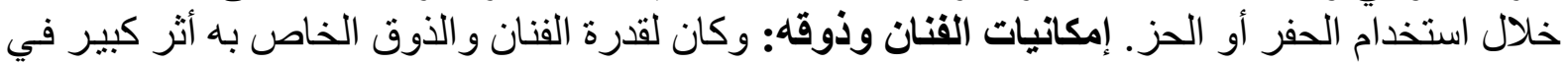

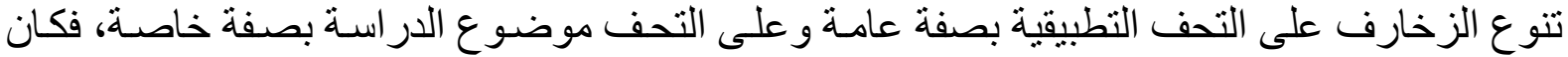

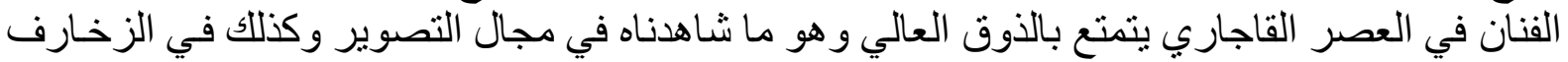

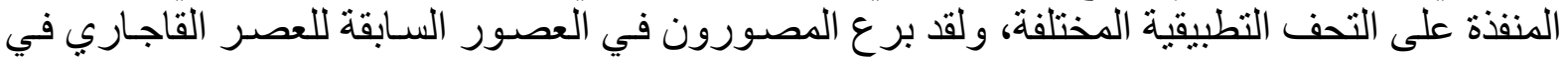

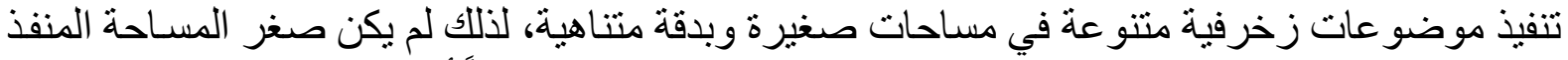

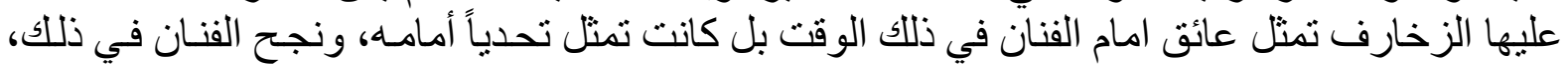

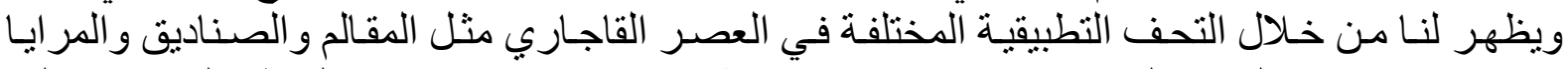

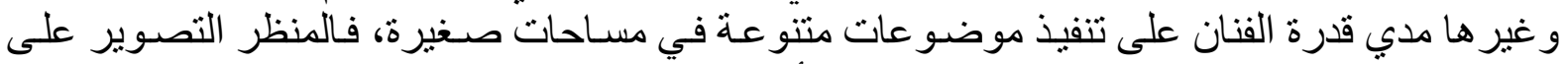

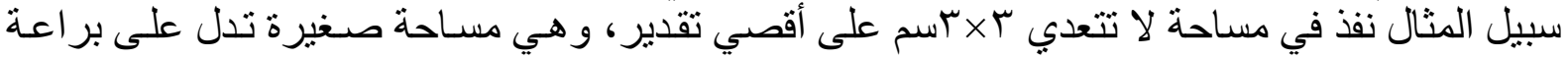

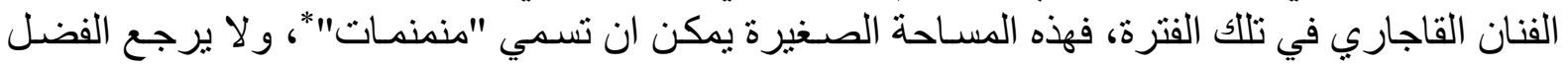

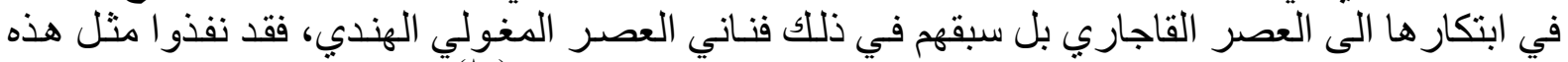

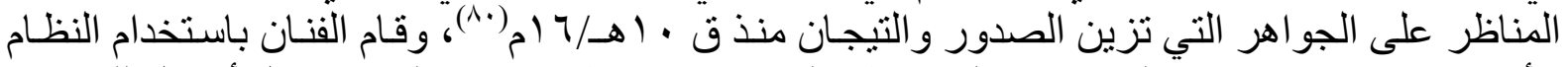

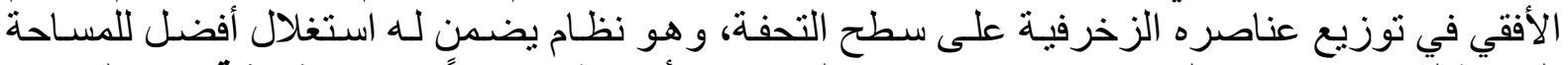

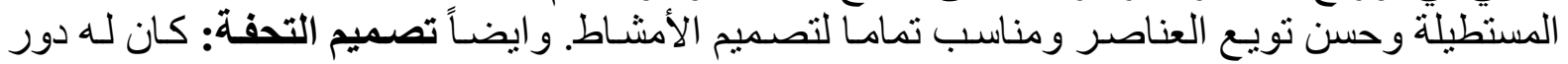

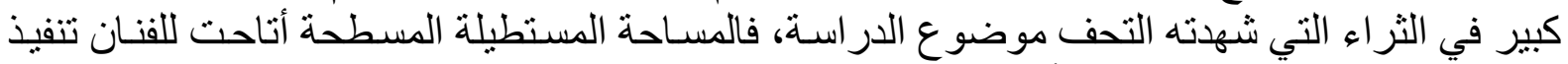

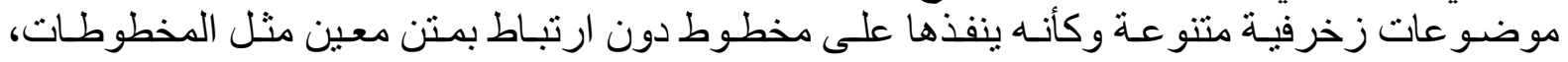

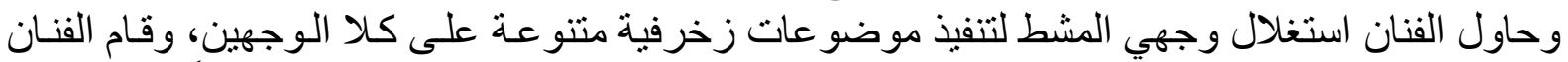

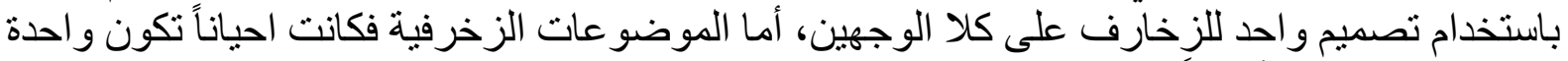

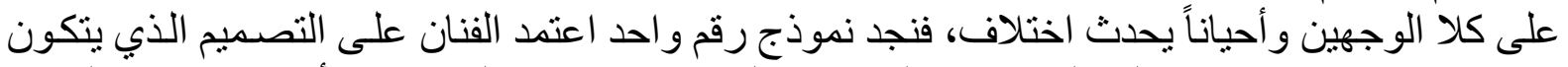

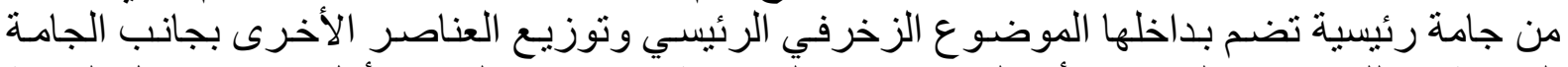

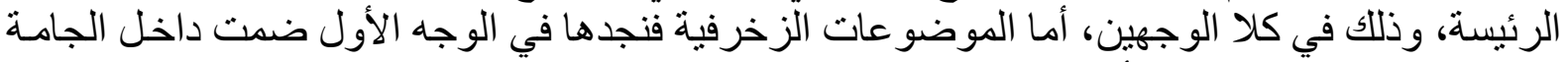

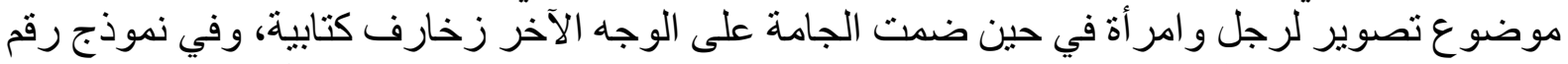

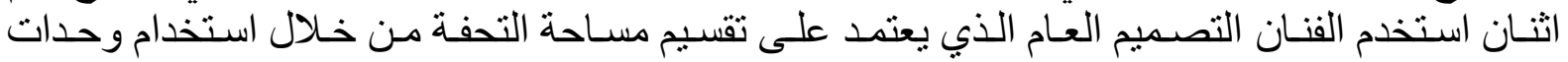
زخرفية مكررة وذللك على كلا الوجهين، و اختلفت الزخارف المنفذة على كل وجه ففي الوجه الاول نجد 
زخارف نباتية فقط في حين الوجه الآخر نجد زخارف نباتية يتخلالها رسوم حيو انية، واستخدم الفنان في

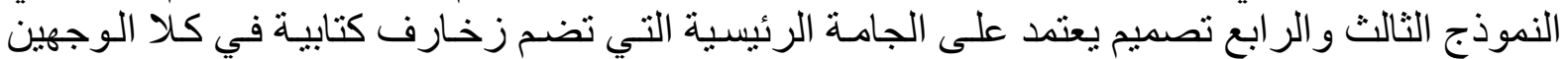

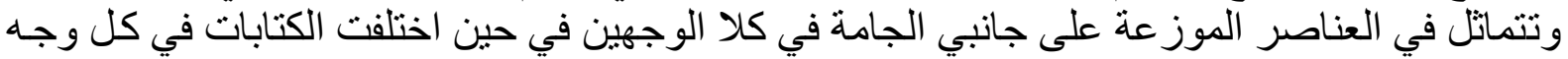

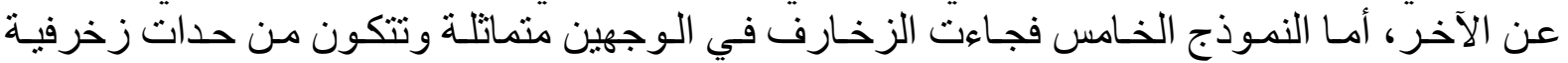
مكررة يتخلاها زخارف الاف نباتية. أماعن علاقة الزخارف بوظة بارفة نايفة التحفة:

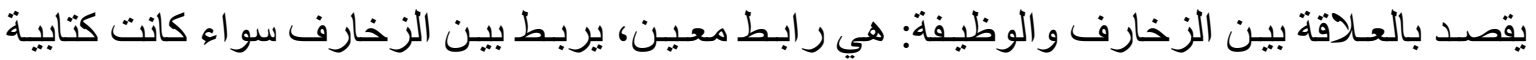

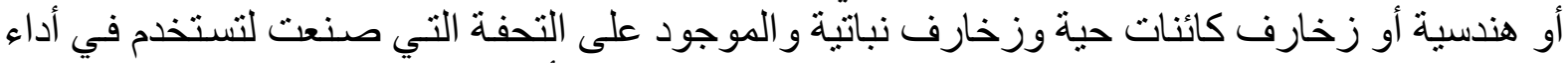

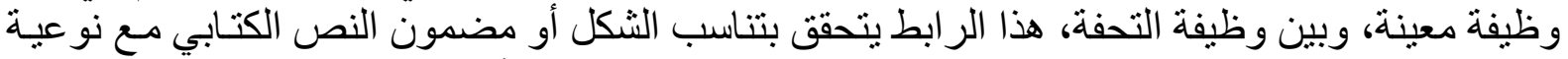

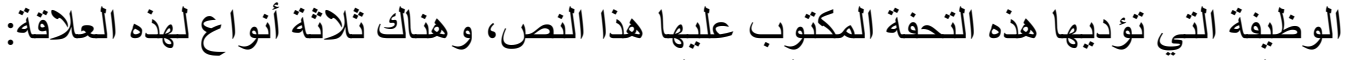

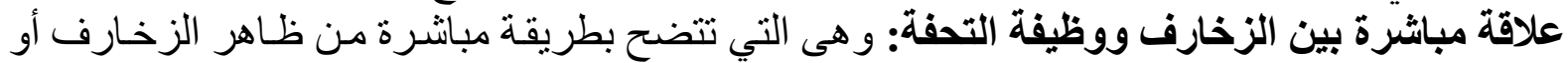

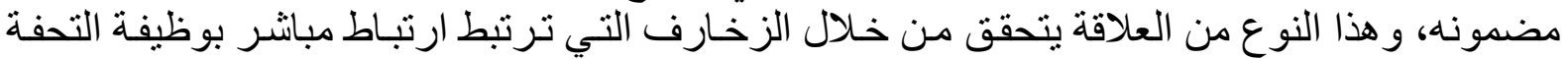

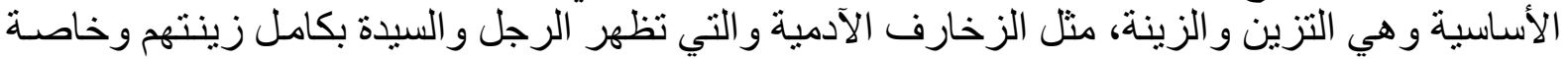

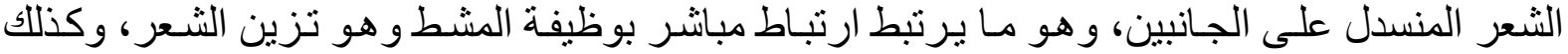

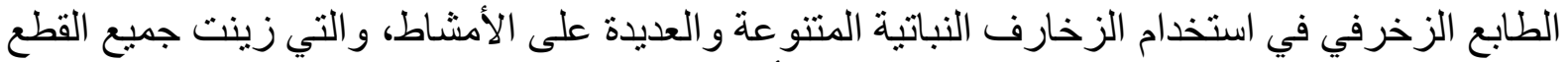

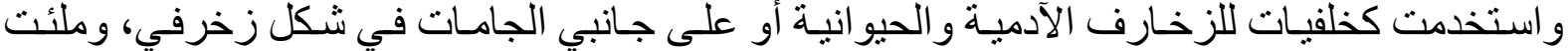

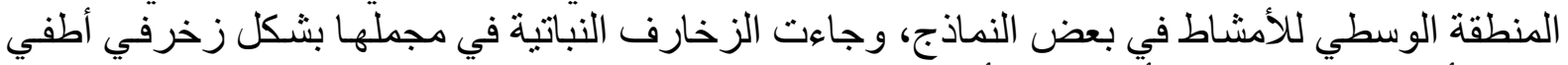

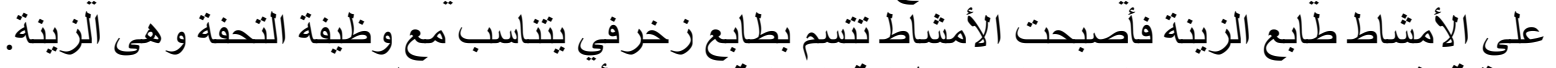

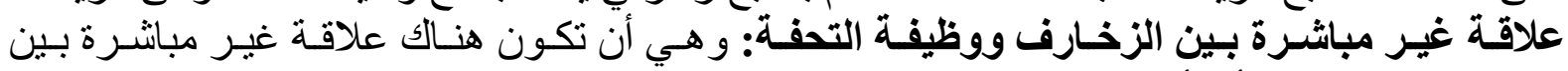

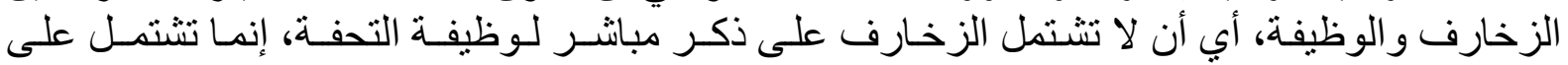

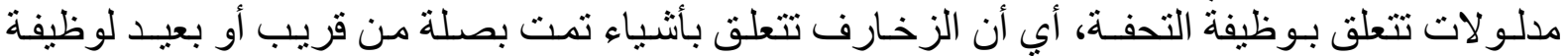

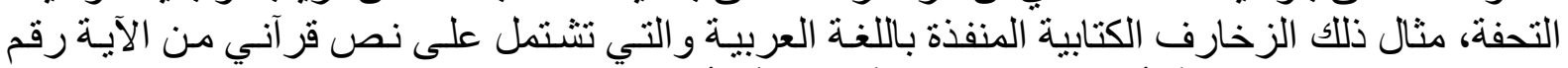

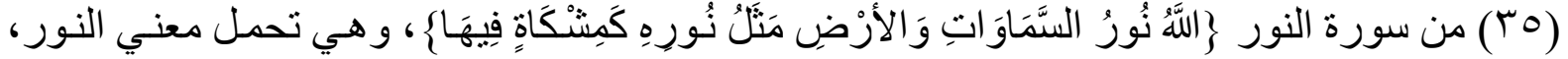

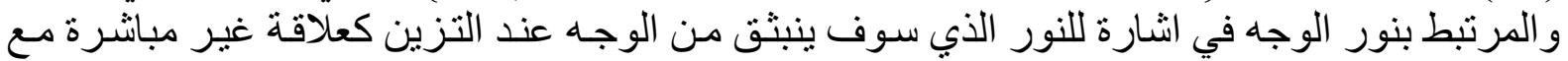

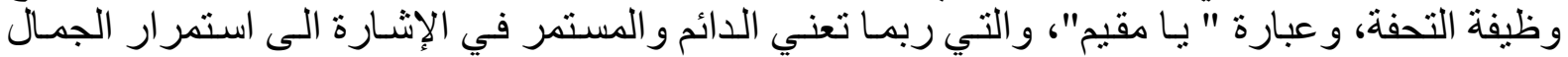

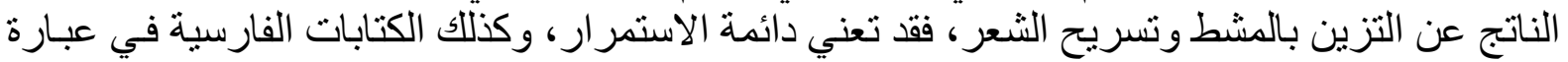

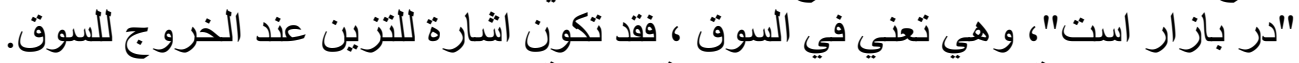

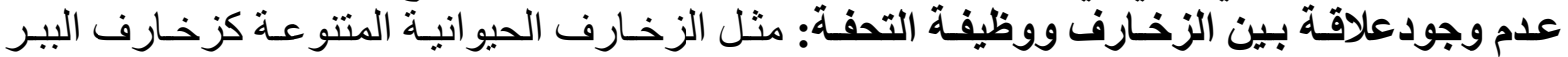

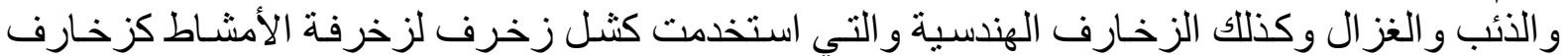
الجامات.

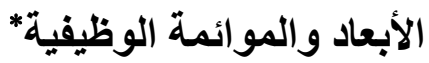

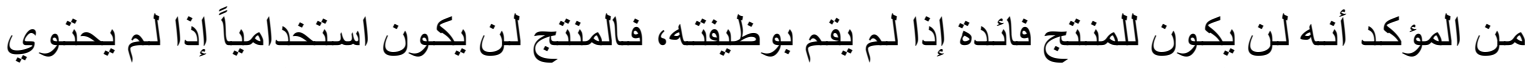

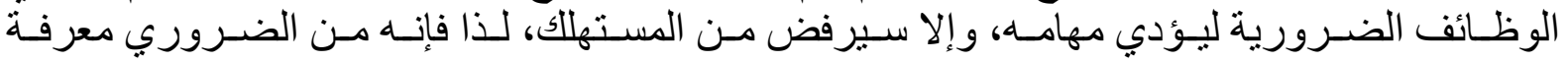

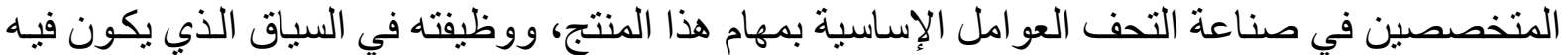
وفي بيئته (ا^)، حتي ينجح في تحقيق المعايير الأساسية التي تتضمن تحقيق الوظّيفة، ويمكن در اسـة مبدأ

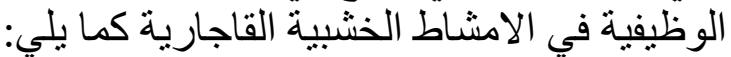

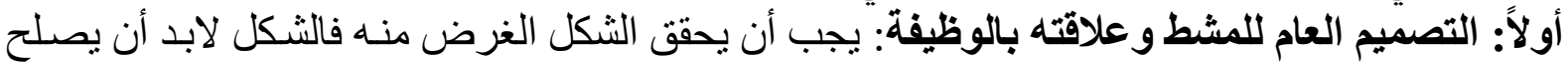

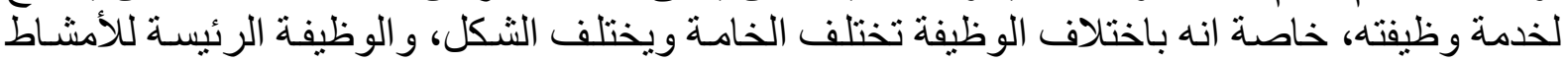

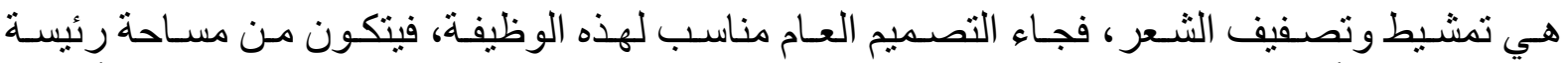

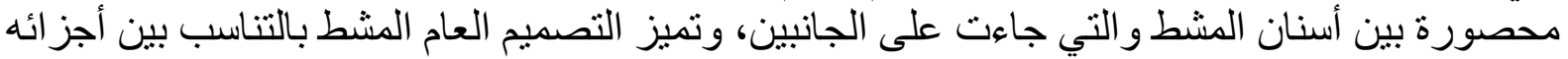
وتحقيق كل جزء الوظيفة المحدة، وأضفي الفنان علي الأمشاط طابع زخرفي الميز ارتبط بوظيفة التحفة وهي 
الزينة، وذلك من خلال الزخارف المنفذة على المشط أو من خلال تصميم التحفة بشكل زخرفي من خلال تكوين الجانبين على هيئات حيو النية الئية

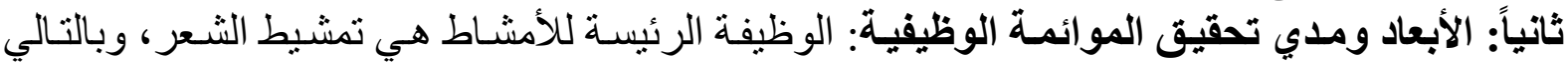

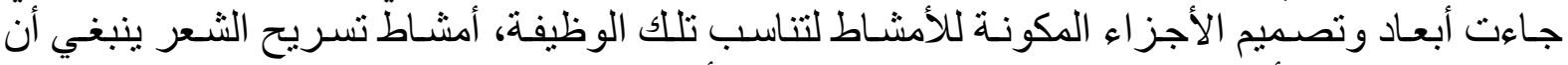

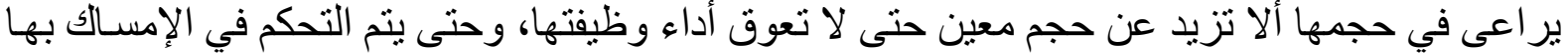

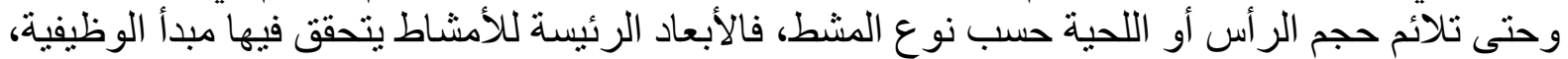

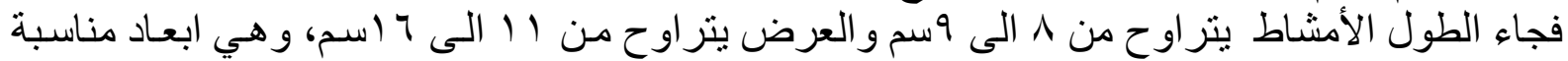

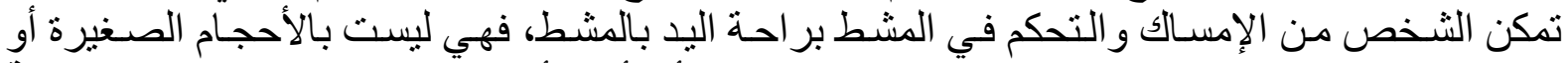

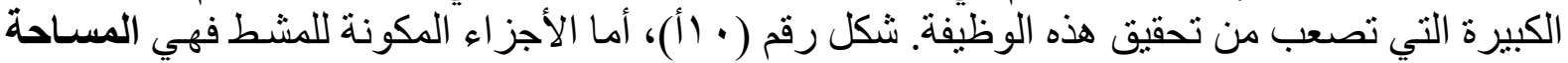

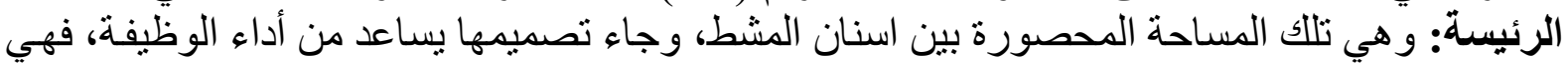

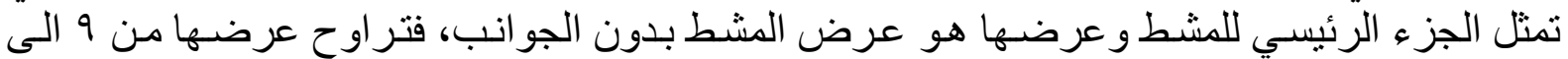

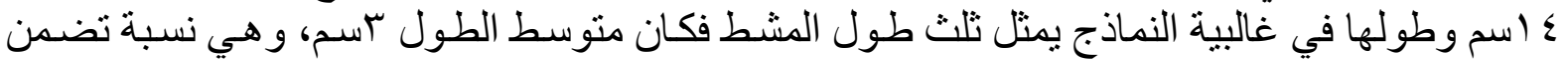

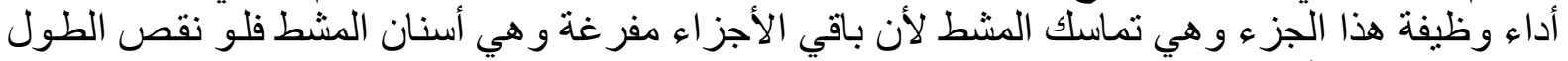

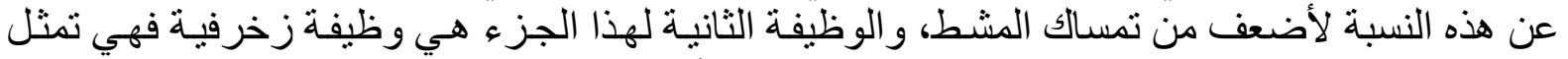

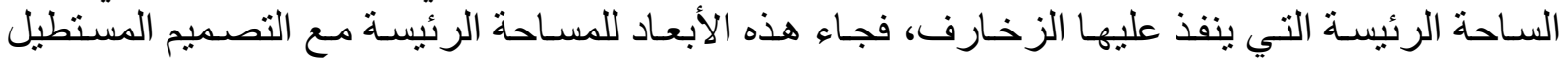

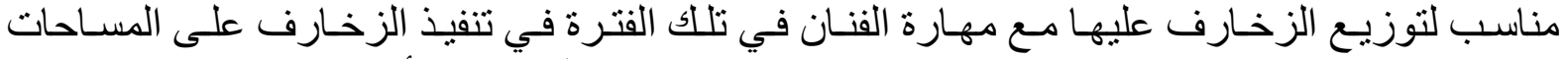

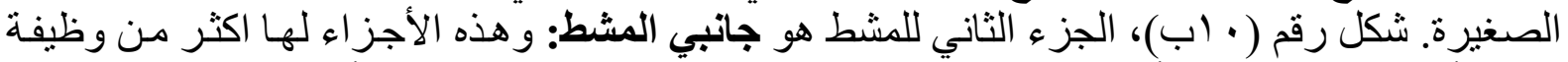

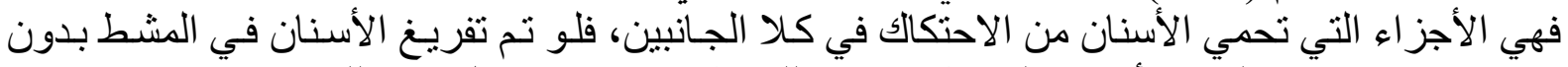

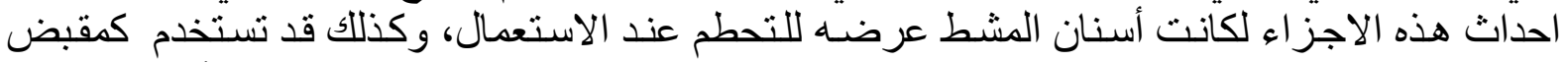

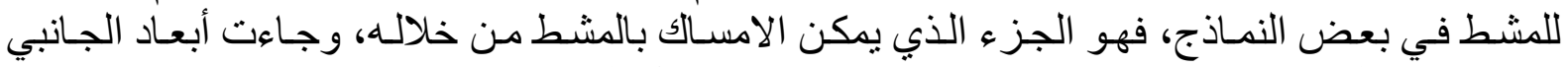

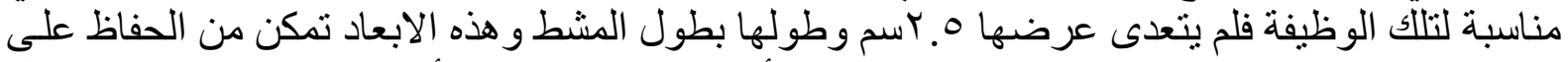

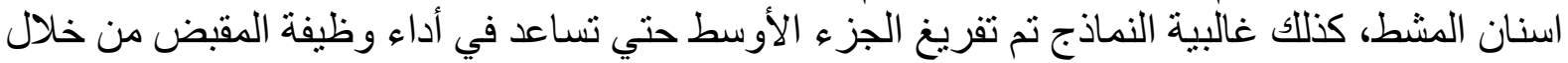

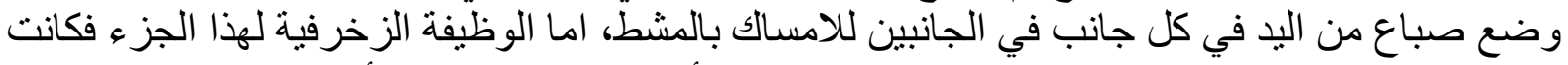

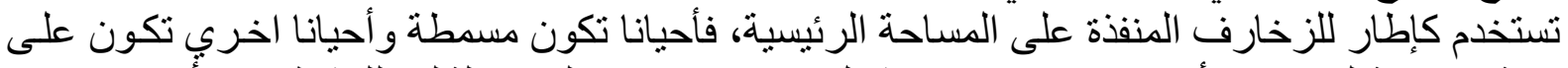

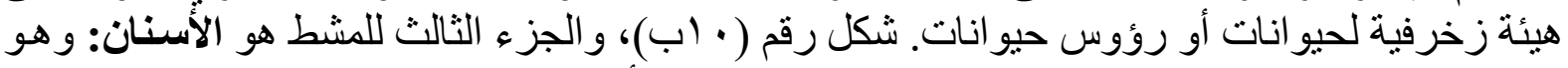

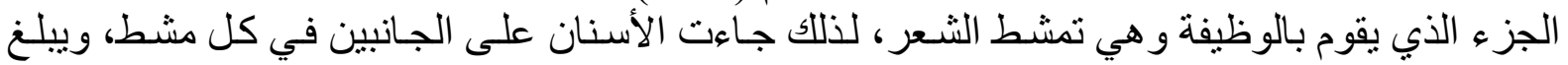

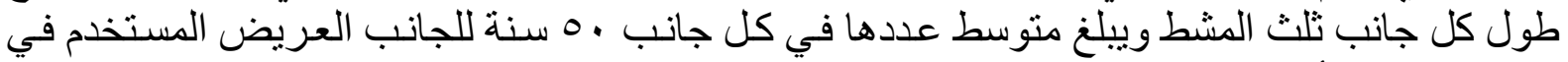
تسريح شعر الر أس و حو الي 70 للجانب الرفيع و المستخدم في تسريح وتهذيب اللحية. شكل رقم (• (ب). 

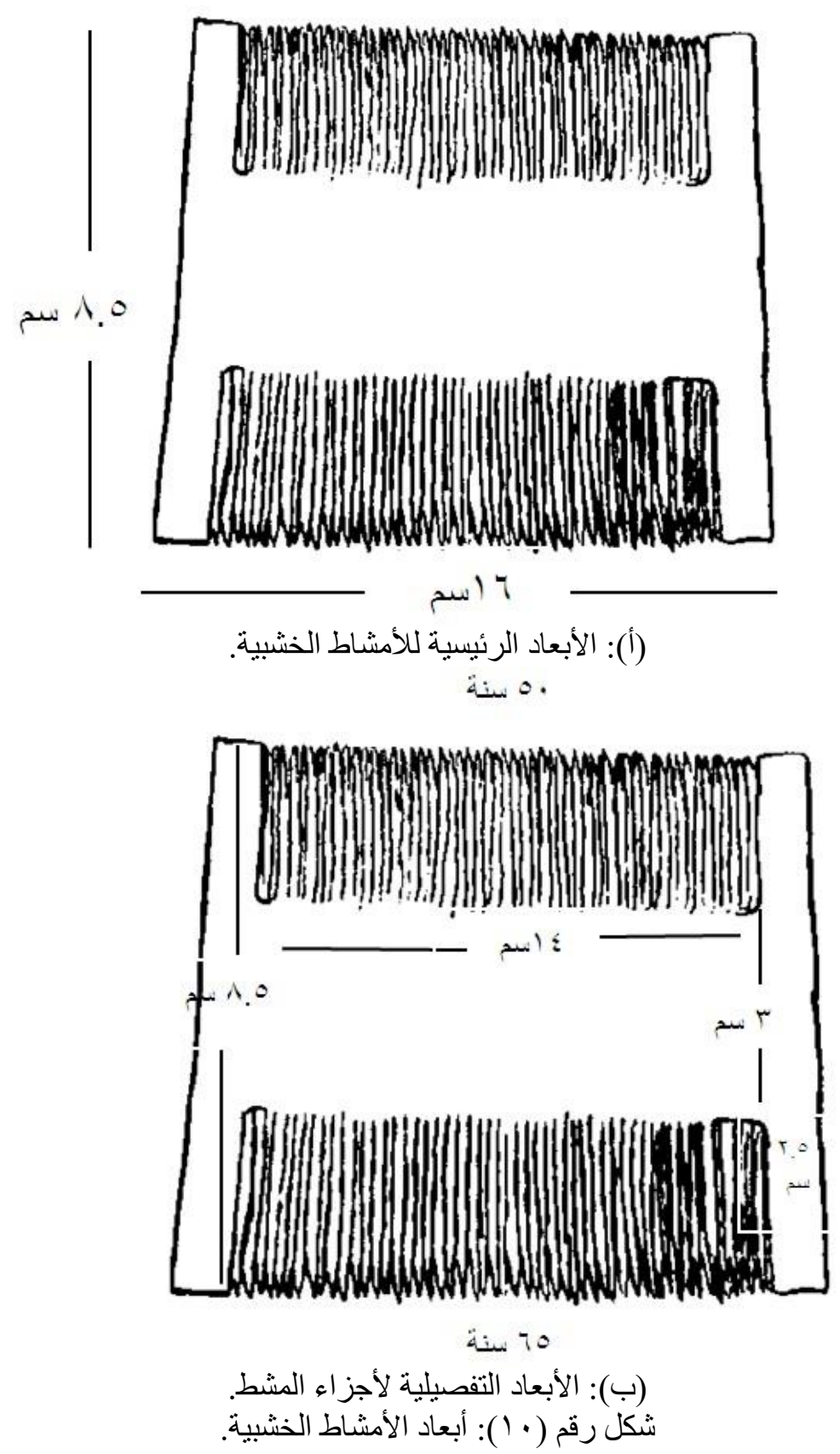

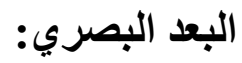

تكمن اهمية مراعاة البعد البصري للتحف التطبيقية بصفة عامة، في مر اعاة الجمهور الذي سوف

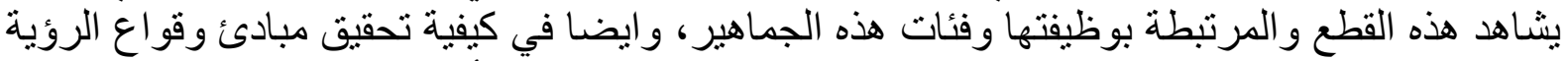

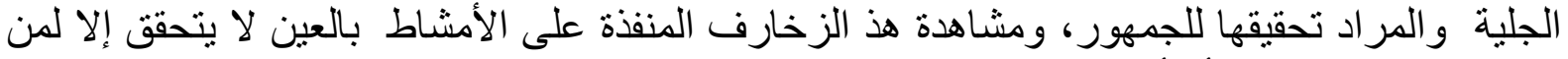

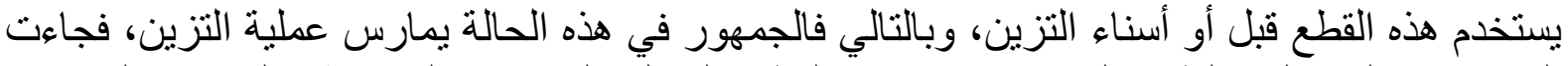

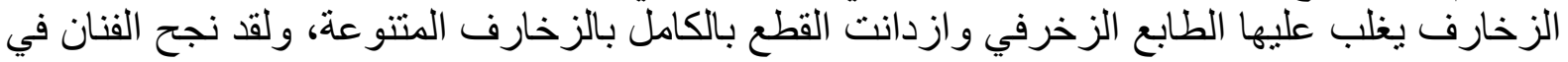

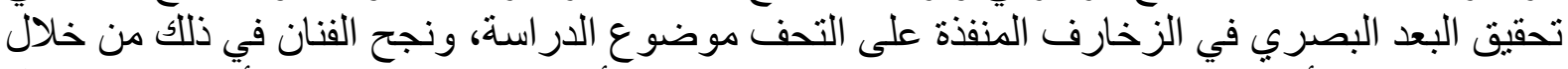

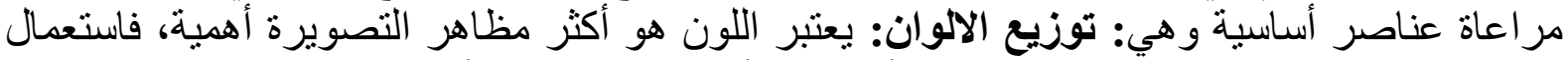

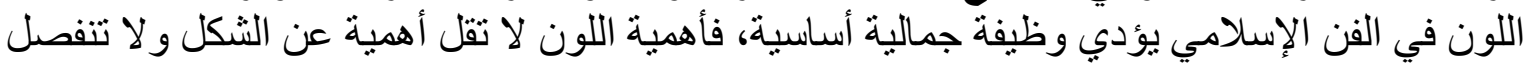




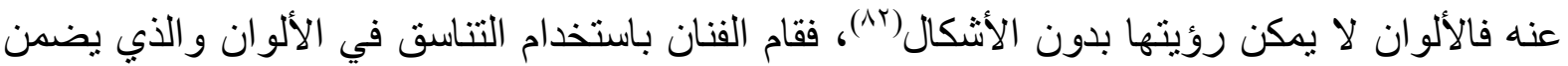

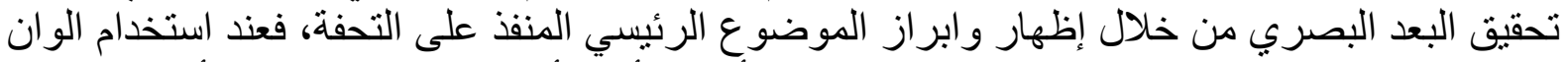

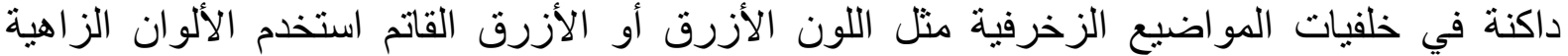

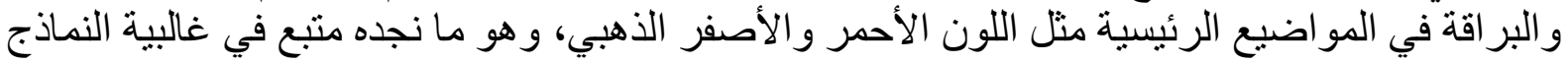

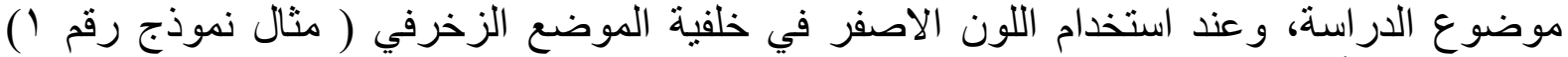

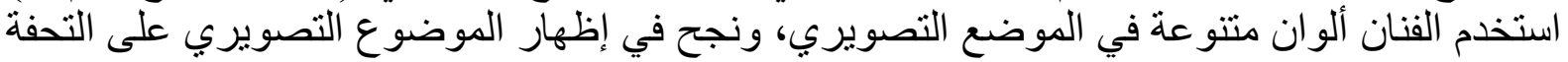

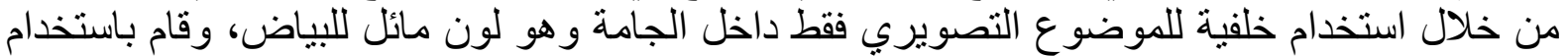

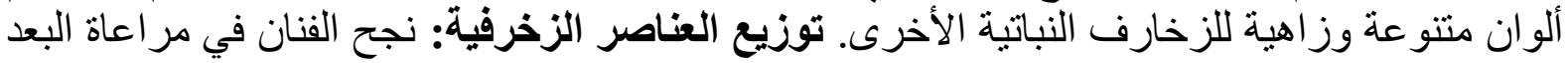

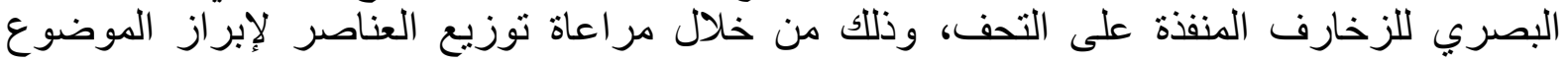

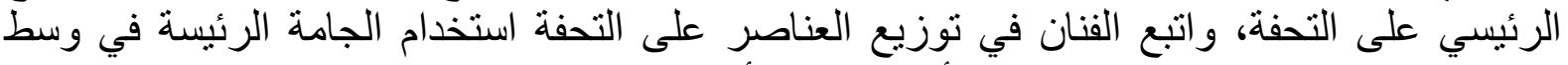

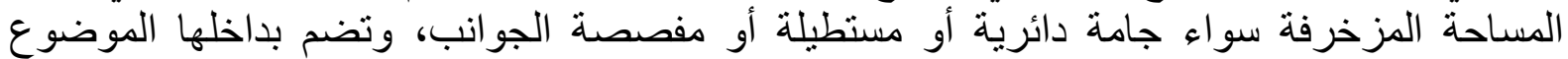

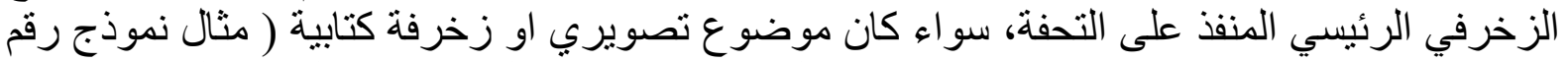

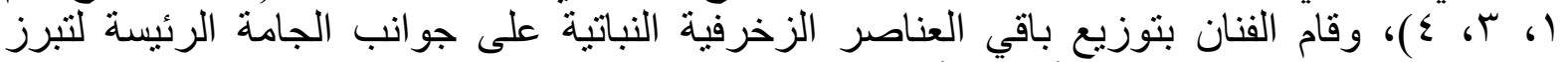

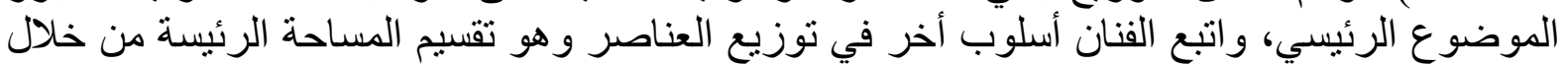

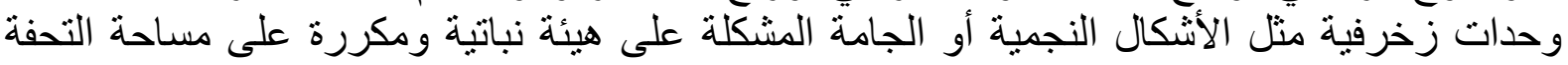

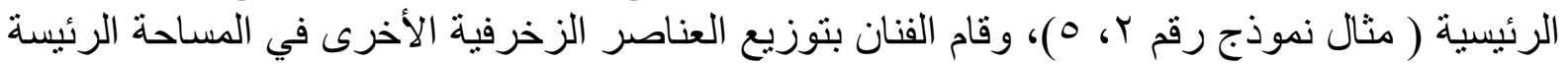

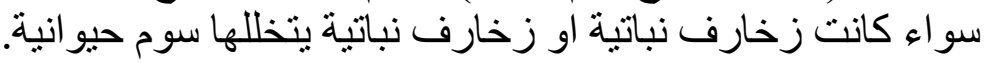

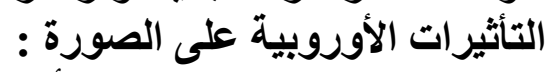

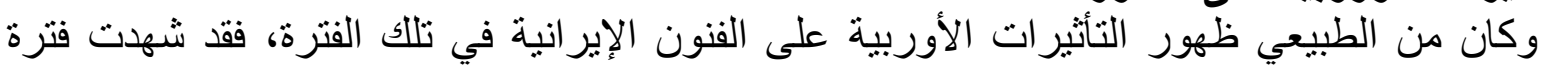

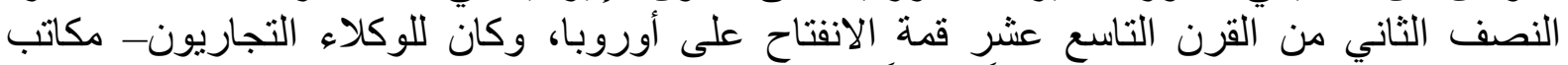

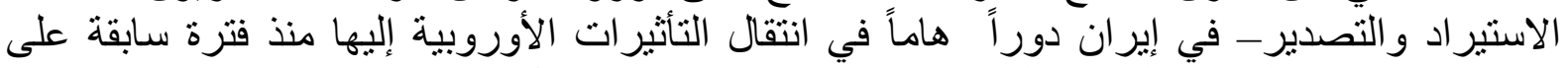

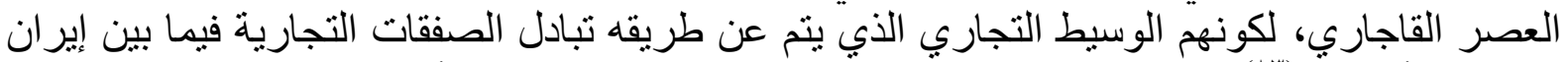

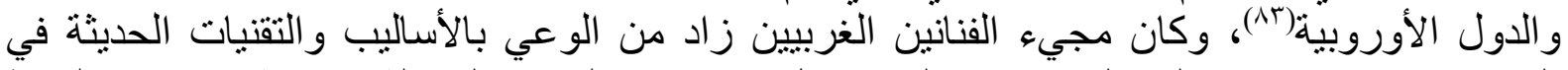

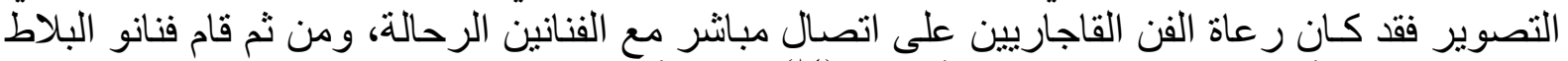

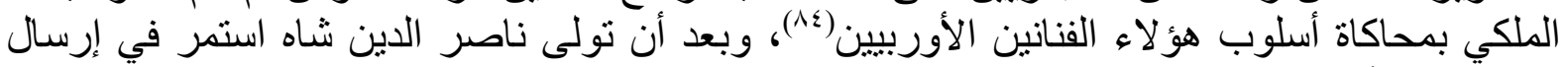

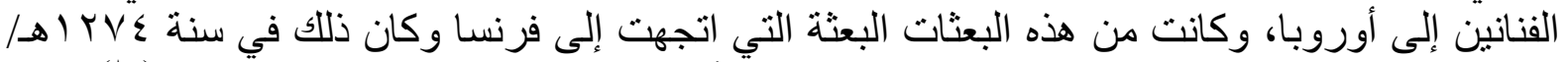

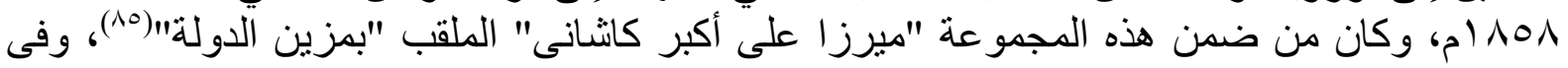

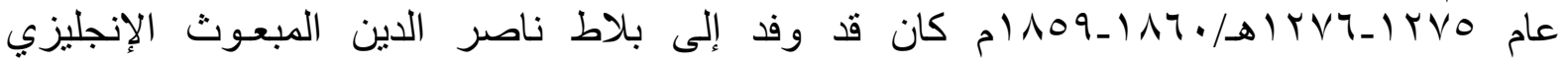

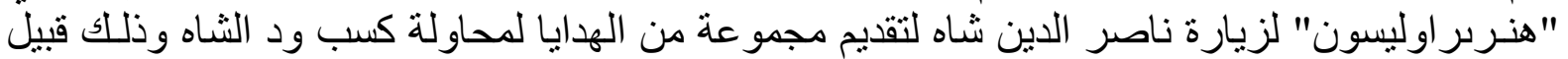

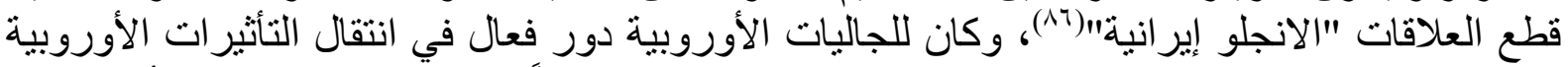

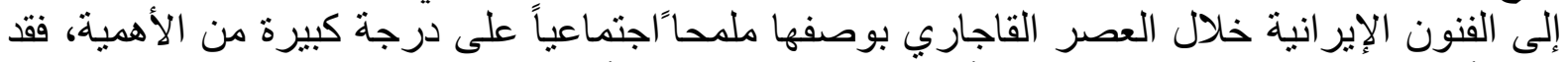

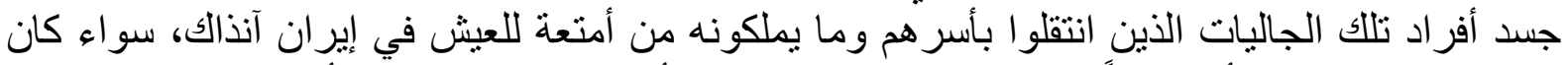

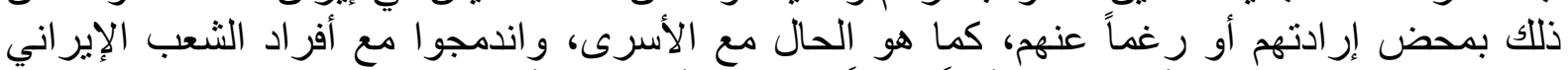

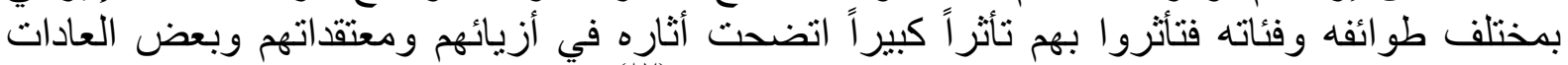

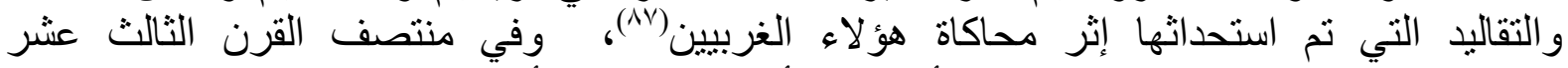

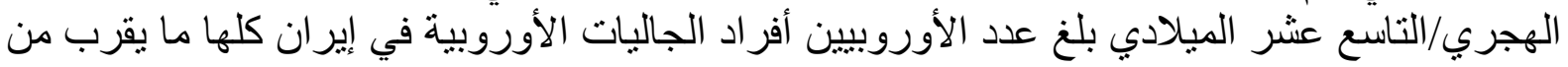

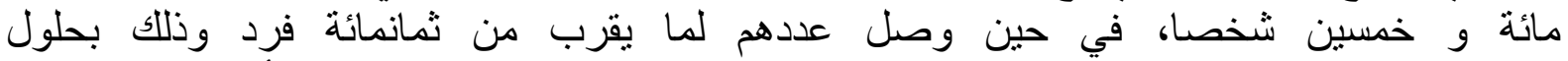

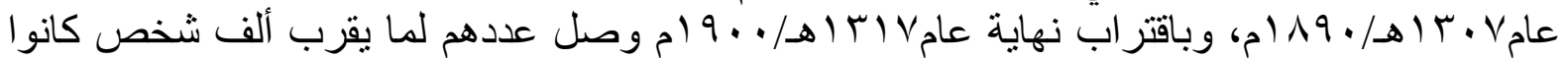

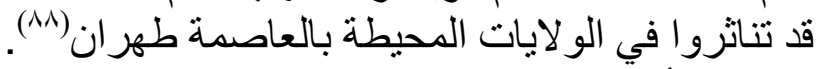

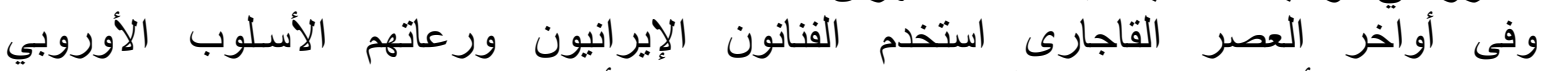
الواقعي، هذا الأسلوب الجديد جعل الإيرانيين يهجرون الأسلوب القديم ويتكيفون مع التصوير الأنير 
الأوروبي وخاصة من منتصف القرن با هـ/9 (م، وعمل العديد من الفنانين الأوروبيين في بلاط

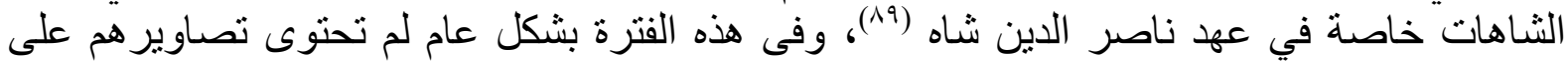

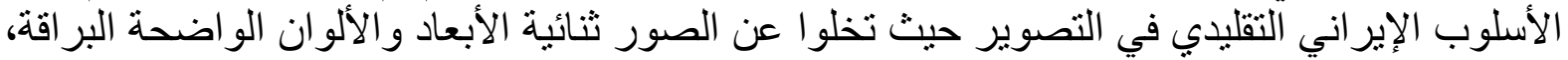

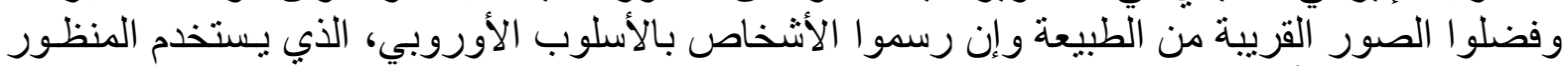

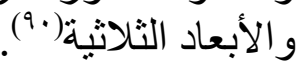

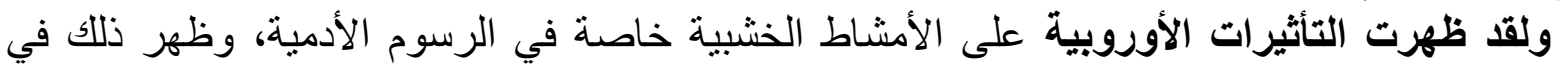

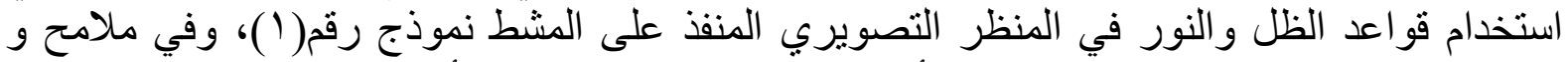

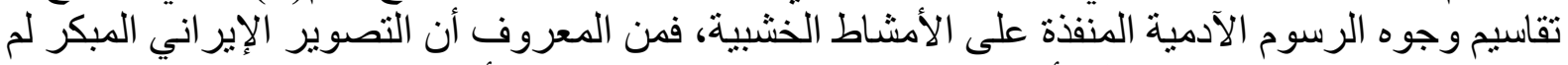

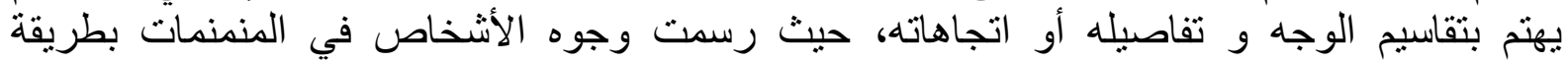

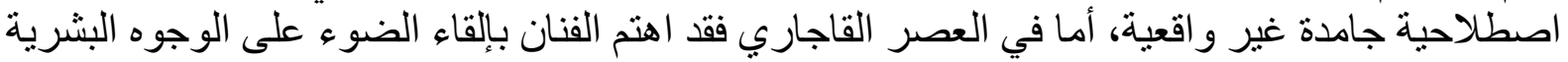

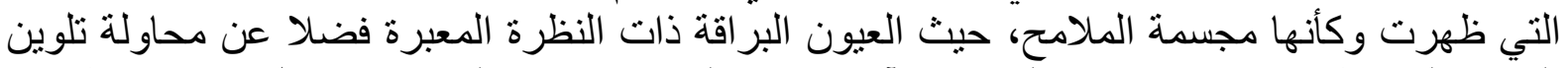

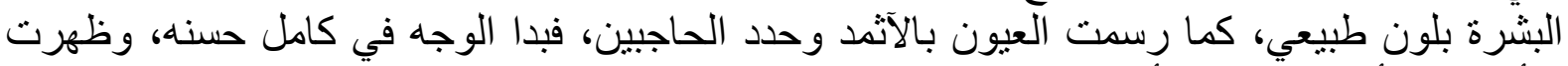

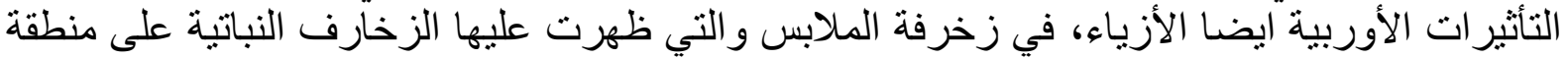

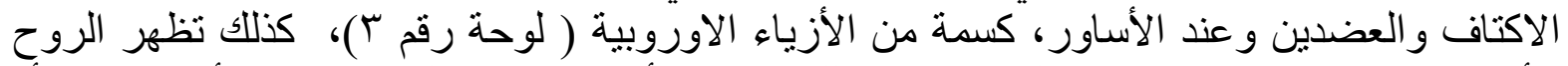

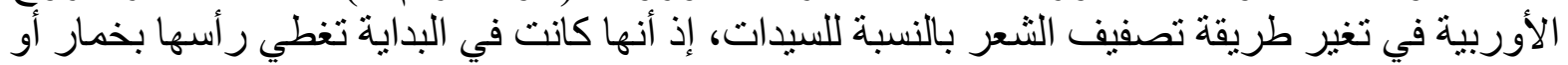

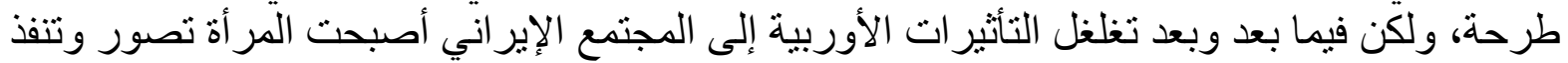

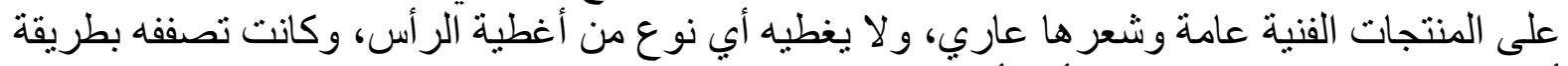

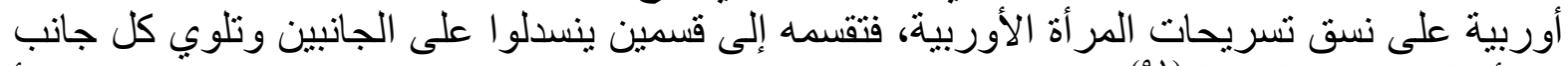

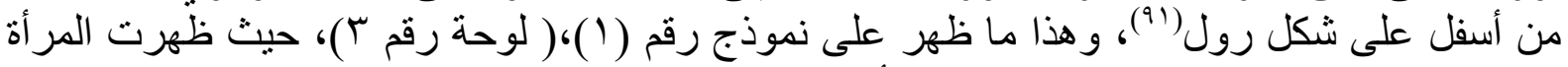

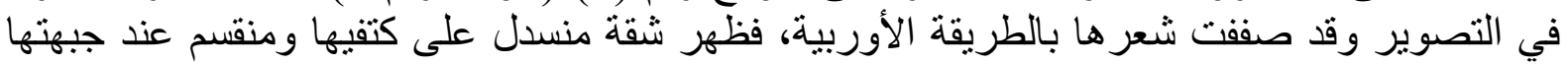

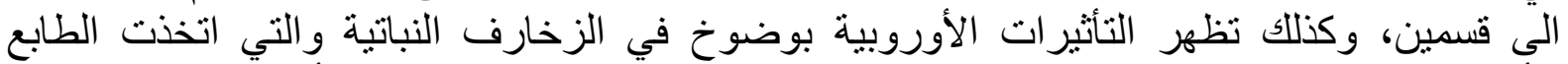

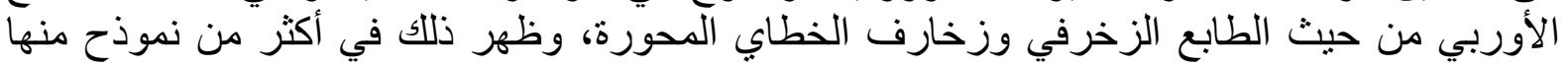

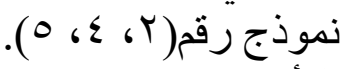

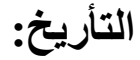

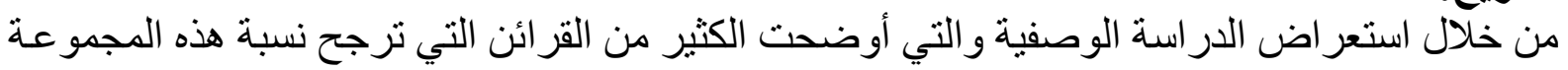

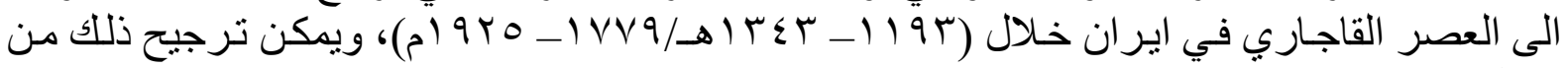

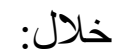

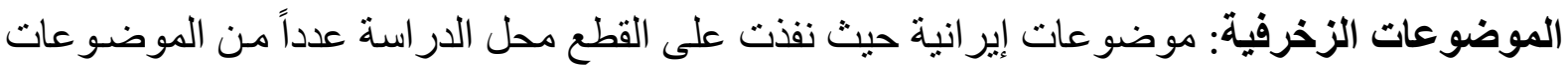

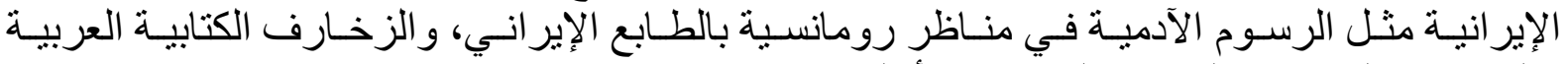

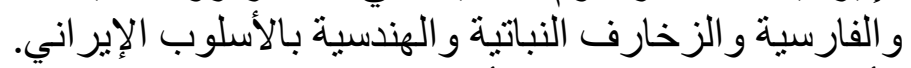

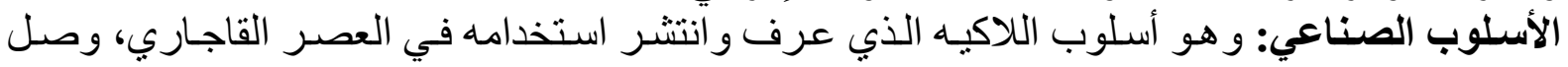

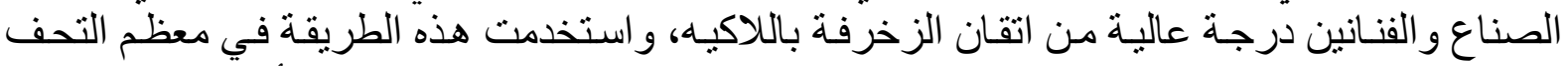

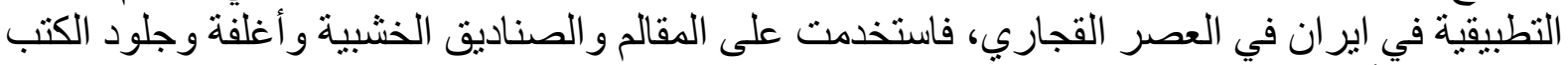

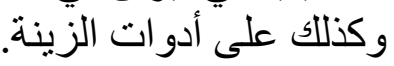

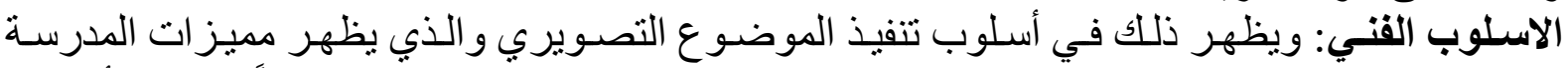

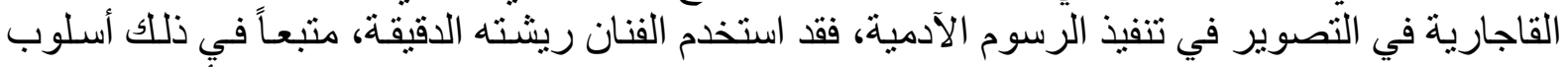

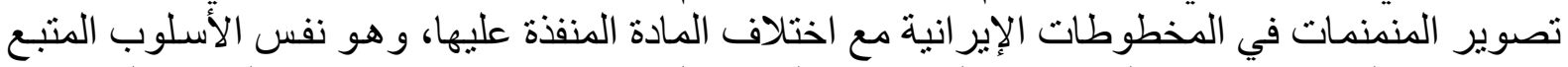

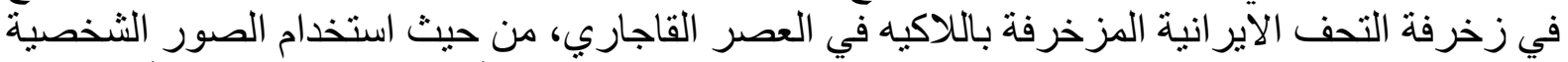

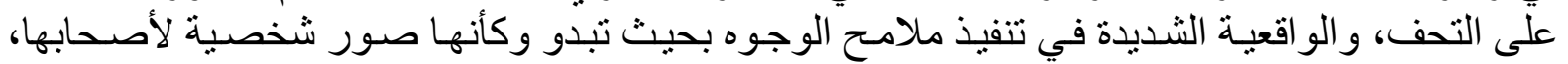

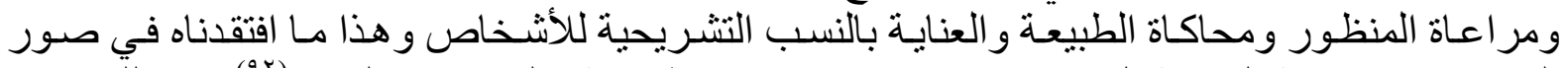

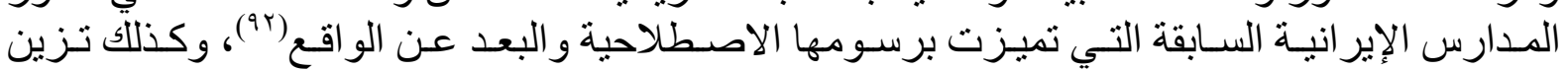
الملابس 


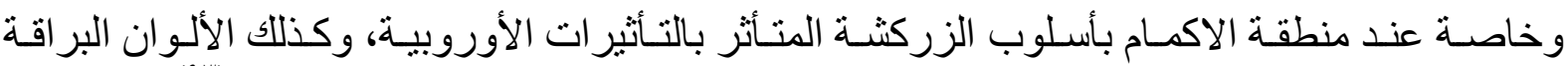

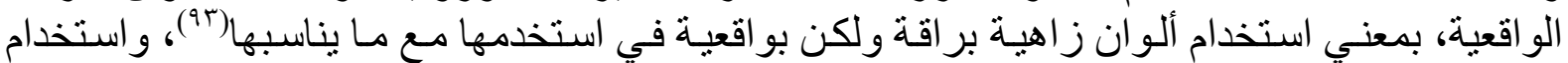

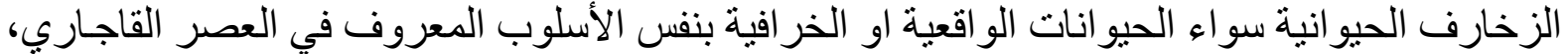

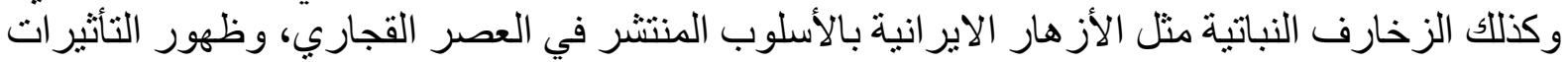

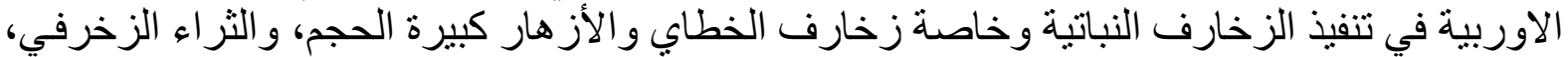

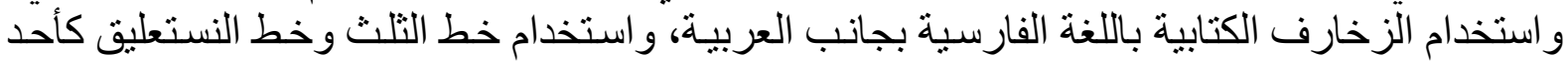
الأساليب الفنية المميزة للفنون القاجارية، واستخدام الزخارف الهندسية كالجاماتيات التي عرفت في العصر

\section{ولعل من أهم النتائج التي توصل إليها البحث:}

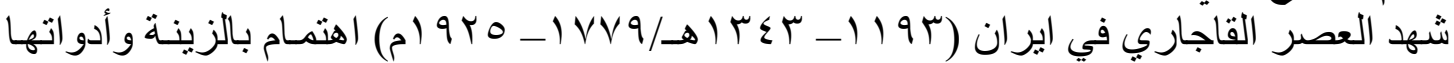

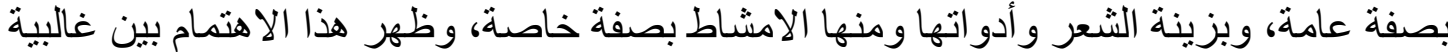

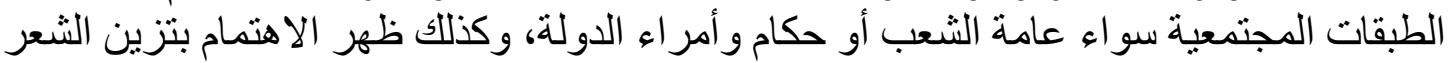

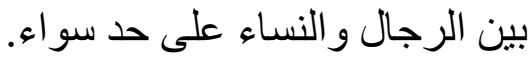

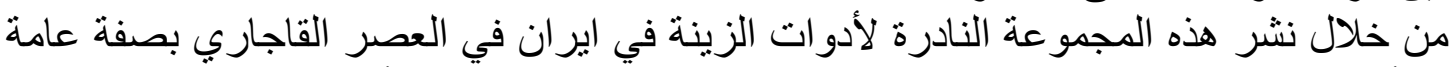

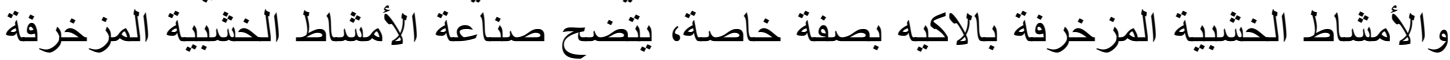
بالاكيه في العصر القجاري. تعدد طرز الأمشاط الخشبية المزخرفة باللاكيه في العصر القاجاري، وهي مشط ذو دو جانبن النين

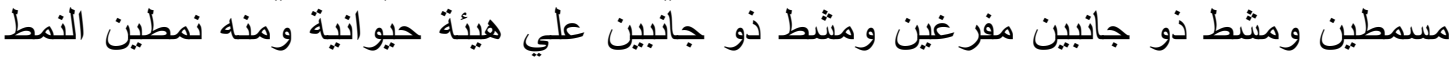

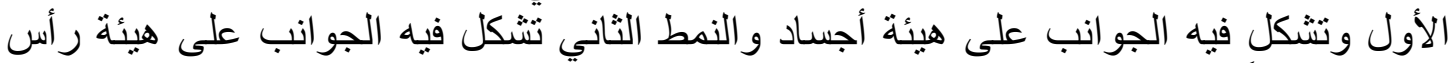

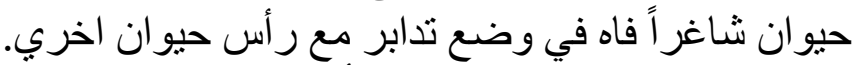

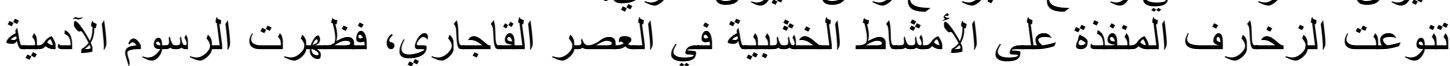

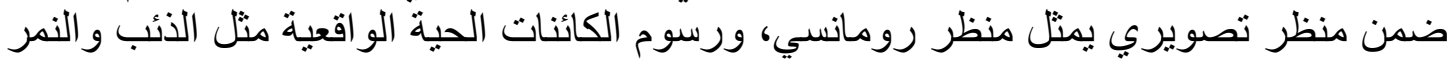

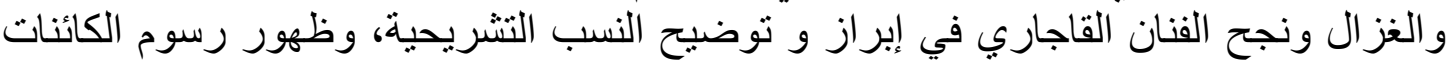

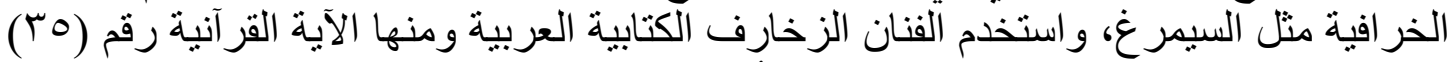

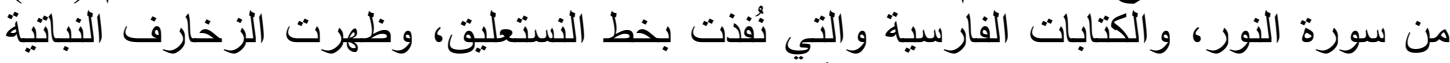

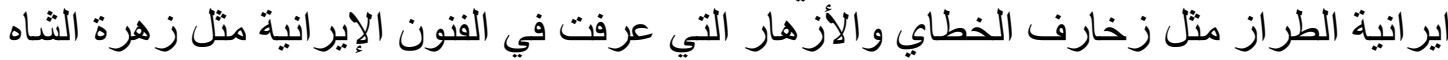

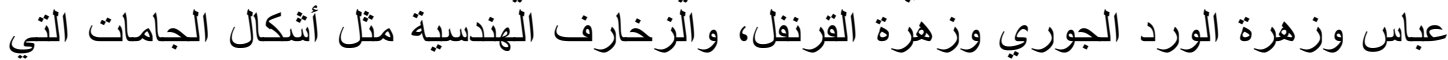

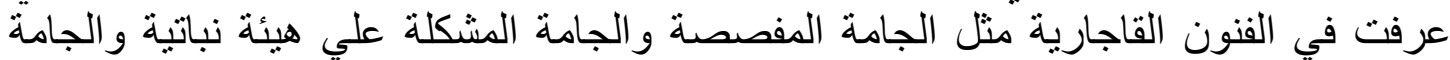

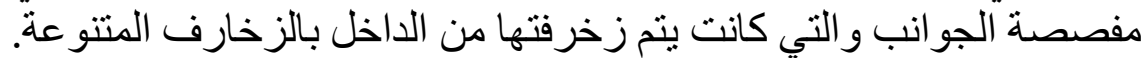

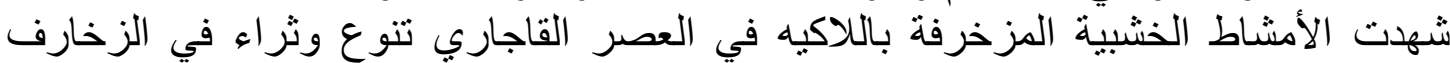

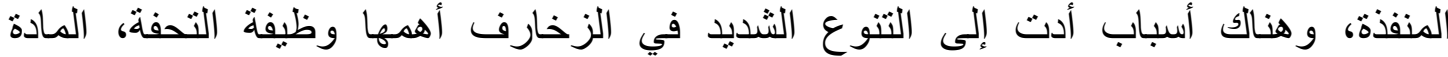

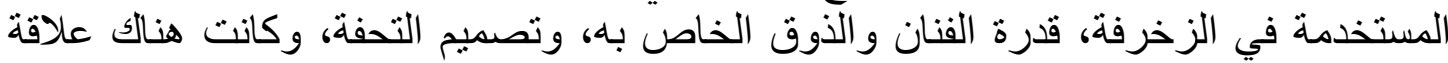

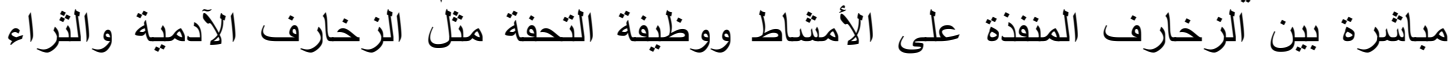

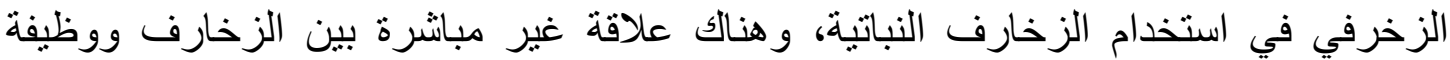

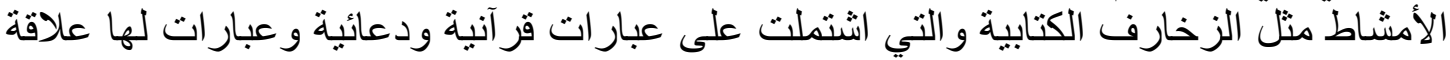

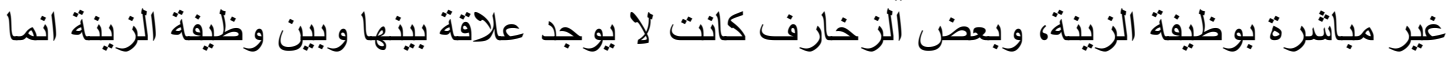

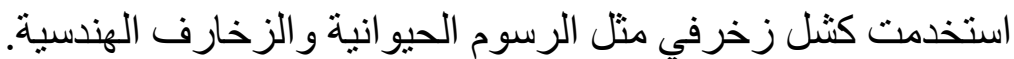

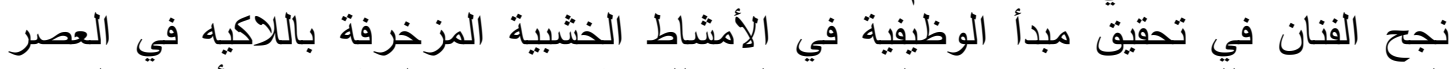

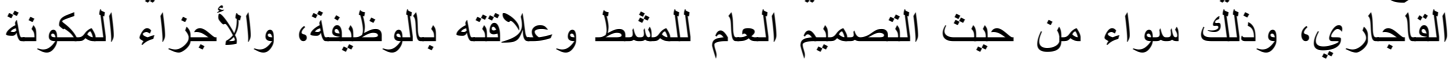
للأمشاط وتحقيقها لمبدأ الوظيفية، فالأبعاد الرئيسة للأمشاط يتحقق فيها مبدأ الوظيفية لونية، فجاء طول 


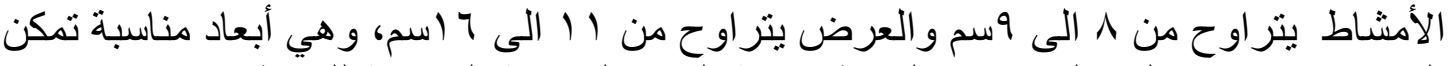

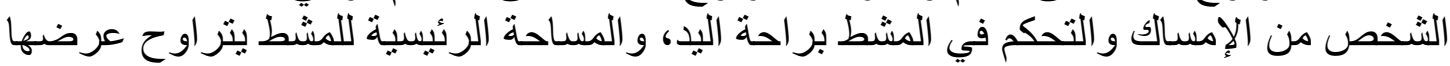

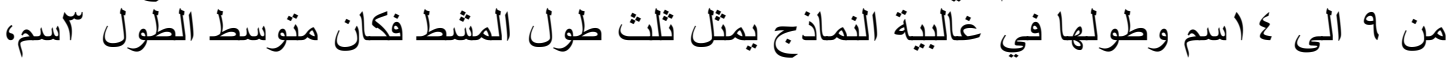

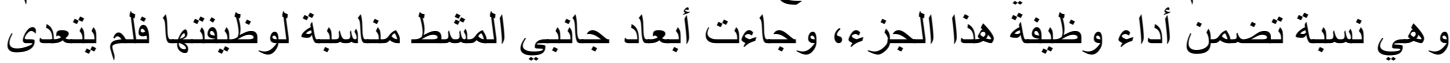

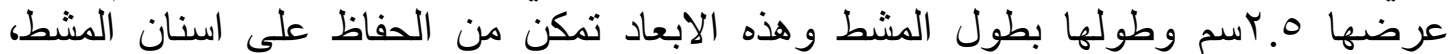

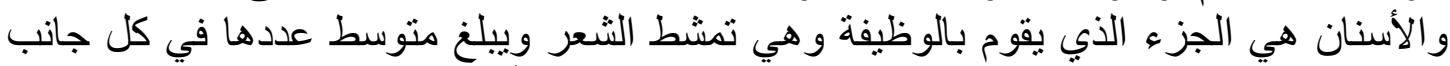

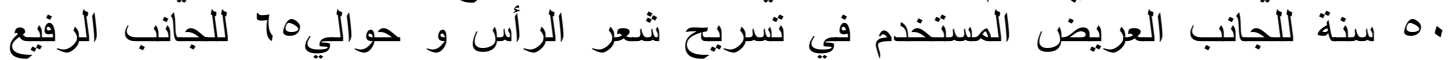
و والمستخدم في تسريح وتهذيب اللحية.

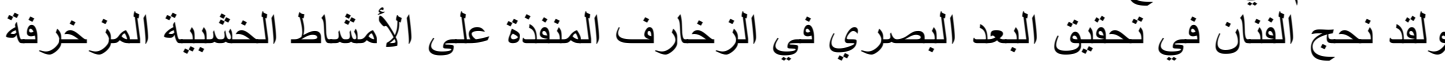

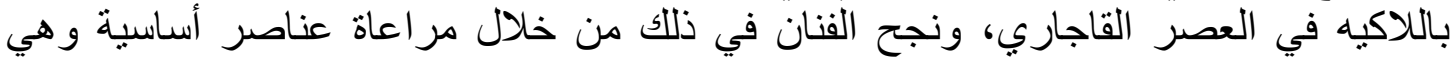

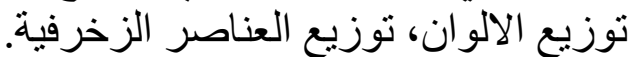
ـ ـ ظهرت التأثير ات الأوروبية على الفنون القاجارية و الأمشاط الخشبية نتيجة العلاقات المتبادلة بين

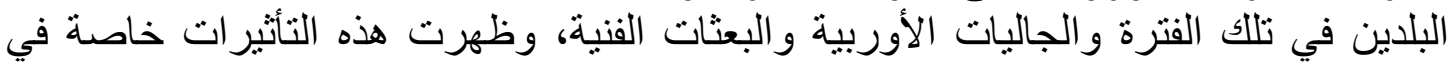

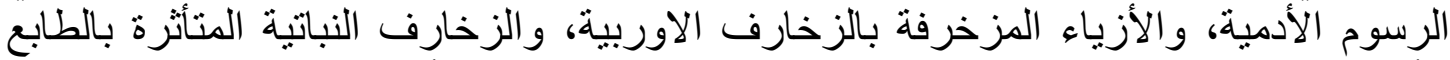

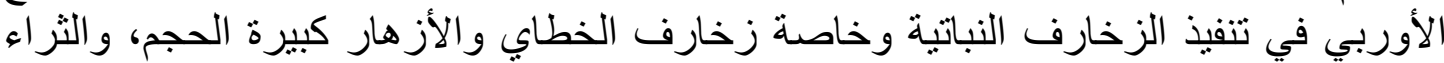

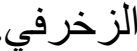

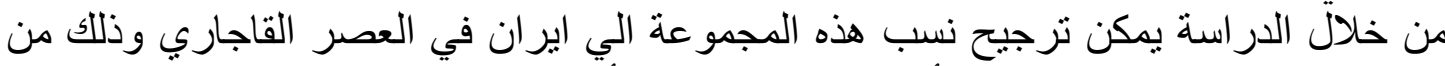
خلال الموضو عات الزخرفية و الأسلوب الصناعي و الأسلوب الفني. 


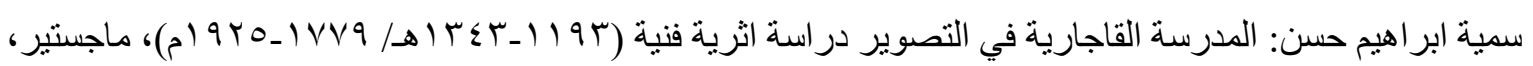

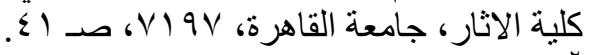

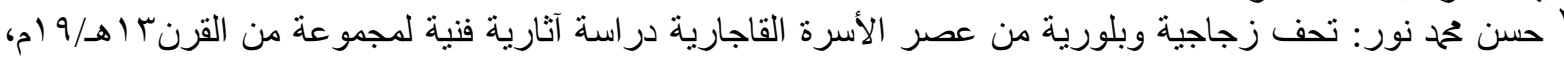

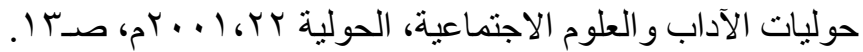

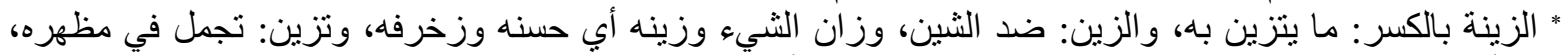

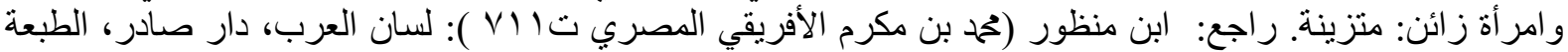

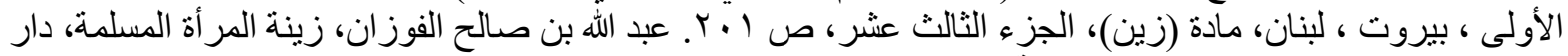

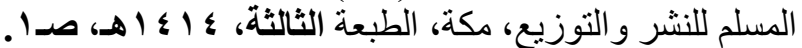

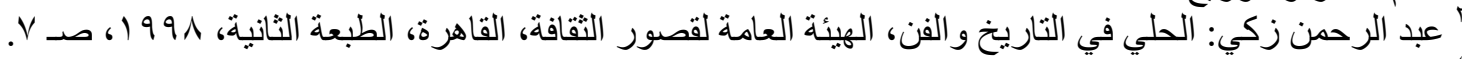

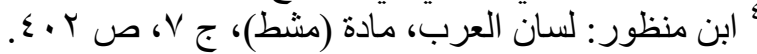

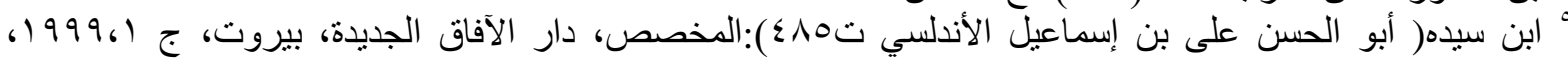

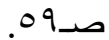
" آمال خحمد رشاد محمد شلبي: تطور المشط الخشبي في مصر كمشغولة فنية وتطبيقاته في التربية الفنية،ماجستير، كلية

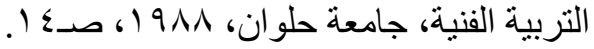

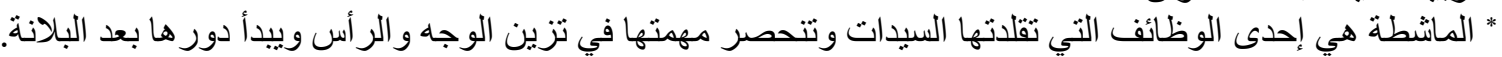
علاء الدين محمود محمد: القطع الفنية التطبيقية للمر أة في مصر وبلاد الثنام في العصر المملوكي، ماجستير ، كلية الآثار ،

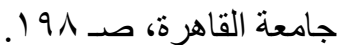

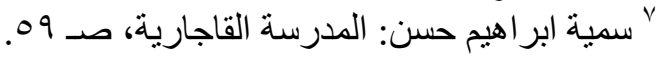

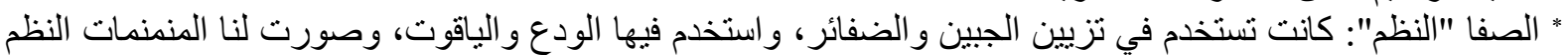

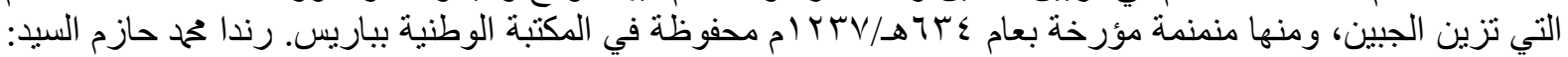

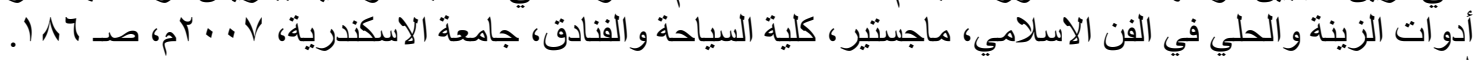

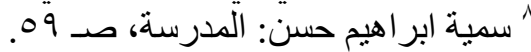

${ }^{9}$ Welch.A \$ Cary.S., Arts of The Islamic Book, The Collection of Prince Sadruddin of Aga Khan, Cornell University Press, Ithaca and London, 1982, p.134.

${ }^{10}$ Ekhtiar.M., Nasir al-Din Shah and the Dar al-Funun: The Evolution of an Institution, Iranian Studies, Vol. 34, No. 1/4, Qajar Art and Society, 2001, p. 154.

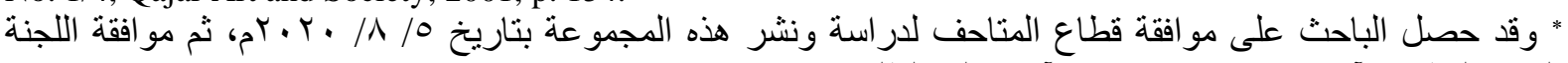

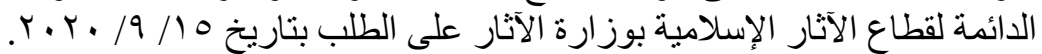

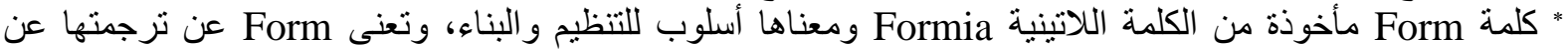

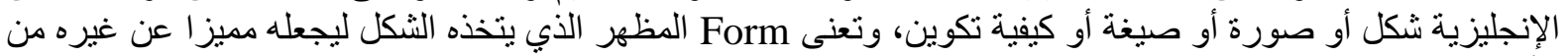

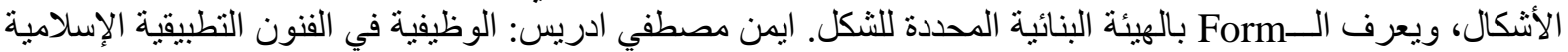

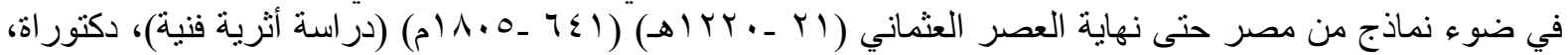

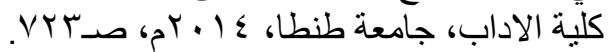

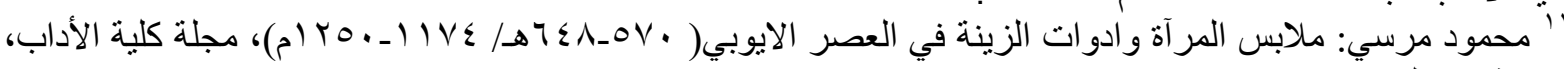

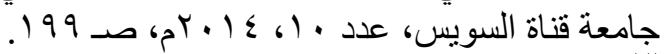

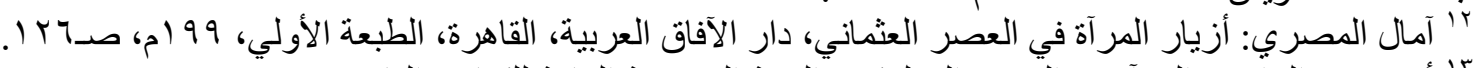

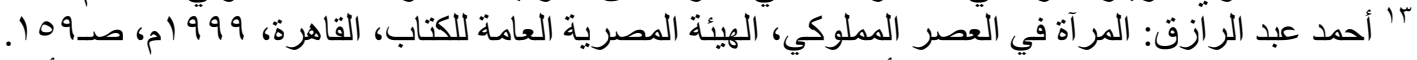

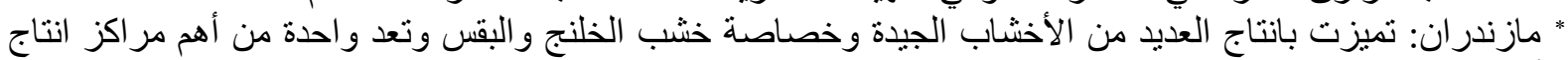
الأحشاب في ايران.

Floo.W., The Woodworking Craft and Its Products in Iran, Muqarnas, 2006, Vol. 23,2006, p.159.

${ }^{14}$ Floo.W., The Woodworking Craft, p.159.

${ }^{15}$ Robinson. B. W., A Royal Qājāir Enamel, Iran, Vol. 10, 1972, p.131.

${ }^{16}$ Robinson. B. W., A Royal Qājār Enamel, p.131.

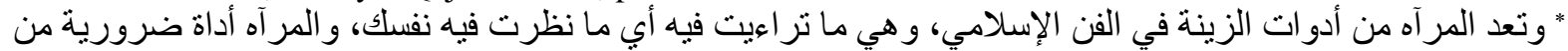

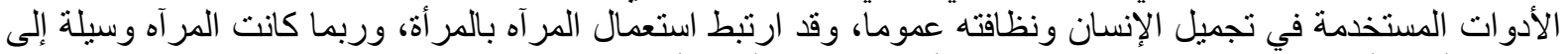

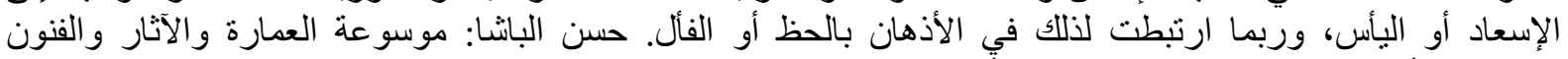

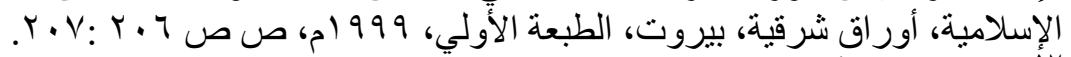

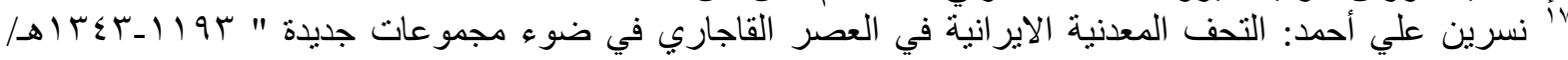

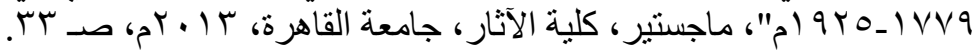


18 Goldenweiser.R., The Miniature Paintings of the Barzū-Nāma: An Illustrated Interpolation to a Qajar Shāhnama from Matenadaran Collection, Iran \& the Caucasus, Vol. 3/4, 1999/2000, p.217.

19 Jones.Y and Others, Black Lacquered Papier-mâché and Turned Wooden Furniture: Unravelling the Art History, Technology and Chemistry of the 19th-Century Japanning Industry, STUDIES IN CONSERVATION, Vol.64, 2019, pp.531:544.

${ }^{20}$ Jones. Y and Others, Black Lacquered, pp.531:544.

${ }^{21}$ Jones.Y and Others, Black Lacquered, pp.531:544.

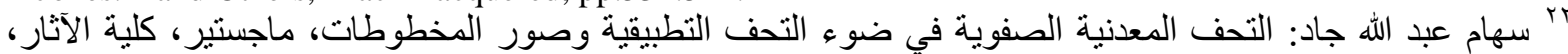

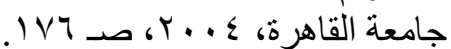
* قصر شهل ستون من اكبر القصور في أصفهان أكمل بنائة الثاه عباس الثاني عام بـ ج أم، ويضم على جدر انة العديد

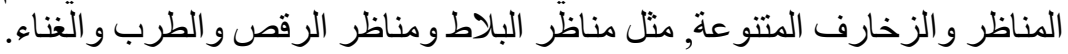

Babaie.S., Shah 'Abbas II, the Conquest of Qandahar, the Chihil Sutun, and Its Wall Paintings, Muqarnas, Vol. 11, 1994, p.126

23 Babaie.S., Shah 'Abbas II,p.126.

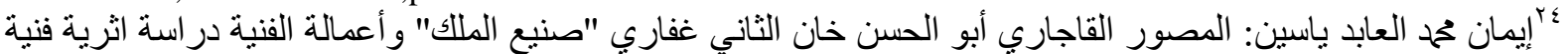

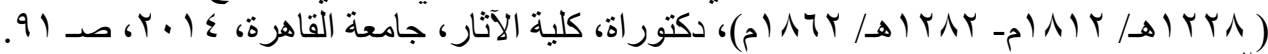

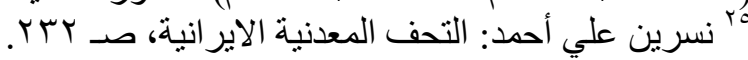

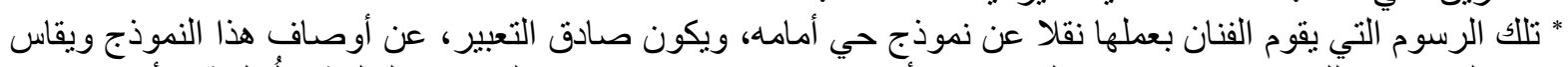

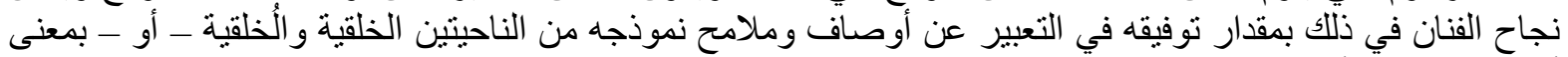

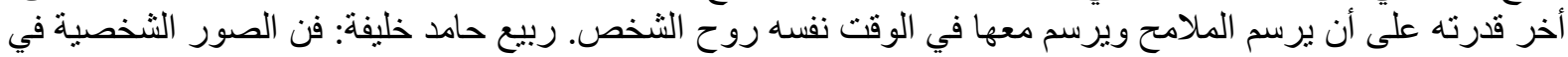

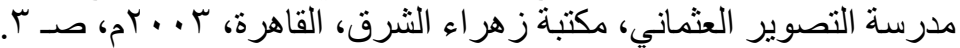

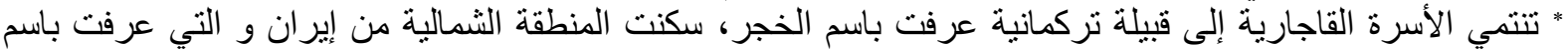

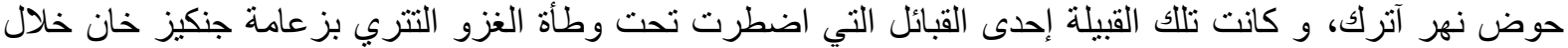

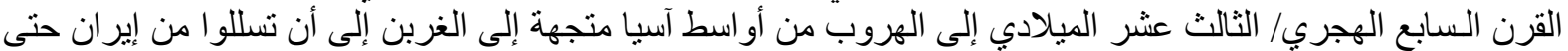

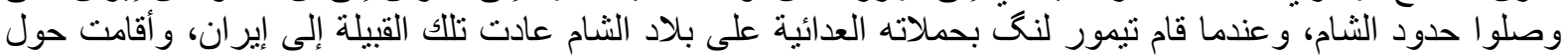
حدودها الثرقية؛ حيث سكنت بلاد استر اباد، ثم أخذت تتوسع حتى سكنت المنطقة الثمالية للحدود الإيرانية لأجيال متعاقبة.

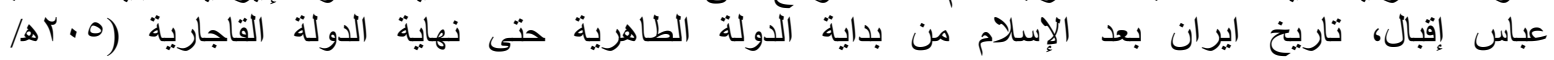

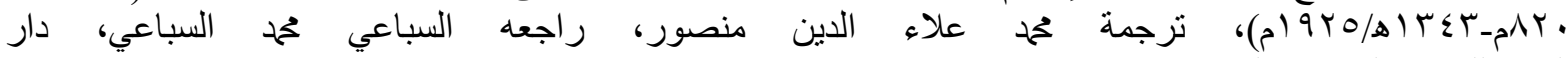

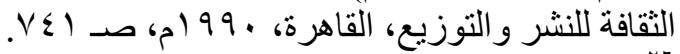

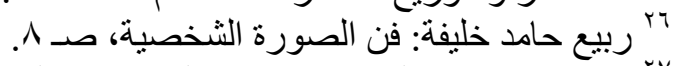

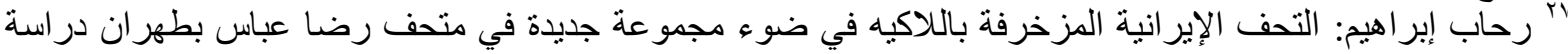

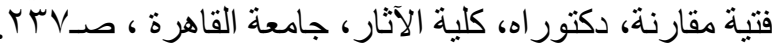

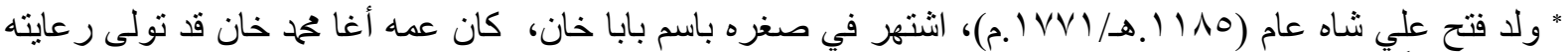

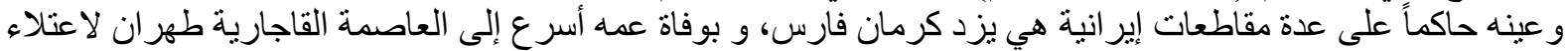

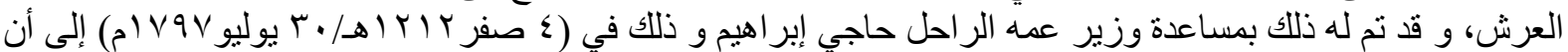

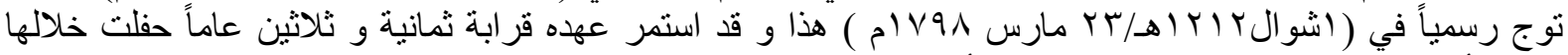

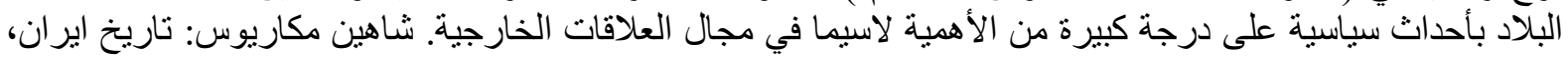

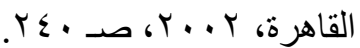

${ }^{28}$ Amanat.A, The Kayanid Crown and Qajar Reclaiming of Royal Authority, Iranian Studies, Vol. 34, No. 1/4, 2001, p.14.

${ }^{29}$ Modares.M., Qajar Painting in The second half of The nineteenth century and Realism,AMaster,The faculty of The Department of art and humanities,San Jose State University,2006,p.43

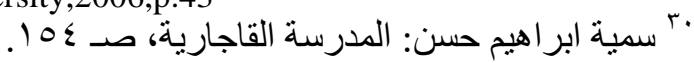

31 Behdad.A., The Power-Ful Art of Qajar Photography, Orientalism and (Self)-Orientalizing in NineteenthCentury Iran, Iranian Studies, Vol. 34, No. 1/4 pl.3-4.

${ }^{32}$ Miller.I., Some Iranian and Afghan Portraits in the Public Record Office, Journal of the Royal Asiatic Society, Third Series, Vol. 8, No. 3,1998,p.344.

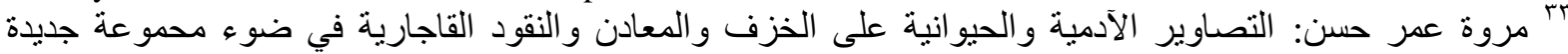

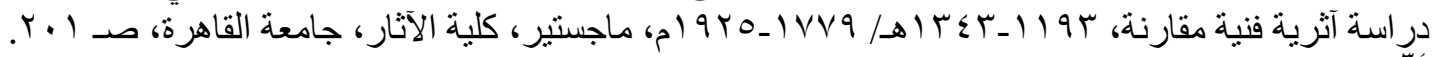

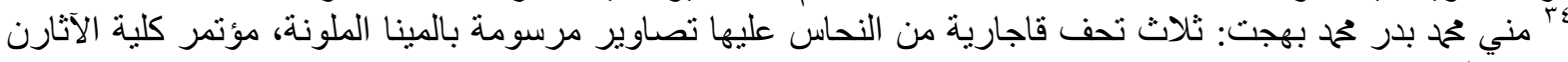

${ }^{35}$ Robinson. B. W., A Royal Qājār Enamel, P.31

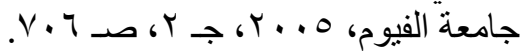


"rr ايهاب احمد حسن: صور السلاطين و الأمر اء ورجال الدولة فى المدرسة القاجارية دراسة أثرية فنبة، ماجستير، كلية

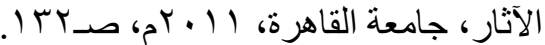

${ }^{37}$ Pope A.U.: A survey of Persian art - Oxford University Press, 1935. Vol. 3 P. 2254

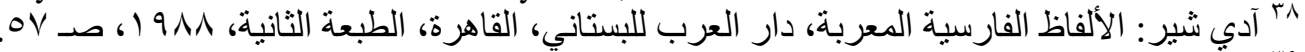

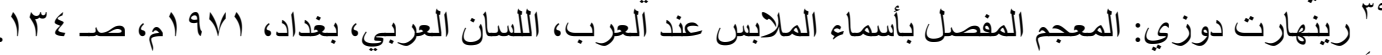

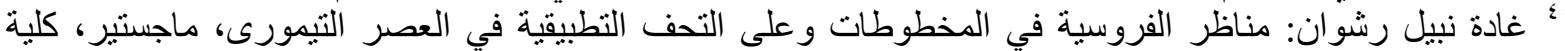

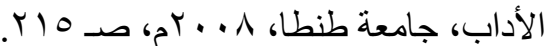

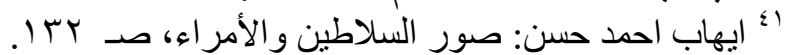

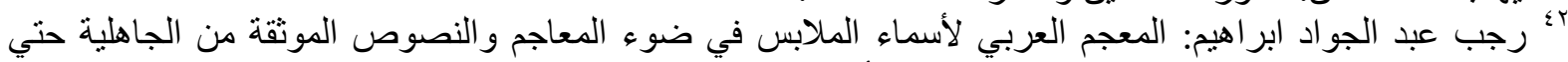

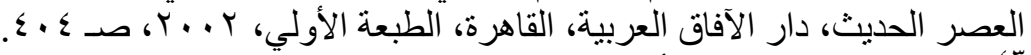

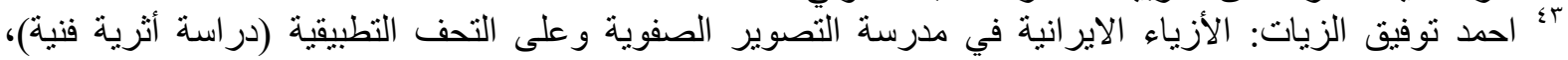

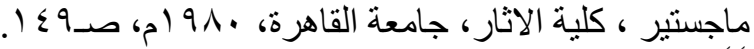

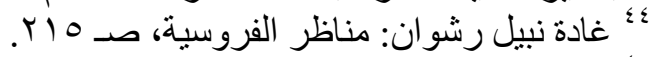

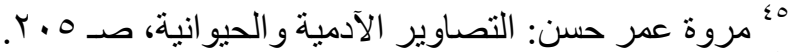

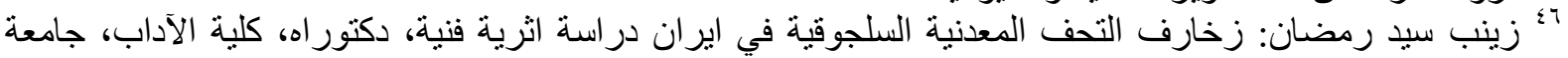
طنطا،

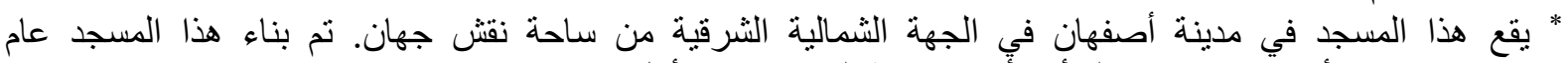

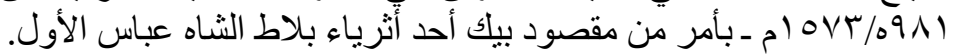

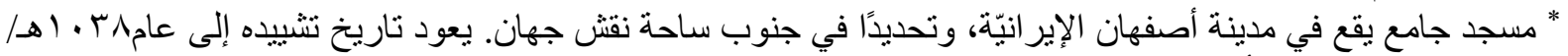

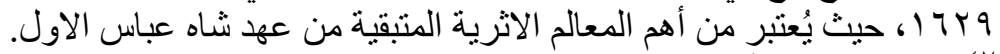

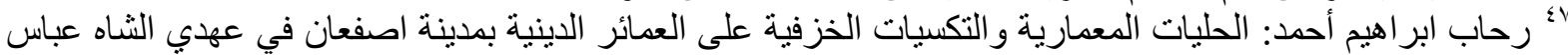

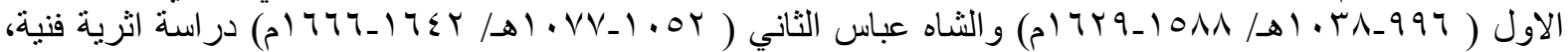

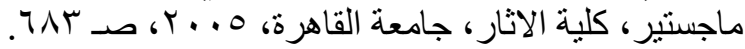
${ }^{48}$ Hamda. T \& Ramy.M., A RARE PERSIAN PORTRAIT RUG “DATING \& ANALYSIS”, SHEDET, vol.4, 2017, p.110.

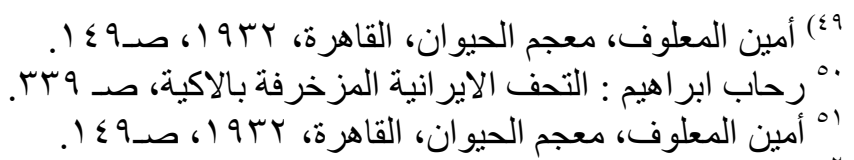

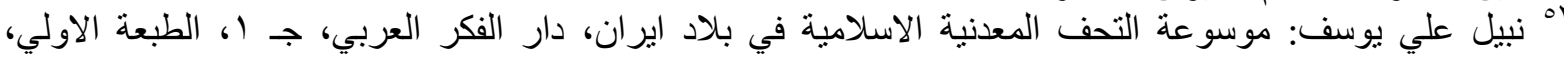

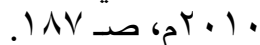
كأثروت عكاثشة: التصوير الإسلامي المغولي بالهند، المؤسسة العربية للاراسات والنشر، الطبعة الأولى، بهو ام،

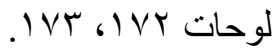

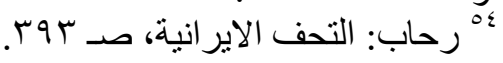

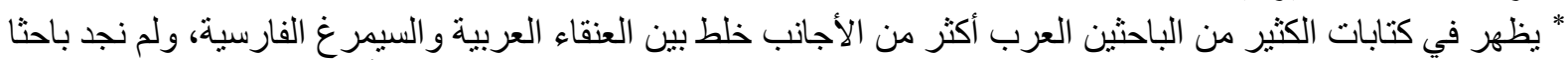

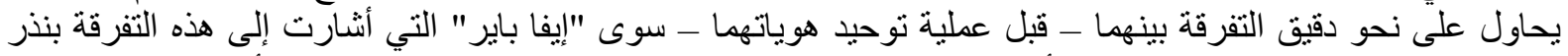

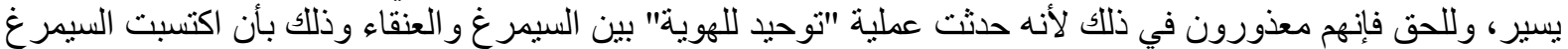

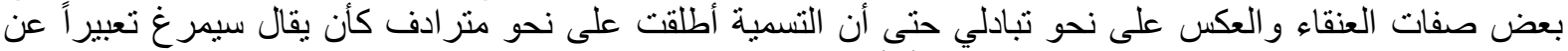

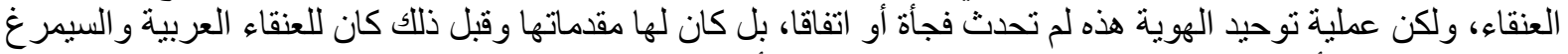

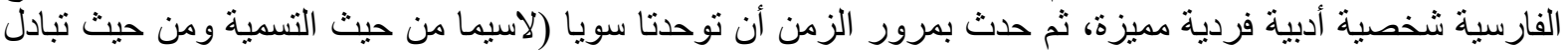

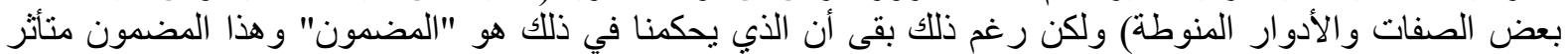

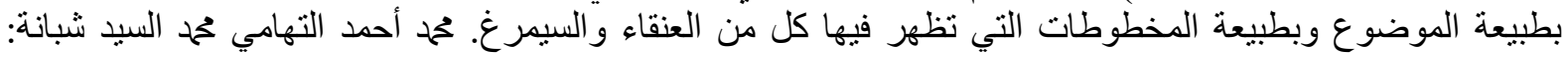

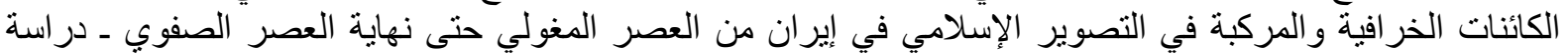

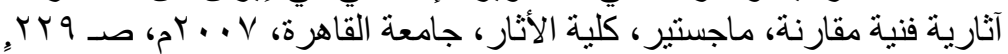

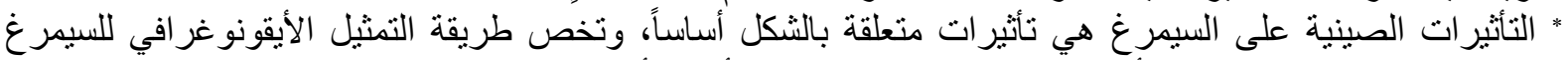

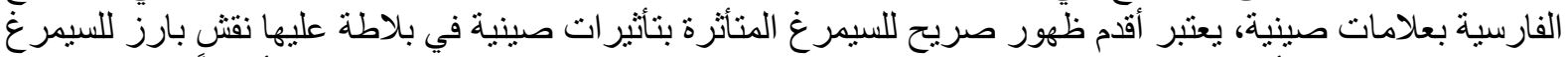

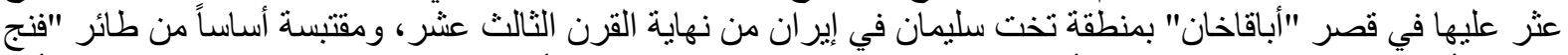

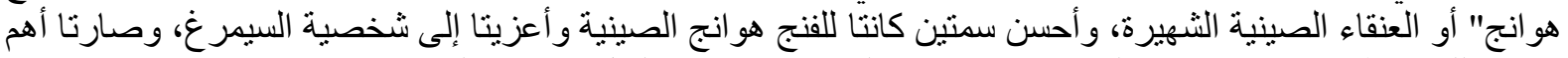
سمتين للسيمر غ يحددان هويتها على نحو لا تخطئه العين هما رياش الذيل الذيل ورياش العنق، وما كانا يمثلان به من تطاير 
وتماوج مميز للغاية معبرين عن فكرة شعلات اللهب الثهيرة، حتى لو مثلتا شكلياً بشكل مختلف عن شعلات اللهب ،

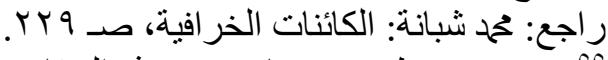

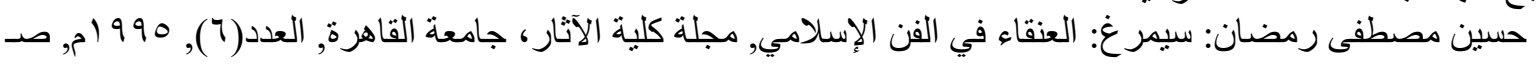

56) Pope: A suervey, vol.5, p.1136.

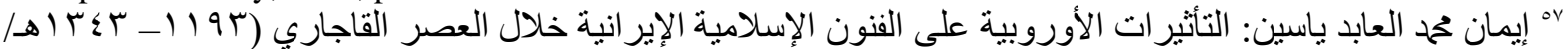

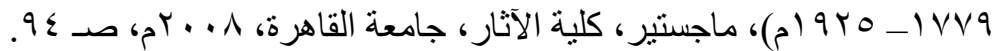

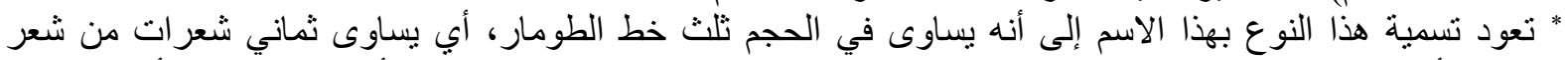

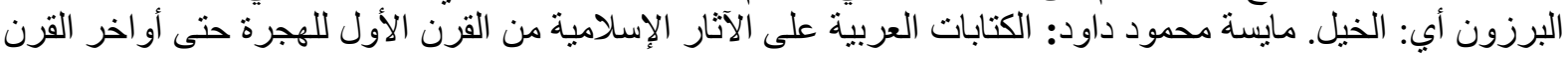

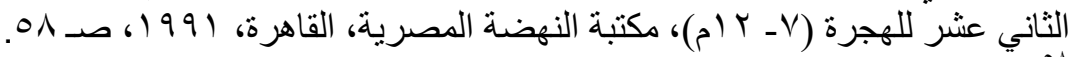

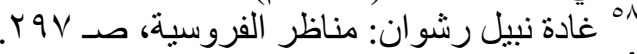

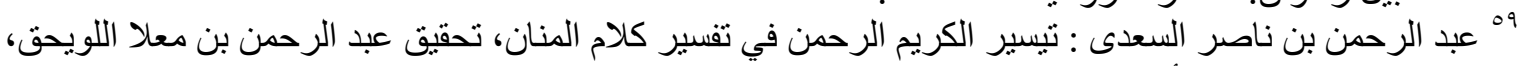

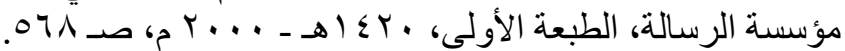

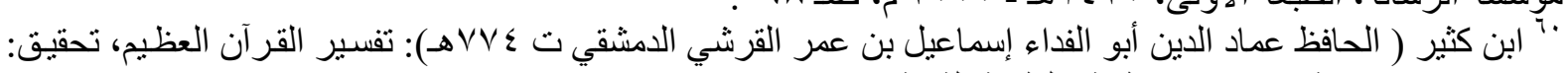

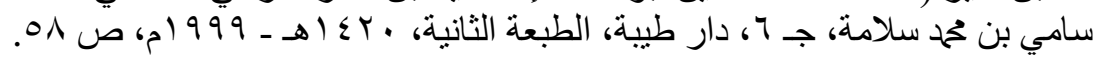

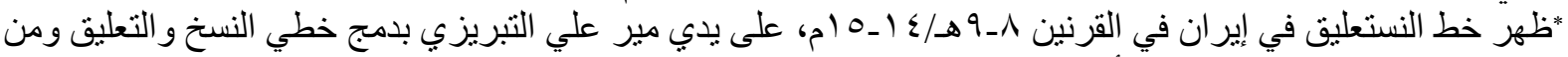

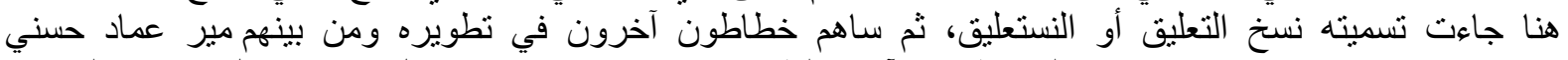

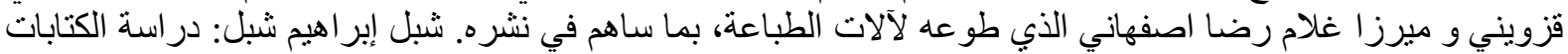

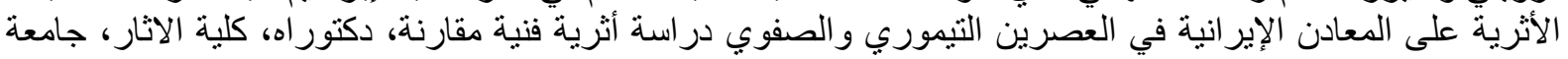

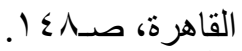

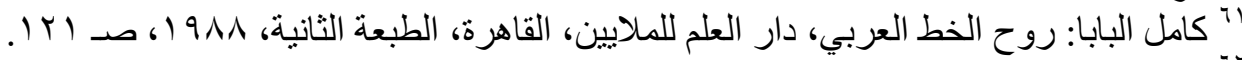

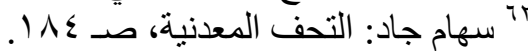

* تمت الترجمة للجملة من قبل أحد أساتذة قسم اللغات الثرقية بكلة التبة الآدآداب جامعة الفيوم، كل الثكر والتقدير للأستاذة

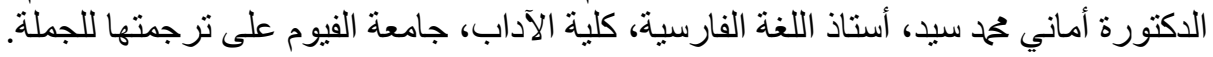
${ }^{63}$ Wyche.L., A Sixteenth-Century Persian Carpet, The Bulletin of the Cleveland Museum of Art, Vol. 50, No. 2, 1963, p.36.

${ }^{65}$ Robinson. B. W., A Royal Qājār Enamel, p.30

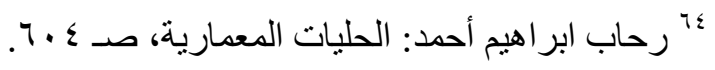

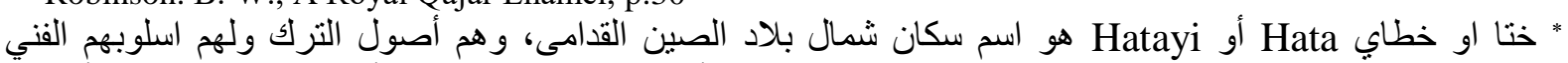

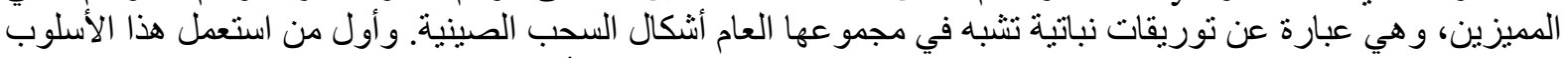

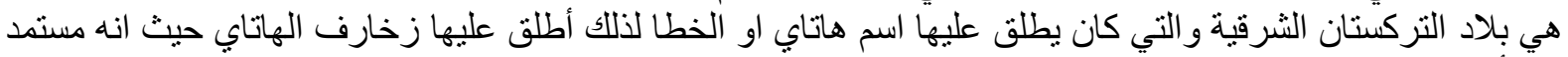

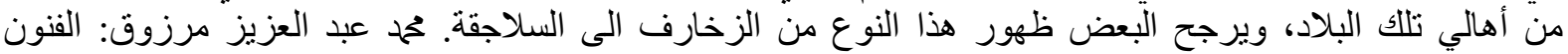

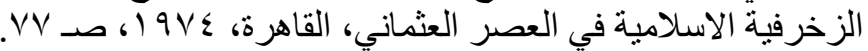

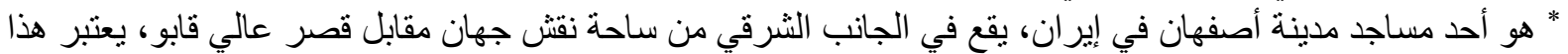

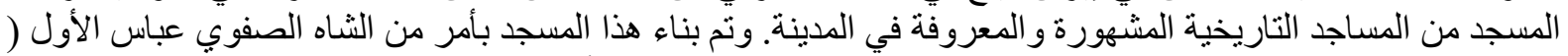

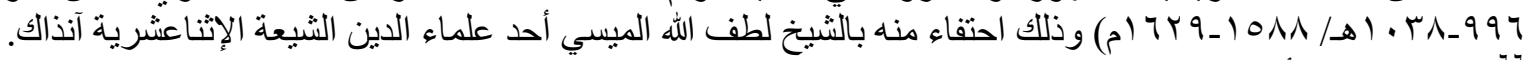

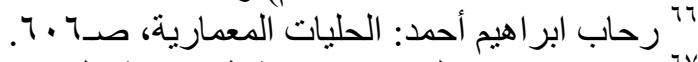

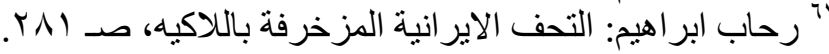

${ }^{68}$ Islamic Republic of Iran: Iranian Cultural Heritage, Handicrafts and Tourism Organization, World Heritage Convention, Tehran 2012,P.392.

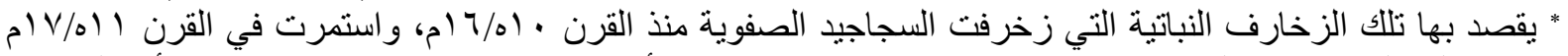

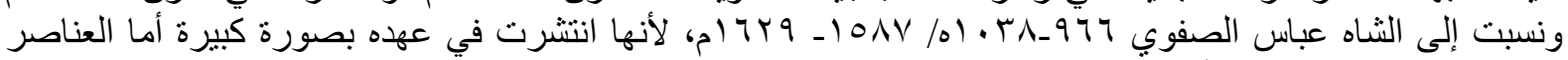

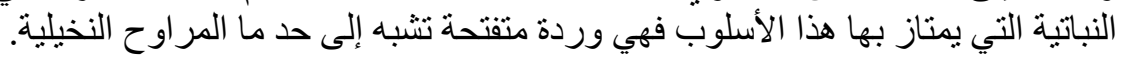

LAN.B., Rugs and Carpets of the world, previously in the Kevorkian collection, London, 1977, P.71.

${ }^{69}$ LAN.B., Rugs and Carpets, p.74.

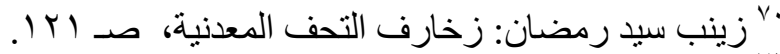

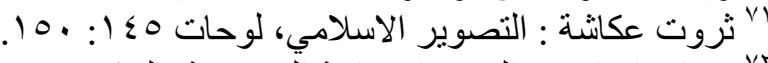

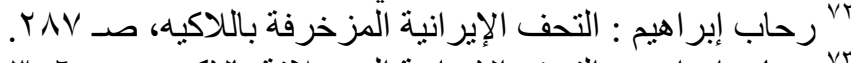

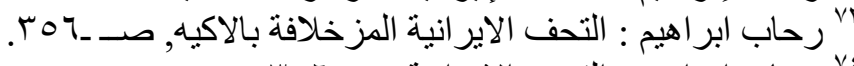

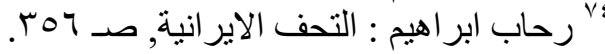




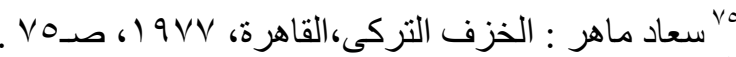

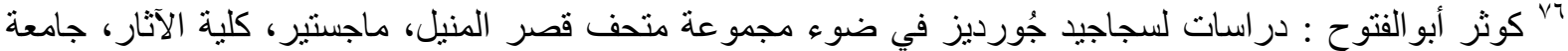

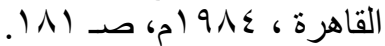

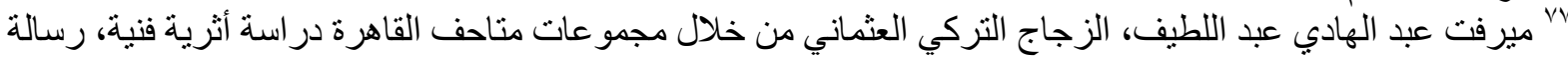

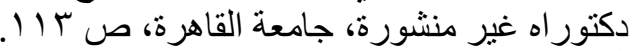

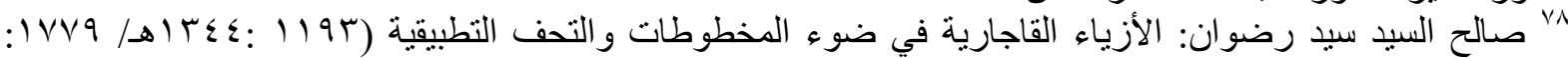

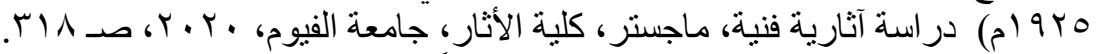

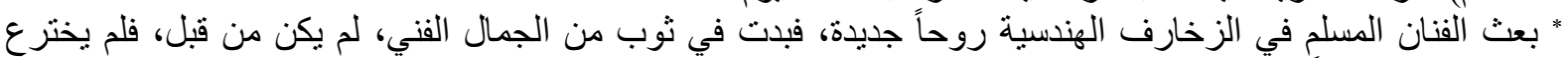

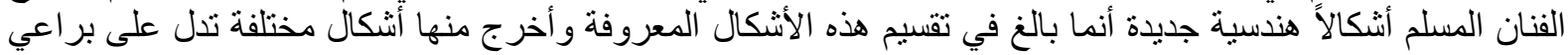

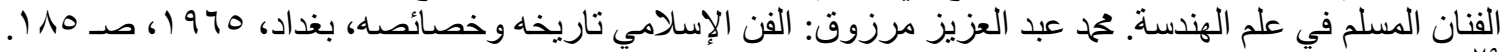

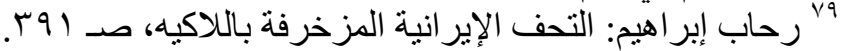

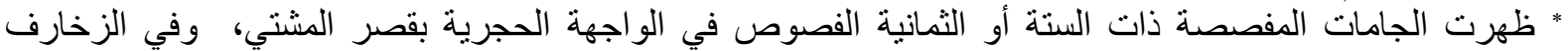

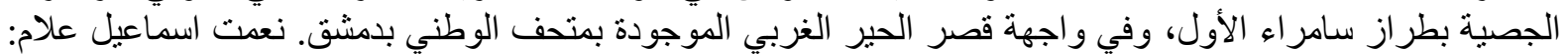

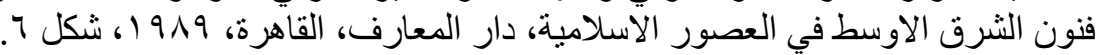

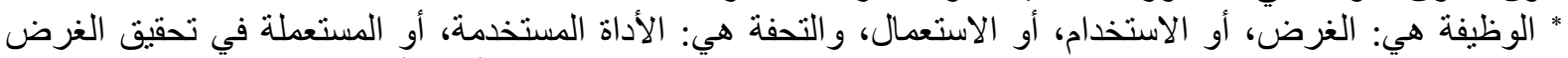

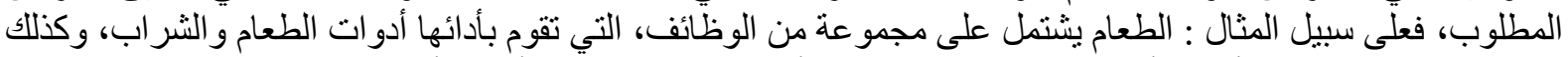

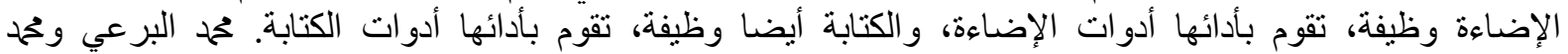

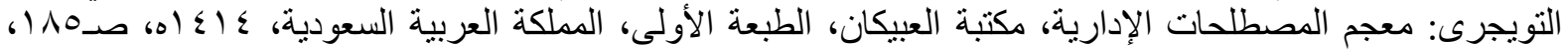

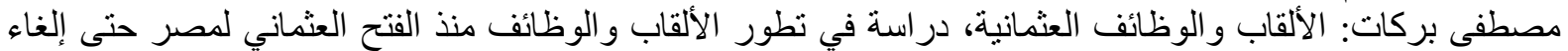

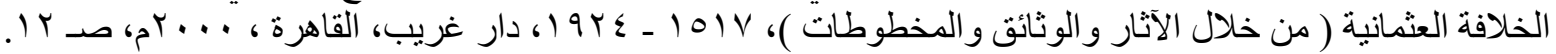

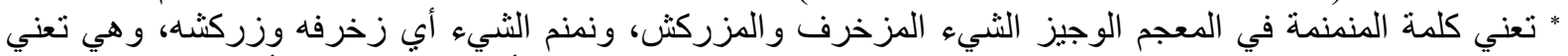

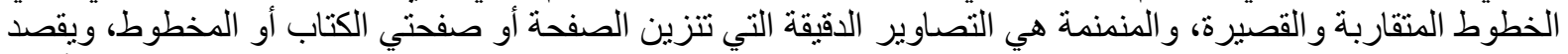

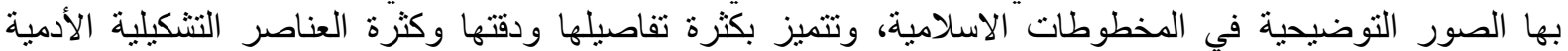

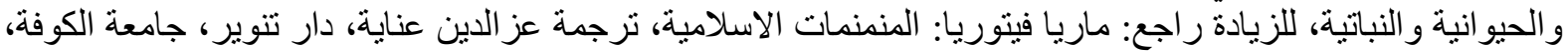

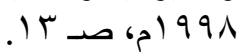

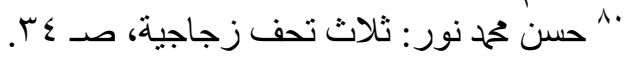

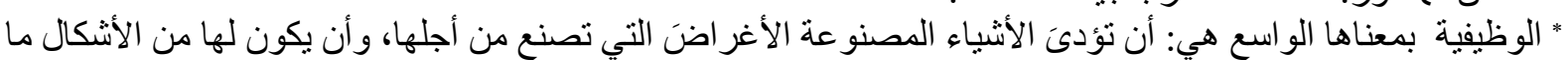

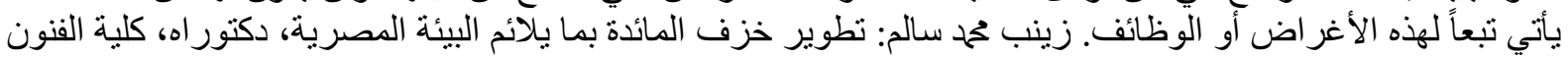

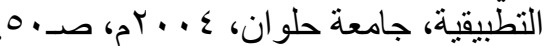

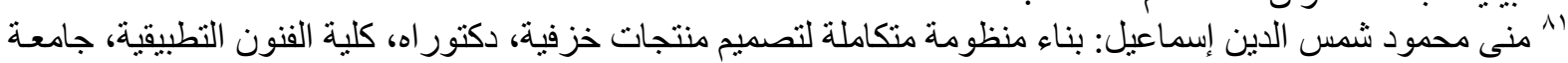

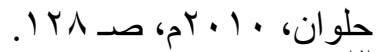

rي نعمة مححد: دراسة مقارنة لرسوم العادية العمائر في مدرسة التصوير الصفوية الثانية وما يعاصر ها في المدرسة المغولية

${ }^{83}$ MahshId. M., Qajar Painting, p.19.

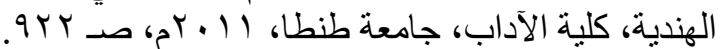

$$
\text { ع إيهاب حسن :صور السلاطين، صـ } 10 \text { أ. }
$$

${ }^{85}$ Kia.M.,: Inside the Court of Naser al-Din Shah Qajar, 1881-96: The Life and Diary of Mohammad Hasan Khan E'temados-Saltaneh, Middle Eastern Studies, Vol. 37, No.1, 2001, p.105.

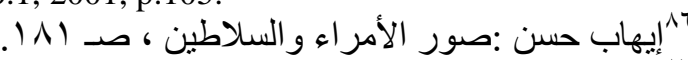

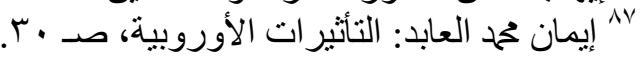

${ }^{88}$ Lambton A.K.S.: Qajar Persia- eleven Studies -I. B. Taurus Co. LTD. Publishers , London, 1983, p. 207.

${ }^{89}$ Floor.M., Art (Naqqashi) and Artists (Naqqashan) in Qajar Persia, Muqarnas, Vol. 16, 1999, p.131.

${ }^{90}$ MahshId. M.,,Qajar Painting. p.92.

Stephen. F., Eisenman:NineteenthCenturyArt,Acritical history, ondon,1998,p7.

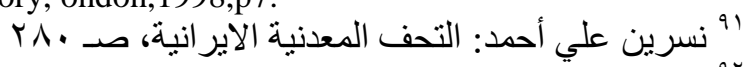

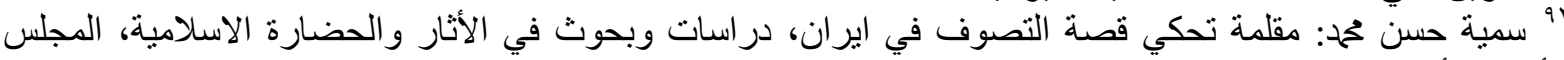

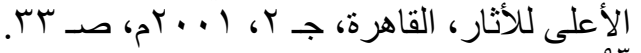

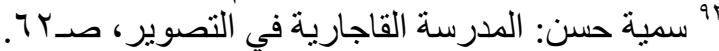

